\title{
WIND ENERGY FEASIBILITY ASSESSMENT FOR THE U.S. VIRGIN ISLANDS
}

\author{
David E. Ball, Editor
}

Sepcomber 1901

prepered by

Southern Solar Energy Centep

Por

U.S. Department of Energy

under contrect DE-ACO2-70Cs30160 


\section{DISCLAIMER}

This report was prepared as an account of work sponsored by an agency of the United States Government. Neither the United States Government nor any agency Thereof, nor any of their employees, makes any warranty, express or implied, or assumes any legal liability or responsibility for the accuracy, completeness, or usefulness of any information, apparatus, product, or process disclosed, or represents that its use would not infringe privately owned rights. Reference herein to any specific commercial product, process, or service by trade name, trademark, manufacturer, or otherwise does not necessarily constitute or imply its endorsement, recommendation, or favoring by the United States Government or any agency thereof. The views and opinions of authors expressed herein do not necessarily state or reflect those of the United States Government or any agency thereof. 


\section{DISCLAIMER}

Portions of this document may be illegible in electronic image products. Images are produced from the best available original document. 


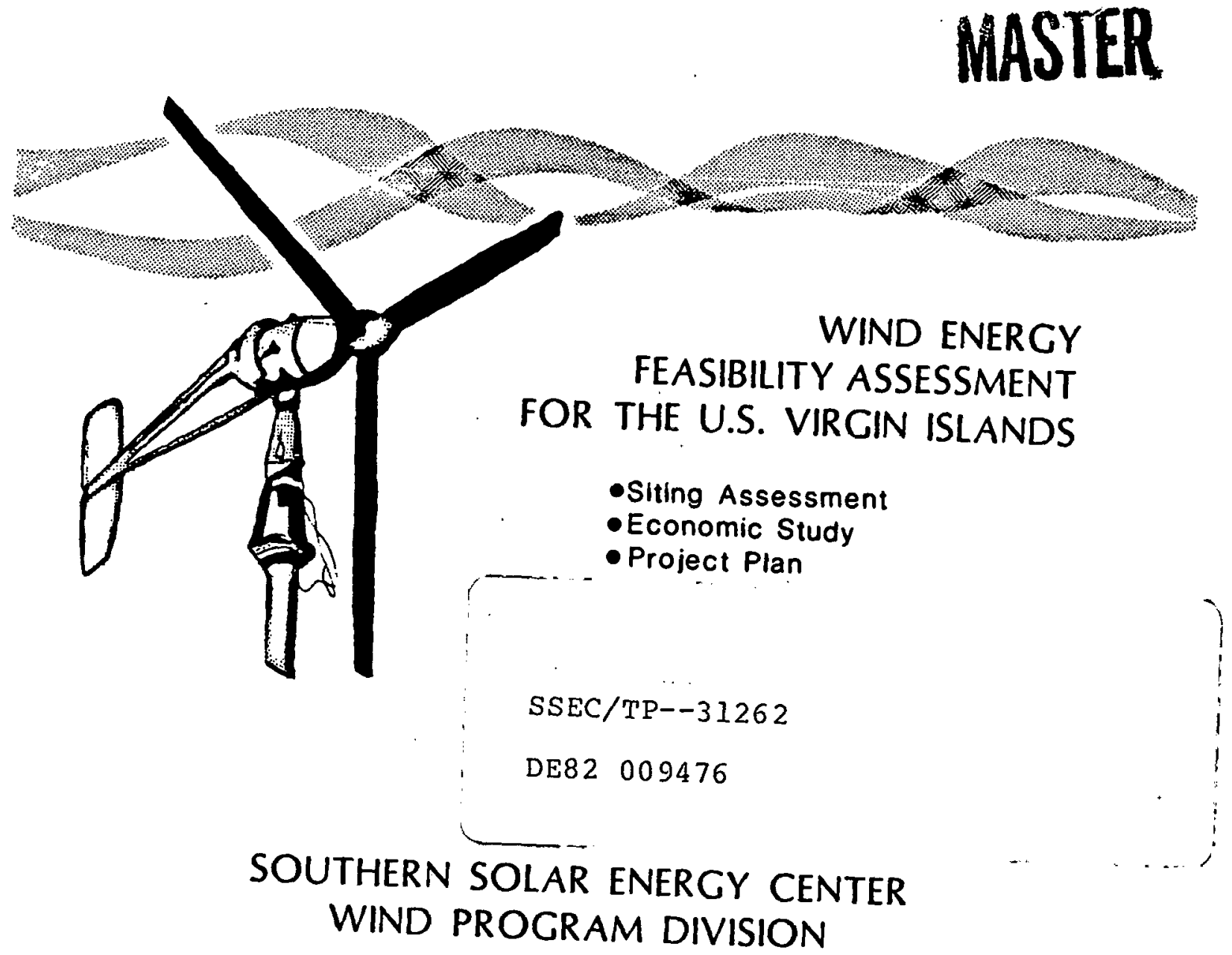

David E. Ball, Editor

September 1981

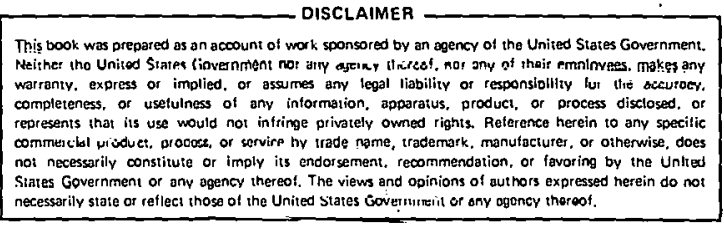


TABLE OF CONTENTS

REPORT A: The Virgin Islands Wind Energy Siting Analysis

REPORT B: The Economic Feasibility of Wind Energy in the U.S. Virgin Is lands

REPORT C: Project Plan for Finalizing Wind Energy Site Selection on the U. S. Virgin Islands 


\section{INTRODUCTION}

The United States Virgin Islands currently is experiencing a critical problem with both the supply and cost of electricity due in part to a dependence upon imported oil for generating electricity. The Southern Solar Energy Center (SSEC) recognized this problem and embarked on a three-part program for researching the technical and economic feasibility of wind energy as a readily available al ternative source of electricity for the Virgin Islands. The first part of the research program involved a preliminary assessment of the wind energy potential in the Virgin Islands. Upon determination of adequate wind resources, an economic feasibility study was performed. Finally, a project plan for finalizing the siting of wind energy conversion systems (WECS) was developed.

This report consists of three separate reports on the three programs integrated into one document. Report A, "The Virgin Islands Wind Energy Siting Analysis" was conducted by the Research Triangle Institute for the Southern Solar Energy Center. Report B, "The Economic Feasibility of Wind Energy in the U.S. Virgin Islands" was performed by the Southern Solar Energy Center. The final section, Report C, "Project Plan for Finalizing Wind Energy Site Selection on the U.S. Virgin Islands" was prepared by the Research Triangle under contract to the Southern Solar Energy Center. 


\section{REPORT A}

THE VIRGIN ISLANDS WIND ENERGY SITING ANALYSIS

Final Report

F. M. Vukovich

W. J. King

D. H. Abbott

Research Triangle Institute

$919-541-600^{\circ}$

P. 0. Box 12194

Research Triangle Park, North Carolina 27707

February 1981

Project Officer
Stephen C. Nelson

Prepared for

The Southern Solar Energy Center

61 Perimeter Park

Atlanta, Georgia 30341

DOE Còntract Number DE-ACO2-79CS30166

Subcontract Number SC-0102 


\section{ABSTRACT}

A preliminary assessment of the wind energy potential in the U. S. Virgin Islands is presented. Based upon the results of this assessment and a study of the topography of the islands, potential sites for wind energy conversion systems (WECS) are identified on St. Croix, St. Thomas, and St. John. Historical wind data from the islands is sparse and the analysis techniques used in this study are relatively unsophisticated. Therefore, the identification of potential WECS sites must be considered extremely preliminary. A detailed study is recommended involving atmospheric modeling and field measurement programs to verify which locations are best suited for the installation of WECS units to alleviate peak electrical load problems in the islands. 
TABLE OF CONTENTS

\section{$\underline{\text { Page }}$}

Abstract . . . . . . . . . . . . . . . . . . . . . . . . . . .

List of Figures . . . . . . . . . . . . . . . . . . . . . . . iii

List of Tables . . . . . . . . . . . . . . . . . . . . . v v

1.0 Introduction . . . . . . . . . . . . . . . . . . . . 1

2.0 Data Base and Processing Techniques. . . . . . . . . . . . . 2

3.0 Statistical Summary and Results . . . . . . . . . . . . . . . . . 4

3.1 The Mean Wind . . . . . . . . . . . . . . . . . . . . . . . 4

3.2 Constancy of the Wind . . . . . . . . . . . . . . . . . 12

3.3 Wind Speed Frequency . . . . . . . . . . . . . . . . . 15

3.4 Other Wind Data . . . . . . . . . . . . . . . . . . 20

3.5 Low Level Wind Profiles . . . . . . . . . . . . . . . . . . 22

3.6 Surface Wind Speed Analysis . . . . . . . . . . . . . . . 24

4.0 Preliminary WECS Site Selection... . . . . . . . . . . . . . 43

4.1 Site Selection Criteria and Procedures....... . . . . . 43

4.2 Candidate WECS Sites................. . 43

5.0 Recommendations . . . . . . . . . . . . . . . . . 52

6.0 References . . . . . . . . . . . . . . . . . . . . . 54

Appendix A . . . . . . . . . . . . . . . . . . . . . . . . . . 55

Appendix B . . . . . . . . . . . . . . . . . . . . . . . 65 


\section{LIST OF FIGURES}

Figure

$\underline{\text { Page }}$

3.1 Diurnal variation of the mean wind speeds $\left[\mathrm{ms}^{-1}\right]$ for

St. Croix and St. Thomas

3.2 Average monthly diurnal maximum and minimum wind speeds [ms ${ }^{-1}$ for St. Croix

3.3 Average monthly diurnal maximum and minimum wind speeds [ms ${ }^{-1}$ ] for St. Thomas 14

3.4 Annual mean wind isotachs $\left[\mathrm{ms}^{-1}\right]$ for St. Croix

3.8 Fall mean wind isotachs $\left[\mathrm{ms}^{-1}\right]$ for $\mathrm{St}$. Croix.

3.9 Annual mean wind isotachs $\left[\mathrm{ms}^{-1}\right]$ for St. Thomas

3.10 Winter mean wind isotachs $\left[\mathrm{ms}^{-1}\right]$ for St. Thomas

4.1 Candidate WECS sites on St. Croix 45

4.2 Candidate WECS sites on St. Thomas 47

4.3 Candidate WECS sites on St. John 5 


\section{LIST OF FIGURES (Cont.)}

Figure

Page

A-1 Typical low altitude wind profile illustrating the mitigating effects of surface friction

A-2 Air flowing across a ridge is accelerated by a quasiventuri effect. Maximum acceleration occurs just downwind of the ridge crest.

A-3 The shear zone associated with some cliffs and bluffs and most flat-topped ridges would create unequal blade loading on WECS equipment

A-4 Plan view of a hill illustrating the compression of streamlines as the air flows around the peak. Tangential flow along the upper flanks of the hill is accelerated.

A-5 Saddles and passes have excellent wind enhancement characteristics.

B-1 The major topographic features of St. Croix showing principal peaks and $100 \mathrm{~m}$ contours

B-2 The major topographic features of St. Thomas showing principal peaks and $100 \mathrm{~m}$ contours

B-3 The major topographic features of St. John showing principal peaks and $100 \mathrm{~m}$ contours 
3.1 Mean surface wind speeds $\left[\mathrm{ms}^{-1}\right.$ ] for St. Croix and St. Thomas for those years when complete data sets were available for both islands. Standard deviations [ms ${ }^{-1}$ ] are given in parentheses

Monthly and seasonal mean surface wind speed $\left[\mathrm{ms}^{-1}\right]$ for St. Croix and St. Thomas with standard deviations given in parentheses

3.3 The seasonal mean wind speeds $\left[\mathrm{ms}^{-1}\right]$ for St. Croix and St. Thomas resulting from the different methods of seasonal partioning employed by Research Triangle Institute (RTI) and Battelle Pacific Northwest Laboratories (PNL)

3.4 Hourly values for the mean wind speeds $\left[\mathrm{ms}^{-1}\right]$ for St. Croix and St. Thomas with standard deviations given in parentheses. Maximum reported wind speeds [ms ] for each hour are also given

3.5 Wind direction frequency distributions for St. Croix with values given as percentages. Summary statistics show constancy with respect to east (C wrt $E$ ), constancy including calm winds ( $\mathrm{C} / \mathrm{w} / \mathrm{calm})$, and other directions (SSE-W-NNE) expressed as percentages

3.6 Wind direction frequency distributions for St. Thomas with values given as percentages. Summary statistics show constancy with respect to east (C wrt E), constancy including calm winds ( $\mathrm{C} / \mathrm{walm}$ ), and other directions (SSE-W-NNE) expressed as percentages

3.7 Wind speed frequency distributions $\lceil \%\rceil$ for St. Croix. Summary statistics show the percent of time wind-speeds are within the normal WECS operating range $\left(3 \mathrm{~ms}^{-1} \leq\right.$ WECS $O R \leq 13 \mathrm{~ms}^{-1}$ ) and also the WECS OR with respect to constancy (OR X C) from Table 3.5

3.8 Wind speed frequency distributions [\%] for St. Thomas . Summary statistics show the percent of time wind ${ }_{1}$ speeds are within the normal WECS operating range $3 \mathrm{~ms}^{-1} \leq$ WECS $O R \leq 13 \mathrm{~ms}^{-1}$ ) and also the WECS OR with respect to constancy (OR X C) from Table 3.6

3.9 Comparison of the long-term surface hourly mean wind speed $\left[\mathrm{ms}^{-1}\right.$ ] data to 1978 data taken at the same locations on St. Croix and St. Thomas 


\section{LIST OF TABLES (Cont.)}

Table

$\underline{\text { Page }}$

3.10 Comparison of long-term surface diurnal mean wind [ms ] data with sporadic data taken in 1978 at marine coastal observation sites on St. Croix and St. Thomas

3.11 Low level wind profiles $\left[\mathrm{ms}^{-1}\right.$ ] constructed for St. Croix and St. Thomas/St. John using San Juan Rawin data as a structural baseline, Benedict Field Pibal data, and surface mean wind speed statistics for St. Croix and St. Thomas 


\subsection{Introduction}

Electrical power in the United States Virgin Islands (USVI) is produced by oil burning generators. With petroleum prices soaring, alternative forms of electrical power generation are becoming attractive. of the three principal types of solar energy (wind, photovoltaic, and ocean thermal), wind energy is presently the most technologically feasible avenue to competitive electrical power generation. It may be possible, therefore, to utilize wind power for supplementary electrical power generation in the USVI, particularly during peak load periods when brown-outs are currently common. This document presents the results of a preliminary assessment of available wind power on St. Croix, St. Thomas, and St. John, the three main islands of the USVI. Based upon the results of this assessment and other factors such as the enhancement of the wind by terrain and thermodynamic effects, preliminary sites are chosen for wind energy conversion systems (WECS). This initial site selection represents a "first pass", and should not be considered conclusive. Recommendations are made regarding the steps necessary to finalize WECS site selection. 


\subsection{Data Base and Processing Techniques}

All data used in this study were obtained from the National Climatic Center (NCC) of the Department of Commerce in Asheville, North Carolina. The data were processed by the Research Triangle Institute (RTI) in seven distinct groupings. A description of each data group, including the source and format of the raw data and periods of record (dates inclusive), is given below:

1) San Juan, Puerto Rico, upper air observations (Rawinsonde), 6/57 $12 / 78$, from magnetic tape with standard format $\mathrm{TD}-5600$;

2) St. Croix, USVI, airways surface observations at Alexander Hamilton Airport, $3 / 51$ - 6/61, from magnetic tape with standard format TD-1440;

3) St. Thomas, USVI, airways surface observations at Harry S. Truman Airport, 1/53 - 6/61, from magnetic tape with standard format TD-1440;

4) St. Croix, USVI, airways surface observations at Hamilton Airport, $1 / 78-12 / 78$, from forms MFI-10C from which date, time, wind speed and direction were extracted and keypunched by RTI data services;

5) St. Thomas, USVI, airways surface observations at Truman Airport, $1 / 78-12 / 78$, from forms MFI-10C from which date, time, wind speed and direction were extracted and keypunched by RTI data services;

6) St. Croix, USVI, marine coastal surface weather observations, 3/78 $12 / 78$, from NOAA forms 72-5A from which date, time, wind speed and direction were extracted and keypunched by RTI data services;

7) St. Thomas, USVI, marine coastal surface weather observations, $3 / 78-10 / 78$, from NOAA forms $72-5 \mathrm{~A}$ from which date, time, wind speed and direction were extracted and keypunched by RTI data ser vices.

All of the above data sets were eventually machine processed by RTI. One additional data set was machine processed by NCC: 1500 m winds aloft summary (Pibal) from Benedict Field (USAF), St. Croix, USVI, from WBAN 120 for 9/41 $1 / 46 ; 1 / 49-12 / 54 ; 1 / 56-9 / 56$; with months $11-12 / 43$ and $4 / 49$ missing.

The general plan for processing the seven major data groups was to apply three processing steps to each group separately: editing and restructuring; calculating means and standard deviations of wind speed; and compiling frequency tables of wind speed versus direction. 
The degree of editing required varied among the groups. The San Juan upper air observations, group 1, required the most editing, all of which was accomplished by means of a short FORTRAN program. The data as received had wind observations at various altitudes. The study required data specifically at the surface and $50,100,200,300,400,500$, and 1500 meters above mean sea level [m MSL]. Data for the required altitudes were derived by linear interpolation, as this method is compatible with standard Rawin computation procedures. The surface observations received on tape, groups 2 and 3 , also were edited and disaggragated by a simple FORTRAN program. The data encoded by RTI data services, groups 4 through 7 , required minimal editing, and this editing was subsumed into later processing steps.

The SUMMARY procedure of the Statistical Analysis System (SAS) ${ }^{1}$ was used to calculate the wind speed means and standard deviations. This procedure allowed, in one pass of the data, the calculation of means and standard deviations for all relevant partitions of the data. The partitions of interest were by year, by month, by hour, and by month and hour. Seasonal statistics were constructed from appropriate monthly values.

The procedure FREQ of SAS was used to create frequency tables by wind speed and direction for different years, months, and hours. This step of the processing required several sortings of the data. Seasonal tables were constructed from appropriate monthly tables.

1 SAS Institute, Incorporated, Cary, N. C. 


\subsection{Statistical Summary and Results}

\subsection{The Mean Wind}

\subsubsection{Annual Variation in Mean Wind Speed}

Table 3.1 gives the values of the mean wind speeds for all years in which complete sets of surface observations were available for both St. Thomas and St: Croix. For three years (1953-55), the mean wind on St. Croix was stronger than on St. Thomas. For the next three years $(1956,58-59)$, the reverse was true. For 1960 and also over the 7-year period, the mean wind speeds were very nearly equal on the two islands.

The differences in the annual values of the mean wind speeds are well within acceptable bounds, the largest difference, $1.4 \mathrm{~ms}^{-1}\left(3.1 \mathrm{mi}^{-\mathrm{hr}^{-1}}\right)$ in 1953 still being considerably smaller than one standard deviation of the mean $\left(\sim 2.2 \mathrm{~ms}^{-1}\right.$ or $\left.4.9 \mathrm{mi}^{-\mathrm{hr}^{-1}}\right)$. The RMS difference for the whole data set is 0.85 $\mathrm{ms}^{-1}\left(1.9 \mathrm{mi}^{-\mathrm{hr}^{-1}}\right)$. Such differences between measurement stations are common and are due in part to differences in instrument exposure and maintenance, local topography, and observer error.

Actually, differences on this order in the mesoscale are quite normal. Although most of the differences can be attributed to local features, larger scale atmospheric phenomena can contribute. For instance, a suall fraction of the mean wind speed differences noted in Table 3.1 may result from the annual migration of the easterly trades. The central axis of the trade wind flow meanders north and south some $1000 \mathrm{~km}$ (621 mi) each year, approaching the USVI on its northward swing mid-summer. The north-south gradient of wind speed in the vicinity of the trade winds central axis averages $1 \mathrm{~ms}^{-1}$ per $300 \mathrm{~km}$ or 1 $\mathrm{mi}-\mathrm{hr}^{-1}$ per $83 \cdot \mathrm{mi}$ (Riehl, 1954). With St. Croix located some $55 \mathrm{~km}$ (34 mi) south of St. Thomas and cross-gradient with respect to the wind speed isopleths, small differences in annual mean wind speeds between the islands are bound to result. 
Table 3.1. Mean surface wind speeds $\left[\mathrm{ms}^{-1}\right]$ for $S t$. Croix and St. Thomas for those years when complete data sets were avaifable for both islands. Standard deviations [ms ${ }^{-1}$ ] are given in parentheses.

\begin{tabular}{ccc}
\hline YEAR & St. Croix & St. Thomas \\
1953 & 5.3 & 3.9 \\
1954 & 4.7 & 3.6 \\
1955 & 4.2 & 3.8 \\
1956 & 4.0 & 4.7 \\
1958 & 3.6 & 4.1 \\
1959 & 3.6 & 4.6 \\
1960 & 4.0 & 3.9 \\
\hline Average & - & $4.1 \quad(2.2)$ \\
\hline \\
\hline
\end{tabular}

Note: $\quad 1 \mathrm{~ms}^{-1}=2.24{\mathrm{mi}-\mathrm{hr}^{-1}}^{-1}$ 


\subsubsection{Seasonal and Monthly Variation of the Mean Wind}

Table 3.2 gives the values of the mean wind speeds at St. Croix and St. Thomas broken down by month and by season. From November through April, there is very little difference in the mean surface wind speed between $\mathrm{St}$. Croix and St. Thomas. From May through October, the mean on St. Croix is slightly stronger by a little less than $0.5 \mathrm{~ms}^{-1}\left(1.1 \mathrm{mi}^{-\mathrm{hr}^{-1}}\right)$. This small anomaly is most probably due to the frictional influence of local topography. Harry $S$. Truman Airport on St. Thomas is cut off from the north by a mountain barrier and has numerous hills of up to $250 \mathrm{~m}$ MSL within $5 \mathrm{~km}(3.1 \mathrm{mi})$ upwind to the east. By contrast, Alexander Hamilton Airport on St. Croix is located on the south side of the island on relatively flat terrain with virtually no upwind obstructions. Maximum monthly mean wind speed on St. Croix occurs in June; on St. Thomas, in July. Minimum monthly mean wind speed occurs in November on St. Croix; in October, on St. Thomas.

The breaking down of climatic data by season, particularly in the midlatitudes, is normally done as follows: Dec, Jan, Feb / Mar, Apr, May / Jun, Jul, Aug / Sep, Oct, Nov. This is the scheme used by H. L. Wegley (1979) of Battelle Pacific Northwest Laboratories (PNL) in his regional wind energy resource assessment of Puerto Rico and the USVI. However, the seasonal temperature pattern of tropical islands is more often influenced by sea surface temperature than by solar angle (Rieh1, 1954). This is true for the USVI where maximum annual temperatures usually occur in early September; minimums, in February. Although the partitioning used by RTI (Table 3.2) more closely approximates the thermal seasons, it does however split June and July, the two months with the highest mean winds. As a result, spring and summer appear nearly equivalent with respect to wind energy. The PNL partitioning on the 
Table 3.2. Monthly and seasonal mean surface wind speed [ms ${ }^{1}$ ] for St. Croix and St. Thomas with standard deviations given in parentheses.

\begin{tabular}{|c|c|c|}
\hline $\begin{array}{r}\text { SEASON } \\
\text { Month } \\
\end{array}$ & St. Croix & St. Thomas \\
\hline WINTER & $4.2(2.1)$ & $4.2(2.0)$ \\
\hline Jan & 4.0 & 4.1 \\
\hline Feb & 4.3 & 4.3 \\
\hline Mar & 4.3 & 4.2 \\
\hline SPRING & $4.8(2.2)$ & $4.3(2.1)$ \\
\hline Apr & 4.4 & 4.2 \\
\hline May & 4.6 & 4.1 \\
\hline Jun & 5.5 & 4.5 \\
\hline SUMMER & $4.6(2.2)$ & $4.3(2.2)$ \\
\hline Jul & 5.1 & 5.0 \\
\hline Aug & 4.7 & 4.4 \\
\hline Sep & 3.9 & 3.5 \\
\hline FALL & $3.7(1.9)$ & $3.6(2.0)$ \\
\hline Oct & 3.7 & 3.2 \\
\hline Nov & 3.5 & 3.5 \\
\hline Dec & 3.8 & 4.2 \\
\hline Seasonal RMS Difference & & \\
\hline Monthly RMS Difference & & \\
\hline
\end{tabular}

Note: $\quad 1 \mathrm{~ms}^{-1}=2.24 \mathrm{mi}^{-\mathrm{hr}^{-1}}$ 
other hand catches the three month mean wind peak in Jun, Jul, Aug and shows considerably more seasonal variation than does the RTI partitioning (Table 3.3).

\subsubsection{Diurnal Variation of the Mean Wind Speed}

The hourly values of the mean wind speeds for St. Croix and St. Thomas are plotted in Figure 3.1. On St. Croix, the mean wind speed is very steady throughout the night $(2000$ through 0600$)$ at 3.2 and $3.3 \mathrm{~ms}^{-1}(7.2$ and 7.4 $\mathrm{mi}-\mathrm{hr}^{-1}$ ). The daylight portions of the diurnal curves are similar in shape, but the midday peak mean wind speed on St. Thomas is lower than for St. Croix by $0.7 \mathrm{~ms}^{-1}\left(1.6 \cdot \mathrm{mi}^{-\mathrm{hr}^{-1}}\right)$. Consequently, the midday portion of the diurnal mean wind speed curve is somewhat flatter for St. Thomas than for St. Croix.

The hourly values of the mean wind speeds and the standard deviations are given in Table 3.4 along with maximum reported wind speeds for each hour of the day. The RMS difference between the respective hourly values of the mean wind for St. Croix and St. Thomas is $0.37 \mathrm{~ms}^{-1}\left(0.83 \mathrm{mi}^{-\mathrm{hr}^{-1}}\right)$, considerably less than the average standard deviation of around $2.0 \mathrm{~ms}^{-1}\left(4.5 \mathrm{mi}^{-\mathrm{hr}}{ }^{-1}\right)$. The slightly higher standard deviations and slightly lower early morning mean wind speeds on St. Thomas are probably indicative of the sheltering influence of the topography around Harry S. Truman Airport, where a very stable early morning regime with near calm winds is more likely than at the completely exposed airport on St. Croix. Note also that with the exception of 0400 and 0500 on St. Thomas, the mean hourly surface wind speeds on both islands remain above $3 \mathrm{~ms}^{-1}\left(6.7 \mathrm{mi}^{-\mathrm{hr}^{-1}}\right)$, generally accepted as the average threshhold starting speed for most commercial WECS units.

The steadiness of the trade wind flow and the relatively infrequent occurrence of severe storms is reflected in the maximum hourly wind speeds. The three high early morning maximum wind speeds reported from St. Croix were 
Table 3.3. The seasonal mean wind speeds $\left[\mathrm{ms}^{-1}\right]$ for St. Croix and St. Thomas resulting from the different methods of seasonal partioning employed by Research Triangle Institute (RTI) and Battelle Pacific Northwest Laboratories (PNL).

\begin{tabular}{lccccc}
\hline \hline & \multicolumn{2}{c}{ St. Croix } & & \multicolumn{2}{c}{ St. Thomas } \\
\cline { 2 - 6 } Season & $\underline{\mathrm{RTI}}$ & $\underline{\mathrm{PNL}}$ & $\underline{\mathrm{RTI}}$ & $\underline{\mathrm{PNL}}$ \\
Winter & 4.2 & 4.0 & 4.2 & 4.2 \\
Spring & 4.8 & 4.4 & 4.3 & 4.2 \\
Summer & 4.6 & 5.1 & 4.3 & 4.6 \\
Fal1 & 3.7 & 3.7 & 3.6 & 3.3 \\
& & & & \\
\hline
\end{tabular}

Note: $1 \mathrm{~ms}^{-1}=2.24 \mathrm{mi}-\mathrm{hr}^{-1}$ 


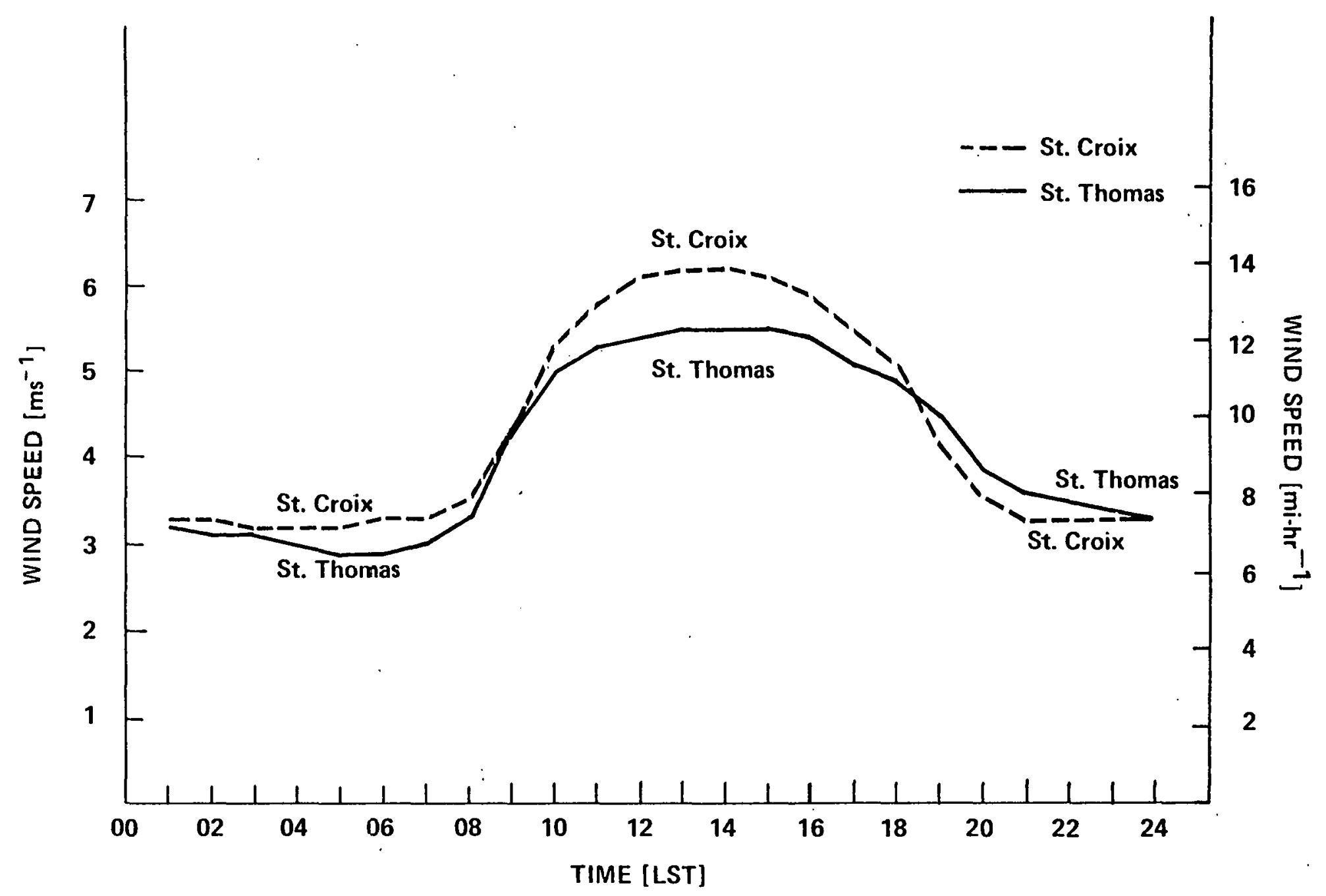

Figure 3.1. Dicrnal variation of the mean wind speed $\left(\mathrm{ms}^{-1}\right)$ for St. Croix and St. Thomas. 
Table 3.4. Hourly values for the mean wind speeds [ms ${ }^{-1}$ ] for St. Croix and St. Thomas with standard deviations given in parentheses. Maximum reported wind speeds [ms ${ }^{1}$ ] for each hour are also given.

\begin{tabular}{|c|c|c|c|c|c|c|}
\hline \multirow[b]{2}{*}{ Hour } & \multicolumn{3}{|c|}{ St. Croix } & \multicolumn{3}{|c|}{ St. Thomas } \\
\hline & Mean & Wind & Max Wind & Mean & Wind & Max Wind \\
\hline 00 & 3.3 & $(1.9)$ & 15 & 3.2 & $(2.1)$ & 11 \\
\hline 01 & 3.3 & $(1.9)$ & 14 & 3.1 & $(2.0)$ & 13 \\
\hline 02 & 3.2 & $(1.9)$ & 14 & 3.1 & $(2.1)$ & 13 \\
\hline 03 & 3.2 & $(1.8)$ & 13 & 3.0 & $(2.1)$ & 11 \\
\hline 04 & 3.2 & $(1.9)$ & 25 & 2.9 & $(2.1)$ & 13 \\
\hline 05 & 3.3 & $(1.9)$ & 28 & 2.9 & $(2.1)$ & 13 \\
\hline 06 & 3.3 & $(1.9)$ & 26 & 3.0 & $(2.1)$ & 15 \\
\hline 07 & 3.5 & $(2.0)$ & 18 & 3.3 & $(2.1)$ & 15 \\
\hline 08 & 4.3 & $(2.2)$ & 15 & 4.3 & $(2.0)$ & 15 \\
\hline 09 & 5.3 & $(2.1)$ & 13 & 5.0 & $(1.9)$ & 15 \\
\hline 10 & 5.8 & $(2.1)$ & 15 & 5.3 & $(1.9)$ & 13 \\
\hline 11 & 6.1 & $(2.1)$ & 18 & 5.4 & $(1.9)$ & 13 \\
\hline 12 & 6.2 & $(2.1)$ & 14 & 5.5 & $(2.0)$ & 12 \\
\hline 13 & $6: 2$ & $(2.2)$ & 14 & 5.5 & $(2.0)$ & 13 \\
\hline 14 & 6.1 & $(2.2)$ & 15 & 5.5 & $(2.0)$ & 13 \\
\hline 15 & 5.9 & $(2.1)$ & 15 & 5.4 & $(2.0)$ & 18 \\
\hline 16 & 5.5 & $(2.1)$ & 13 & 5.1 & $(1.9)$ & 15 \\
\hline 17 & 5.1 & $(2.1)$ & 16 & 4.9 & $(1.9)$ & 12 \\
\hline 18 & 4.2 & $(2.1)$ & 13 & 4.5 & $(2.0)$ & 12 \\
\hline 19 & 3.6 & $(1.9)$ & 13 & 3.9 & $(2.0)$ & 11 \\
\hline 20 & 3.3 & $(1.9)$ & 13 & 3.6 & $(2.0)$ & 13 \\
\hline 21 & 3.3 & $(1.8)$ & 14 & 3.5 & $(2.0)$ & 11 \\
\hline 22 & 3.3 & $(1.8)$ & 12 & 3.4 & $(2.0)$ & 12 \\
\hline 23 & 3.3 & $(1,9)$ & 14 & .3 .3 & $(2.0)$ & 11 \\
\hline
\end{tabular}

Note: $\quad 1 \mathrm{~ms}^{-1}=2.24 \mathrm{mi}^{-1} \mathrm{hr}^{-1}$ 
associated with Hurricane Betsy, August 12, 1956. Discounting these, the range of maximum hourly wind speeds for St. Croix is $12-18 \mathrm{~ms}^{-1}$ (27-40 $\left.\mathrm{mi}-\mathrm{hr}^{-1}\right)$. The range for St. Thomas is $11-18 \mathrm{~ms}^{-1}\left(25-40 \mathrm{mi}^{-\mathrm{hr}^{-1}}\right)$. These data seem to indicate that extremely high winds that might damage WECS installations are likely to be associated with tropical storms which are subject to intensive surveillance. Thus, adequate lead time to secure WECS equipment for severe weather would normally be expected.

From 1871 through 1979, thirty-seven (37) tropical cyclones have passed within 50 nautical miles $(93 \mathrm{~km})$ of the USVI. Of these 37 storms, thirteen (13) have been of hurricane intensity with sustained surface wind speeds greater than $33 \mathrm{~ms}^{-1}\left(74 \mathrm{mi}^{-\mathrm{hr}^{-1}}\right)$ near the eye. Only five times in this 109 year period of record has the eye of a hurricane passed directly over one of the major islands of the USVI group: once in 1899; twice in 1916; and once each in 1931 and 1932 .

The average daily maximum and minimum wind speeds for each month are presented for St. Croix (Figure 3.2) and for St. Thomas (Figure 3.3). On St. Croix, the average maximum daily wind speed surpasses $6 \mathrm{~ms}^{-1}\left(13.4 \mathrm{mi}^{-\mathrm{hr}^{-1}}\right)$ from January through August, peaking in June at $7.5 \mathrm{~ms}^{-1}\left(16.8 \mathrm{mi}^{-\mathrm{hr}^{-1}}\right)$. The average minimum daily wind speed falls below $3 \mathrm{~ms}^{-1}\left(6.7 \mathrm{mi}^{-\mathrm{hr}^{-1}}\right)$ from September through December. On St. Thomas, the average maximum daily wind speed surpasses $5.5 \mathrm{~ms}^{-1}\left(12.3 \mathrm{mi}^{-\mathrm{hr}^{-1}}\right)$ from December through August, peaking in July at $6.6 \mathrm{~ms}^{-1}\left(14.8 \mathrm{mi}^{-\mathrm{hr}^{-1}}\right)$. The average minimum daily wind speed falls below $3 \mathrm{~ms}^{-1}\left(6.7 \mathrm{mi}^{-\mathrm{hr}^{-1}}\right)$ for two 3 -month periods: March through May and September through November.

\subsection{Constancy of the Wind}

Riehl (1954) defines constancy as "the percent frequency of all observations with wind direction within $45^{\circ}$ of the most frequent direction." Accord- 


\section{THIS PAGE \\ WAS INTENTIONALLY \\ LEFT BLANK}




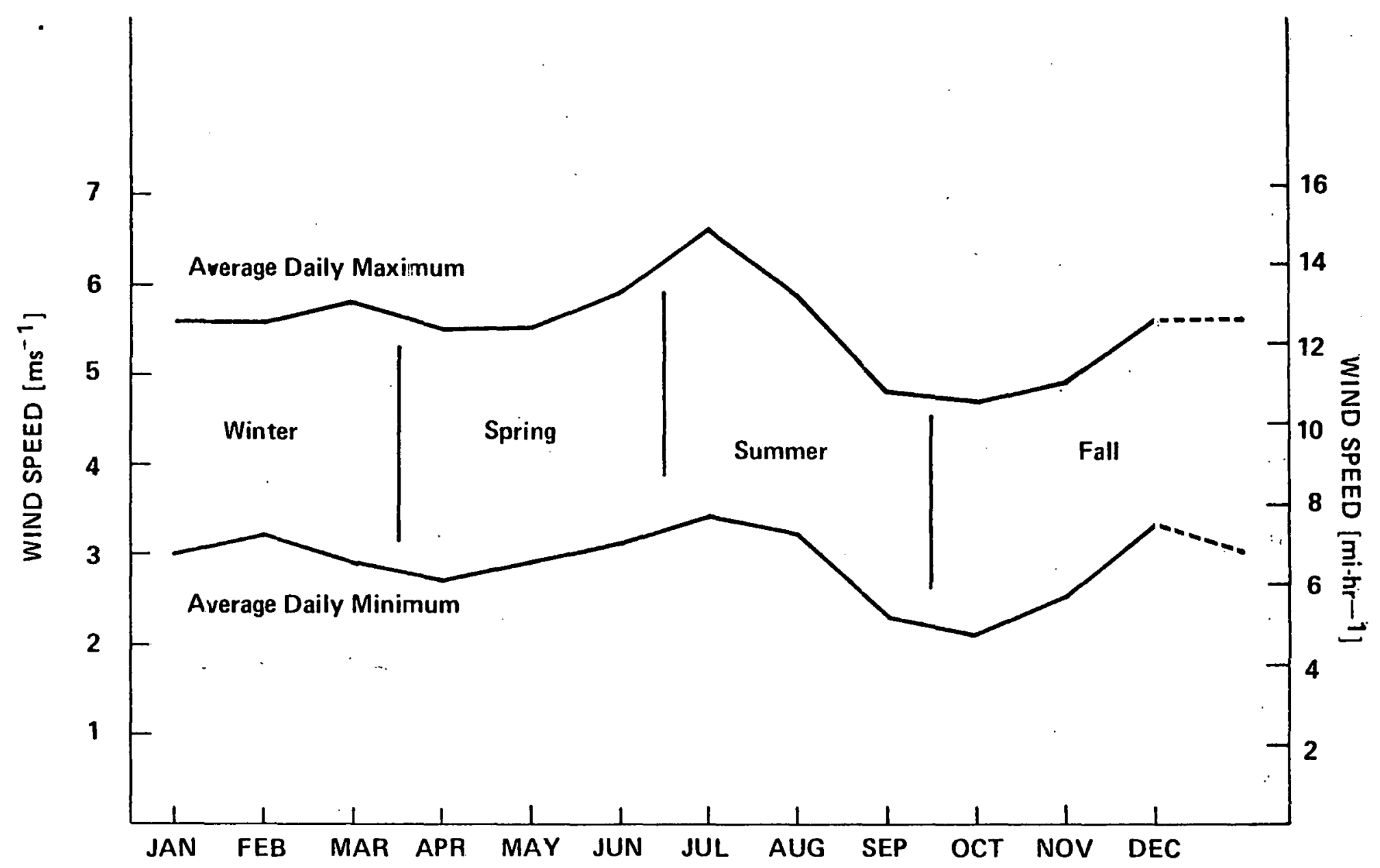

Figure 3.3. Average monthly diurnal maximum and minimum wind speeds $\left[\mathrm{ms}^{-1}\right.$ ] for St. Thomas. 
ing to Riehl, "In the trades the constancy attains 80 percent; in no other regime on earth do the winds blow so steadily." High percentage constancy is a desireable wind characteristic for WECS equipment which can be simpler mechanically by virtue of not having to make many major directional adjustments during operation.

Tables 3.5 and 3.6 contain seasonal and annual wind direction frequency distributions for St. Croix and St. Thomas respectively. Constancy with respect to east (C wrt F) is computed for each season. Constancy is also computed to include calm winds $(\mathrm{C} / \mathrm{walm})$, and then the percentage of measureable winds from SSE through $W$ through NNE is shown. SSE-W-NNE winds are an infrequent occurence in the easterly trades.

For reasons that are not readily apparent, east winds on St. Croix are the 4th most frequent direction, whereas east is by far the most frequently reported direction on St. Thomas. However, constancy with respect to east is slightly higher on St. Croix than on St. Thomas. Both islands seem to have an E-ENE predominance for most of the year except in the Spring when the winds shift slightly to E-ESE. On both islands, constancy is highest during the Spring and Summer. Winds from SSE-W-NNE occur less than 10 percent of the time on St. Croix and just over 5 percent of the time on St. Thomas. Calm winds on St. Croix are a relatively infrequent occurrence $(5.6 \%$ of the time) but are more prevalent on St. Thomas (10.6\%) where the airport is somewhat sheltered and thereby subject to stable, light wind conditions before daybreak.

\subsection{Wind Speed Frequency}

Tables 3.7 and 3.8 contain seasonal and annual wind speed frequency distributions for St. Croix and St. Thomas respectively. The important wind speeds in this analysis are those within the normal operating range of the averagc WECS installation ( 3 through $13 \mathrm{~ms}^{-1}$ or 7 through $29 \mathrm{mi}-\mathrm{hr}^{-1}$ ). By 
Table 3.5. Wind direction frequency distributions for St. Croix with values given as percentages. Summary statistics show constancy with respect to east (C wrt E), constancy including calm winds ( $\mathrm{w} / \mathrm{calm}$ ), and other directions (SSE-W-NNE) expressed as percentages.

\begin{tabular}{crrrrr} 
Direction & Winter & Spring & $\underline{\text { Summer }}$ & $\underline{\text { Fall }}$ & $\underline{\text { Annual }}$ \\
\cline { 2 - 3 } & 6.15 & 4.32 & 4.49 & 7.45 & 5.60 \\
N & 2.35 & 0.68 & 1.02 & 3.17 & 1.80 \\
NNE & 4.45 & 1.38 & 1.93 & 5.26 & 3.24 \\
NE & 16.07 & 8.39 & 13.33 & 20.26 & 14.44 \\
ENE & 35.29 & 26.90 & 33.43 & 30.49 & 31.46 \\
E & 10.70 & 18.23 & 14.43 & 9.92 & 13.37 \\
ESE & 15.29 & 27.63 & 21.63 & 14.73 & 19.91 \\
SE & 5.69 & 8.42 & 5.42 & 4.52 & 6.05 \\
SSE & 1.62 & 2.83 & 2.00 & 1.82 & 2.08 \\
S & 0.47 & 0.67 & 0.73 & 0.66 & 0.63 \\
SSW & 0.33 & 0.24 & 0.42 & 0.31 & 0.32 \\
SW & 0.20 & 0.04 & 0.13 & 0.36 & 0.18 \\
WSW & 0.12 & 0.02 & 0.18 & 0.14 & 0.11 \\
W & 0.11 & 0.03 & 0.18 & 0.17 & 0.12 \\
WNW & 0.13 & 0.02 & 0.13 & 0.08 & 0.09 \\
NW & 0.27 & 0.11 & 0.18 & 0.27 & 0.21 \\
NNW & 0.77 & 0.09 & 0.30 & 0.41 & 0.39 \\
\hline Wrt E & 83.44 & 89.57 & 88.30 & 79.92 & 85.23 \\
C w/calm & 89.59 & 93.89 & 92.79 & 87.37 & 90.83 \\
SSE-W-NNE & 10.41 & 6.11 & 7.21 & 12.63 & 9.17
\end{tabular}


Table 3.6. Wind direction frequency distributions for St. Thomas with values given as percentages. Summary statistics show constancy with respect to east ( $C$ wrt $E$ ), constancy including calm winds ( $\mathrm{C}$ w/calm), and other directions (SSE-W-NNE) expressed as percentages.

\begin{tabular}{|c|c|c|c|c|c|}
\hline Direction & Winter & Spring & Summer & Fall & Annual \\
\hline CALM & 11.07 & 8.77 & 8.48 & 14.35 & 10.63 \\
\hline N & 1.30 & 0.59 & 0.33 & 0.95 & 0.80 \\
\hline NNE & 1.79 & 0.79 & 0.54 & 1.20 & 1.09 \\
\hline $\mathrm{NE}$ & 7.65 & 3.26 & 4.46 & 6.71 & 5.51 \\
\hline ENE & 23.58 & 17.10 & 25.33 & 23.93 & 22.37 \\
\hline E & 32.13 & 38.93 & 38.55 & 34.13 & 35.92 \\
\hline ESE & 12.08 & 20.21 & 14.26 & 10.54 & 14.38 \\
\hline SE & 5.53 & 7.58 & 5.17 & 4.33 & 5.70 \\
\hline SSE & 1.00 & 1.33 & 0.93 & 0.99 & 1.07 \\
\hline $\mathbf{S}$ & 1.24 & 0.81 & 0.87 & 1.34 & 1.06 \\
\hline SSW & 0.49 & 0.21 & 0.32 & 0.29 & 0.33 \\
\hline SW & 0.20 & 0.07 & 0.09 & 0.07 & 0.11 \\
\hline WSW & 0.08 & 0.01 & 0.07 & 0.05 & 0.05 \\
\hline W & 0.35 & 0.10 & 0.18 & 0.32 & 0.24 \\
\hline WNW & 0.32 & 0.09 & 0.16 & 0.16 & 0.19 \\
\hline NW & 0.59 & 0.08 & 0.12 & 0.37 & 0.29 \\
\hline NNW & 0.26 & 0.08 & 0.11 & 0.25 & 0.27 \\
\hline$C$ wrt $E$ & 80.97 & 87.08 & 87.77 & 79.64 & 83.88 \\
\hline C w/calm & 92.04 & 95.85 & 96.25 & 93.99 & 94.51 \\
\hline$S S E-W-N N E$ & 7.96 & 4.15 & 3.75 & 6.01 & 5.49 \\
\hline
\end{tabular}


Table 3.7. Wind speed frequency distributions [\%] for St. Croix. Summary statistics show the percent of time wind speeds are within the ngrmal WECS operating range (3 $\mathrm{ms}^{-1} \leq$ WECS OR $\leq 13 \mathrm{~ms}^{-1}$ ) and also the WECS OR with respect to constancy (OR X C) from Table 3.5 .

\begin{tabular}{|c|c|c|c|c|c|}
\hline Wind Speed & Winter & Spring & Summer & Fal1 & Annual \\
\hline CALM & 6.15 & 4.32 & 4.49 & 7.45 & 5.60 \\
\hline 1 & 2.22 & 0.91 & 0.91 & 2.06 & 1.52 \\
\hline 2 & 15.34 & 11.41 & 12.60 & 20.16 & 14.85 \\
\hline 3 & 17.27 & 15.91 & 17.38 & 20.57 & 17.76 \\
\hline 4 & 16.63 & $14: 47$ & 16.95 & 17.28 & 16.30 \\
\hline 5 & 16.79 & 16.88 & 17.06 & 15.84 & 16.64 \\
\hline 6 & 9.47 & 11.46 & 10.45 & 7.56 & 9.75 \\
\hline 7 & 5.84 & 8.09 & 7.29 & 3.99 & 6.32 \\
\hline 8 & 6.44 & 10.52 & 7.57 & 3.49 & 7.04 \\
\hline 9 & 2.09 & 3.34 & 2.73 & 0.79 & 2.25 \\
\hline 10 & 1.30 & 2.02 & 1.74 & 0.50 & 1.39 \\
\hline 11 & 0.20 & 0.44 & 0.42 & 0.15 & 0.30 \\
\hline 12 & 0.09 & 0.10 & 0.18 & 0.08 & 0.11 \\
\hline 13 & 0.15 & 0.14 & 0.15 & 0.05 & 0.12 \\
\hline 14 & 0.01 & 0.00 & 0.04 & 0.01 & 0.02 \\
\hline 15 & & 0.00 & 0.01 & 0.00 & 0.01 \\
\hline 16 & & & & 0.00 & 0.00 \\
\hline 17 & & & 0.00 & & 0.00 \\
\hline 18 & & & 0.01 & & 0.00 \\
\hline 25 & & & 0.00 & & 0.00 \\
\hline 26 & & & 0.00 & & 0.00 \\
\hline 28 & & & 0.00 & & 0.00 \\
\hline WECS OR & 76.28 & 83.36 & 81.94 & 70.32 & 78.00 \\
\hline$(\mathrm{OR} \times \mathrm{C})$ & $(63.65)$ & $(74.67)$ & $(72.35)$ & $(56.20)$ & $(66.48)$ \\
\hline
\end{tabular}


Table 3.8. Wind speed frequency distributions [\%] for St. Thomas. Summary statistics show the percent of time wind speeds are within the ngrmal WECS operating range (3 $\mathrm{ms}^{-1} \leq$ WECS OR $\leq 13 \mathrm{~ms}^{-1}$ ) and also the WECS OR with respect to constancy (OR X C) from Table 3.6 .

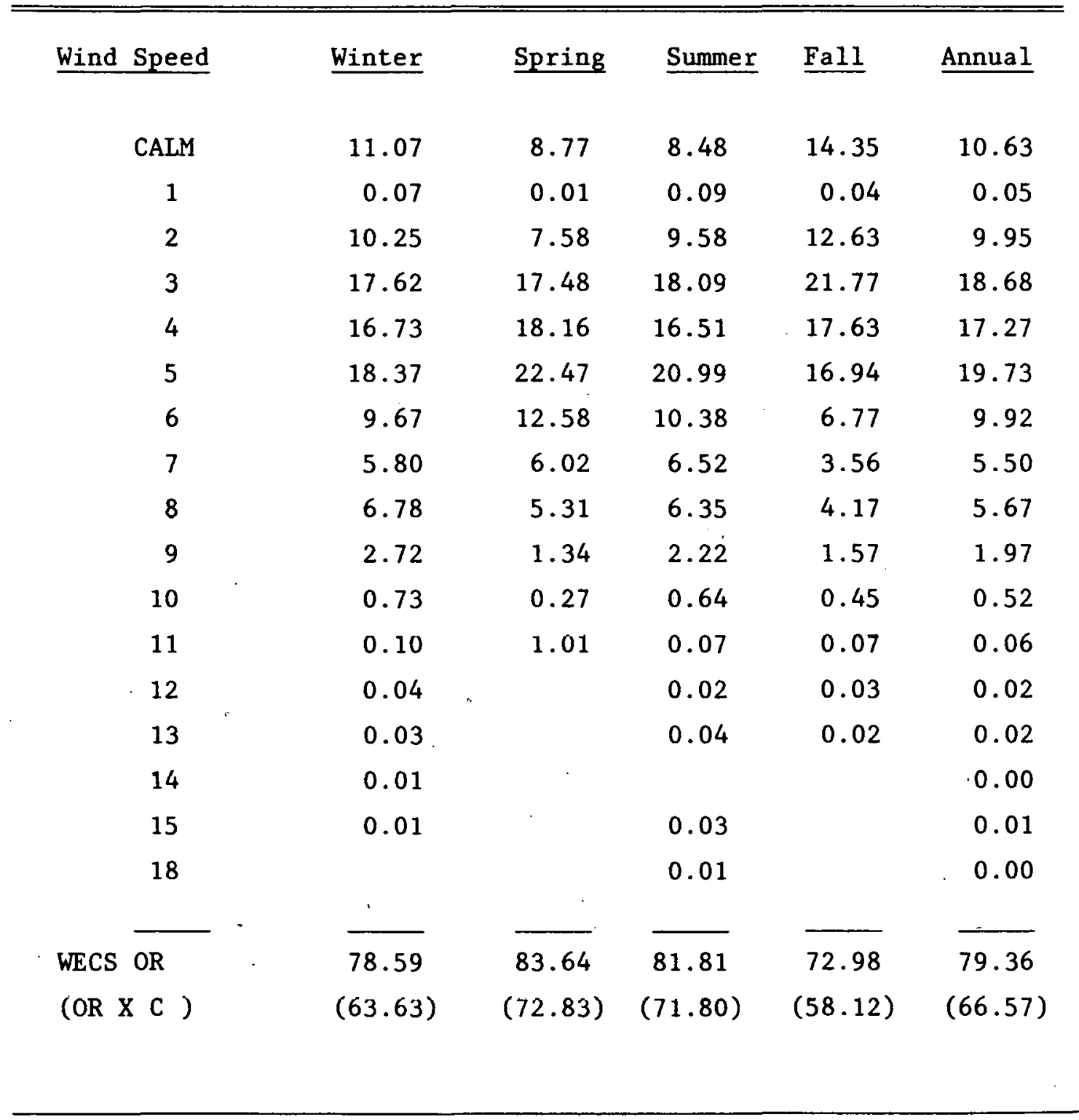


multiplying the percentage of time wind speeds are within the normal WECS operating range (WECS $O R$ ) by the respective constancy (C) values from Tables 3.5 and 3.6, the amount of time useable wind movement (OR X C) available for a WECS with a fixed east orientation is obtained (Tables 3.7 and 3.8 ).

These data show great similarities in the amount of available wind energy at the surface for the two islands, both annually and by season. The frequency of wind speeds greater than $13 \mathrm{~ms}^{-1}\left(29 \mathrm{mi}^{-\mathrm{hr}^{-1}}\right)$ is considerably less than $0.05 \%$, again indicating that potentially damaging winds are relatively rare occurrences. Useable wind power on both islands peaks during the Spring and holds at a high level through the Summer, dropping to a minimum in the Fall.

\subsection{Other Wind Data}

Since much of the surface observation data available for St. Croix and St. Thomas is several decades old, it was felt that a recent year should be analyzed using the same techniques. The year 1978 was chosen for the comparison, as it was the most recent year for which complete observations were available from both islands. Unfortunately, in the interim between 1961 and 1978, nighttime observations were discontinued and wind direction reports were changed from 16 compass points to 10 degree increments. Thus, the only data for which direct comparisons are possible are the means of the hourly observations of wind speed (Table 3.9). The RMS differences in these data sets are well within the average standard deviations (around $2 \mathrm{~ms}^{-1}$ or $4.5 \mathrm{mi}^{-\mathrm{hr}^{-1}}$ ) of the long term data, indicating compatibility.

Another set of wind data was obtained from sporadic observations taken in 1978 at the U. S. Coast Guard Marine Safety Detachment at a rather sheltered location on Long Bay in Charlotte Amalie on St. Thomas and at the Fairleigh Dickinson West Indies Laboratory at Tague Bay near the windward end of St. 
Table 3.9. Comparison of the long-term surface hourly mean wind speed [ms ${ }^{-1}$ ] data to 1978 data taken at the same locations on St. Croix and St. Thomas.

\begin{tabular}{|c|c|c|c|c|}
\hline \multirow[b]{2}{*}{ Hour } & \multicolumn{2}{|c|}{ St. Croix } & \multicolumn{2}{|c|}{ St. Thomas } \\
\hline & 1951-61 & $\underline{1978}$ & 1953-61 & $\underline{1978}$ \\
\hline 07 & 3.5 & 3.9 & 3.3 & 4.1 \\
\hline 08 & 4.3 & 4.5 & 4.3 & 4.9 \\
\hline 09 & 5.3 & 5.1 & 5.0 & 5.5 \\
\hline 10 & 5.8 & 5.5 & 5.3 & 5.7 \\
\hline 11 & 6.1 & 5.7 & 5.4 & 5.8 \\
\hline 12 & 6.2 & 5.8 & 5.5 & 5.9 \\
\hline 13 & 6.2 & 5.6 & 5.5 & 6.1 \\
\hline 14 & 6.1 & 5.6 & 5.5 & 6.0 \\
\hline 15 & 5.9 & 5.3 & 5.4 & 5.8 \\
\hline 16 & 5.5 & 5.1 & 5.1 & 5.7 \\
\hline 17 & 5.1 & 4.9 & 4.9 & 5.5 \\
\hline 18 & 4.2 & 4.5 & 4.5 & 5.1 \\
\hline 19 & 3.6 & 4.1 & 3.9 & 4.4 \\
\hline 20 & 3.3 & 3.9 & 3.6 & 4.1 \\
\hline 21 & 3.3 & 3.9 & 3.5 & 4.0 \\
\hline RMS Difference & \multicolumn{2}{|c|}{0.44} & \multicolumn{2}{|c|}{$0.54^{\circ}$} \\
\hline
\end{tabular}

Note: $\quad 1 \mathrm{~ms}^{-1}=2.24 \mathrm{mi}^{-\mathrm{hr}^{-1}}$ 
Croix. Most observations were taken during daylight hours and began in March. It was hoped that such sketchy data would provide further information on the available wind power. Again, only mean hourly wind speed values could be meaningfully compared.

The comparison between the airport and the respective coastal stations on each island (Table 3.10) shows that both coastal sites tend to have a lower mean wind speed. The lower mean speed at the station in Long Bay may be due to the influences of sheltering topography and the city; but the station at Tague Bay is on the upwind side of St. Croix where higher speeds would be expected relative to the airport station. Because of the questionable results of the comparison on St. Croix and since no information is available concerning the measuring equipment, calibration procedures, and the observation techniques at the coastal stations, these data were disregarded.

\subsection{Low Level Wind Profiles}

In order to assess the available wind power at various potential WECS sites, it was necessary to be able to estimate wind speeds at locations different from Hamilton and Truman Airports. It was decided to accomplish this by matching wind speed with elevation. The long term source of upper winds data closest to the USVI is the National Weather Service (NWS) rawinsonde station at San Juan, Puerto Rico, some $120 \mathrm{~km}(75 \mathrm{mi})$ west of St. Thomas and about $160 \mathrm{~km}$ (99 $\mathrm{mi}$ ) WNW of $\mathrm{St}$. Croix. A rawinsonde observation involves radio tracking of an instrumented balloon.

From these data, low level wind profiles were constructed. Also available was a 12-year compilation of $1500 \mathrm{~m}$ MSL pilot balloon (pibal) winds from.U. S. Air Force observations taken at Benedict Field (now Alexander Hamilton Airport) on St. Croix. A pibal ovservation involves visual tracking of a balloon with a theodolite. The San Juan data are representative of winds at around sunrise 
Table 3.10. Comparison of long-term surface diurnal mean wind [ms ] data with sporadic data taken in 1978 at marine coastal observation sites on St. Croix and St. Thomas.

\begin{tabular}{|c|c|c|c|c|}
\hline \multirow[b]{2}{*}{ Hour } & \multicolumn{2}{|c|}{ St. Croix } & \multicolumn{2}{|c|}{ St. Thomas } \\
\hline & $1951-61$ & 1978 & 1953-61 & 1978 \\
\hline 08 & 4.3 & 4.1 & 4.3 & 2.6 \\
\hline 11 & 6.1 & 4.7 & 5.4 & 3.0 \\
\hline 14 & 6.1 & 4.7 & 5.5 & 3.7 \\
\hline RMS Difference & & & & \\
\hline
\end{tabular}

Note: $\quad 1 \mathrm{~ms}^{-1}=2.24 \mathrm{mi}-\mathrm{hr}^{-1}$ 
and sunset, while the Benedict Field observations were taken at midnight and midday. Both data sets are thus biased, as the San Juan observations miss the peak diurnal maximum wind that occurs midday, and the Benedict Field data is weighed too heavily to the midday maximum. However, by averaging the $1500 \mathrm{~m}$ MSL rawin winds from San Juan with the $1500 \mathrm{~m}$ MSL St. Croix pibal winds, a fairly good approximation of the average daily $1500 \mathrm{~m}$ MSL winds for the USVI area may be obtained.

Utilizing the averaged daily $1500 \mathrm{~m}$ MSL wind, the mean diurnal surface winds from St. Croix and St. Thomas (Table 3.2), and the long-term averaged upper air profiles from San Juan as a structural baseline, the annual and seasonal low level wind profiles for St. Croix and St. Thomas/St. John were constructed by means of a simple linear interpolation model. The results of this modeling appear in Table 3.11. These low level wind profiles were used in conjunction with topographic maps to construct surface wind speed analyses.

\subsection{Surface Wind Speed Analysis}

Utilizing the low level wind profiles in Table 3.11 and the topographic maps of St. Croix, St. Thomas, and St. John (Appendix B), an isotach (a line of constant wind speed) analysis was performed for each island. Maps of the annual mean wind speed distribution and the mean wind speed distribution for each season were constructed for St. Croix (Figures 3.4 - 3.8), St. Thomas (Figures $3.9-3.13$ ), and St. John (Figures $3.14-3.18$ ). These maps are strictly guides to pinpoint areas of high wind energy potential. The isotachs were drawn with respect to the surface elevation and represent the free air flow at those elevations. The analyses did not take into account height of forest canopy, surface roughness, windward versus leeward exposure, or terrain enhancement, all of which will be considered in Section 4.0, Preliminary WECS Site Selection. 


\title{
REPORT B
}

\author{
ECONOMIC FEASIBILITY. OF WIND ENERGY \\ FOR THE U.S. VIRGIN ISLANDS
}

\author{
David E. Ball \\ David M. Boyd \\ Stephen C. Nelson \\ Laurie E. Smith
}

June 1981

Southern Solar Energy Center

61 Perimeter Park

Atlanta, Georgia 30341 


\section{ABSTRACT}

A preliminary assessment of the economic feasibility of wind energy conversion systems (WECS) for the U.S. Virgin Islands is presented. The current and near-term economics of available WECS for residential, commercial, and wind farm applications were analyzed. The sensitivity of WECS economic worth to a variety of factors was also investigated. Preliminary conclusions highlighted the favorable economics regarding larger, commercial, and wind farm scale machines. 
Abstract................................................ i

List of Figures...............................................

List of Tables............................................ iv

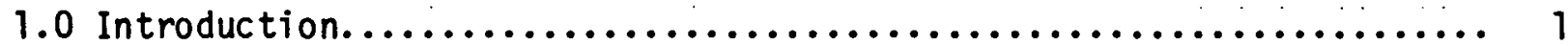

1.1 Levelized Cost of Energy............................... 1

1.2 Breakeven Analysi s...................................... 3

1.3 Sensitivity Analysi $5 . . \ldots \ldots \ldots \ldots \ldots \ldots \ldots \ldots \ldots \ldots \ldots \ldots \ldots,{ }^{3}$

1.4 Cumulative Savings................................. 5

1.5 WECS Characteristics and Basic Assumptions................. 5

2.0 Residential Application.................................. 8

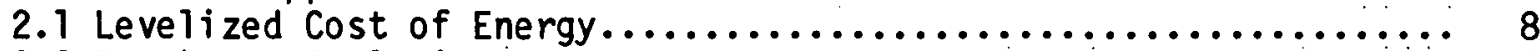

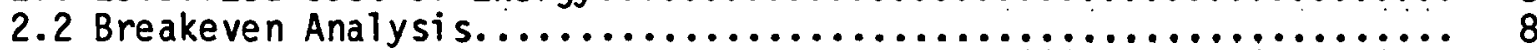

2.3 Sensitivity Analysi $. . \ldots \ldots \ldots \ldots \ldots \ldots \ldots \ldots \ldots \ldots \ldots \ldots,{ }^{8}$

2.4 Cumulative Savings............................. 8

3.0 Commercial Application.................................... 13

3.1 Levelized Cost of Energy ................................... 13

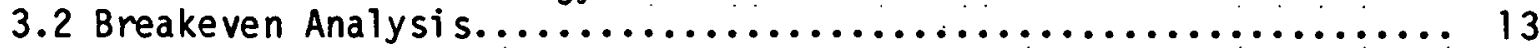

3.3 Cumulative Savings................................. 13

4.0 Wind Farm Application....................................... 16

4.1 Levelized Cost of Energy................................. 16

4.2 Breakeven Analysis...................................... 16

4.3 Cumulative Net Earnings............................. 16

5.0 Preliminary Conclusions................................ 19

5.1 WECS Annual Output.................................... 19

5.2 System Sizing/Load Match................................. 19

5.3 Installed WECS System Cost................................. 19

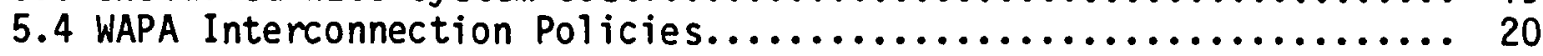

6.0 Recommendations for Further Studies....................... 21 


\section{LIST OF FIGURES}

Figure

$\underline{\text { Page }}$

1. Levelized Cost of Energy: Residential Application

2. Sensitivity of Cost of Energy

3. Residential Application: Cumulative Savings

4. Levelized Cost of Energy: Commercial Application

5. Commercial Application: Cumulative Savings

6. Levelized Cost of Energy: Wind Farm Application

7. Wind Farm Application: Cumulative Net Earnings 


\section{$\underline{\text { LIST OF TABLES }}$}

$\underline{\text { Table }}$

$\underline{\text { Page }}$

1. Levelized Cost of Energy: Four Viewpoints

4

2. Characteristics of WECS 6

3. Basic Assumptions 7

4. Comparison of WECS Breakeven Periods 10 


\subsection{Introduction}

The current energy supply situation in the U.S. Virgin Islands consists of a dependence upon imported petroleum products. Consequently, the electric utility rates are among the most expensive in the United States, with 1981 residential rates averaging $22 \phi / \mathrm{kWh}$ (in contrast to average mainland rates of $4 \notin$ to $7 \notin$ per $\mathrm{kWh})$. Fortunately, the Virgin Islands possess good wind energy resources, as has been documented in "The Virgin Islands Wind Energy Siting Analysis" prepared for the Southern Solar Energy Center by the Research Triangle Institute.

The purpose of this report is to evaluate the economic feasibility of currently available wind energy conversion systems (WECS) for an immediate and near-term contribution to the Virgin Islands' energy supply. Specific applications to be analyzed include residential, commercial, and large scale wind farm/utility applications. Among the WECS available for installation on the Virgin Islands, the following WECS system sizes (representative of commercial models) were evaluated:

$1 \quad \mathrm{KW}$ Residential Application

$1.5 \mathrm{KW}$ Residential Application

2 KW Residential Application

25 KW Commercial Application

500 KW Wind Farm/Utility Application

The criteria for evaluating economic feasibility will include calculating the levelized cost of energy, performing a breakeven analysis, testing the sensitivity of WECS cost of energy to various factors, and performing a cash flow analysis so as to determine cumulative savings that accrue from the WECS.

\subsection{Levelized Cost of Energy}

Assessing the economic worth of a wind turbine generator requires the examination of costs over the lifetime of the equipment. Virtually all renewable energy sources require an auxiliary or backup system. This means that the user is confronted with assessing the cost of the combined system, not. just the cost of electricity from wind. The methods used in this analysis present concise techniques to evaluate the cost of energy under different options.

In the paragraphs below, expressions for life-cycle costs, levelized cost of energy, and years to breakeven are defined under various assumptions. Throughout the discussion we will rely on the following notation:

$\begin{array}{lll}\text { COST } & =\text { installed system costs } & (\$) \\ \text { TC } & =\text { tax credit } & (\$) \\ \text { OMI } & =\text { first-year cost of operations, maintenance \& insurance } & (\$) \\ \text { EOMI }= & \text { nominal annual escalation rate for OMI } & (\%) \\ \text { RBUY }= & \text { retail electric rate (base year) } & (\$ / \mathrm{kWh}) \\ \text { EBUY }= & \text { nominal annual escalation rate for RBUY } & (\%) \\ \text { RSELL } & \text { electric rate available to sell electricity to utility } & (\$ / \mathrm{kWh}) \\ & \text { (base year) } & \end{array}$




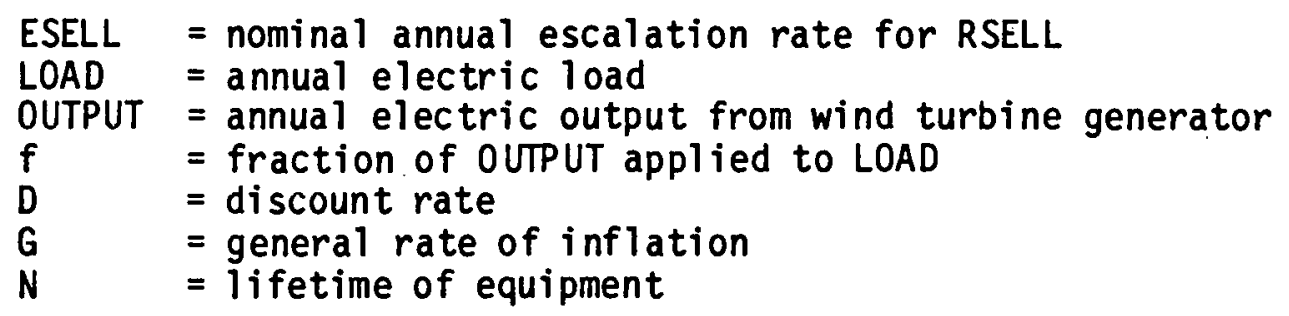

(\%)

(kWh)

(kWh)

(years)

A. $\quad \mathrm{COE}_{1}$ : Cost of Wind-Generated El ectricity

Without regard to application, the costs associated with installing and maintaining a wind turbine can be expressed as:

$L C C_{w}=\operatorname{COST}-T C+O M I * \sum \frac{(1+\text { EOMI })^{i}}{(1+D)^{i}}$

This is the present worth of the life cycle costs of the wind turbine generator. If the annual electric output can be estimated (based on available wind, etc.) the levelized cost of energy can be expressed as:

$$
\operatorname{COE}_{1}=\frac{\operatorname{LCC}_{W} * \operatorname{CRF}(D, N)}{\text { OUTPUT }}
$$

where $\operatorname{CRF}(D, N)$ is the standard capital recovery factor for rate $D$ and lifetime $N$.

Note that this value $\mathrm{COE}_{7}$ is the levelized cost of electricity from the manufacturer's viewpoint, since there is no consideration of how well the load matches the system output.

B. $\operatorname{COE}_{2}$ : Cost of Load-Utilized Wind-Generated Electricity

When a wind turbine generator is used for a particular application (residential service, water pumping, etc.), the question of load match may decrease the value of the electricity. Thus, the cost increases per unit of output. For this reason the levelized cost of electricity based on the load match $f$ is a more appropriate measure to evaluate the cost of electricity.

$$
\mathrm{COE}_{2}=\frac{\mathrm{LCC}_{w} \star \operatorname{CRF}(D, N)}{\mathrm{f}^{\star} \text { OUTPUT }}
$$

This can be viewed as the cost to the user of the wind-generated electricity as it can be utilized for his application. If the user can modify his requirements so that he relies on this source of electricity alone, he can view this as his cost of energy. An example might be irrigation or battery charging. 
C. $\mathrm{COE}_{3}$ : Cost of Electricity to User

When the requirements for electricity cannot be met through the use of the wind turbine alone, electricity must be purchased. Thus, the life-cycle cost of the entire system $L C C_{s}$ depends on the projected cost of back-up energy.

$L C C_{s}=L C C_{w}+(L O A D-f \star$ OUTPUT $) *$ RBUY $\star \sum \frac{(1+E B U Y)^{i}}{(1+D)^{i}}$

Corresponding to this cost, we represent the levelized cost of energy as:

$$
\operatorname{COE}_{3}=\frac{\operatorname{LCC} C_{S} \star \operatorname{CRF}(D, N)}{\operatorname{LOAD}}
$$

This is the cost of energy from the user's perspective, in that it recognizes the reliance on back-up energy and assesses the cost of the combined system in meeting the total load.

D. $\mathrm{COE}_{4}$ : Cost of Electricity to User Under Sell back Agreement

The difficulty in matching the output of the wind turbines to the load often leads to excess electrical output. Under agreement from the local utility to purchase this electricity, the economic worth of the system can benefit. The form of sellback usually is in the form of an agreement that the owner can sell electricity to the utility at a rate less than the utility's retail electric rates. Thus, the life-cycle cost $L_{C C} C^{\prime}$ under this arrangement can be computed as

$$
\operatorname{LCC}_{S}^{\prime}=\mathrm{LCC}_{S}-(1-f) \text { * OUTPUT * RESELL * } \sum \frac{\left(1+\text { ESELL }^{i}\right.}{(1+D)^{i}}
$$

The corresponding levelized cost of electricity can be represented as:

$$
\mathrm{COE}_{4}=\frac{\mathrm{LCC}_{\mathrm{S}}{ }^{\prime} * \operatorname{CRF}(\mathrm{D}, \mathrm{N})}{\operatorname{LOAD}}
$$

Again, this represents the cost of energy from the user's perspective, assuming the ability to sell his excess power.

Table 1 summarizes the levelized cost of energy equations.

\subsection{Breakeven Analysis}

Another useful method for evaluating the economic feasibility of one energy investment versus another is the breakeven method. Breakeven analysis, as defined in this discussion, refers to the year that the sum of annual savings from the WECS equals the investment in the WECS. The year to breakeven provides an indication of how long it will take for the system to 
1. Cost of Wind-Generated Electricity (manufacturer's viewpoint)

$$
\begin{gathered}
\mathrm{LCC}_{W}=\mathrm{COST}-\mathrm{TC}+\text { OMI } * \sum \frac{(1+\text { EOMI })^{i}}{(1+D)^{4}} \\
\mathrm{COE}_{1}=\frac{\mathrm{LCC} \mathrm{C}_{W} * \mathrm{CRF}}{\text { OUTPUT }}
\end{gathered}
$$

2. Cost of Load-Utilized Wind-Generated Electricity (load match).

$$
\mathrm{COE}_{2}=\frac{\mathrm{LCC}_{w} * \text { CRF }}{\mathrm{F} * \text { OUTPUT }}
$$

3. User's Cost of Electricity (including back-up)

$$
\begin{aligned}
L C C_{s}= & L C C_{w}+(L O A D-F * \text { OUTPUT }) * R B U Y * \sum \frac{(1+E B U Y)^{1}}{(1+D)^{1}} \\
& \operatorname{COE}_{3}=\frac{L C C_{s} * C R F}{L O A D}
\end{aligned}
$$

4. User's Cost of Electricity (including back-up and sellback)

$$
\begin{aligned}
& L C C_{s^{\prime}}=L C C_{S}-(1-F) * \text { OUTPUT * RSELL } * \sum \frac{(1+\text { ESELL })^{1}}{(1+D)^{1}} \\
& \mathrm{COE}_{4}=\frac{L C C_{s^{\prime}} * C R F}{L O A D}
\end{aligned}
$$


pay for itself. Breakeven analysis does not, however, provide any indication of how the system performs after the breakeven period or whether the return on investment for a particular application is attractive.

\subsection{Sensitivity Analysis}

The sensitivity of WECS cost of energy for a residential application is provided to illustrate the impact of changes in various factors on the cost of energy. Factors analyzed include system cost, wind speed, operations, maintenance, and insurance $(0+M+I)$ expenses, the sellback rate provided by the utility, and the load match to output characteristics.

\section{i.4 Cumulative Savings}

A cash flow analysis was performed for each WECS application to determine the cumulative savings that accrue from the WECS. Cumulative savings over the life of the WECS illustrate the effects over time of the savings that are being accumulated. It also shows the effect of rising electric utility rates compared to the relatively constant cost of wind-generated electricity.

\subsection{WECS Characteristics and Basic Assumptions}

The power production and estimated system costs for the WECS is outlined in Table 2. The residential applications are assumed to be installed in 1981, and the commercial and wind fam/utility applications are assumed to be installed in 1983, due to the lead time necessary for obtaining the equipment. Other basic assusmptions are outlined in Table 3. 
TABLE 2. CHARACTERISTI OF WECS

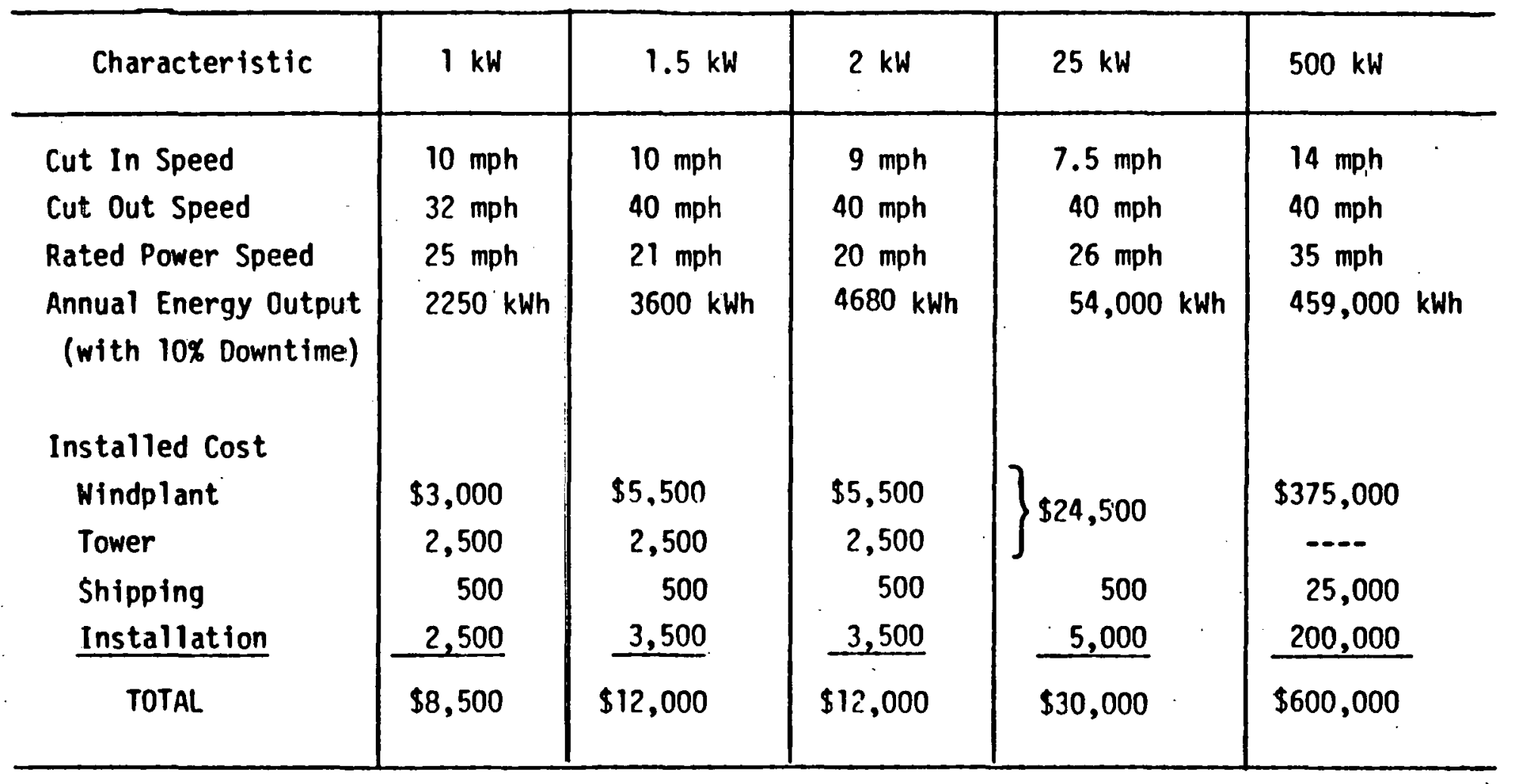


TABLE 3. BASIC ASSUMPTIONS ${ }^{1}$

\begin{tabular}{lccc}
\hline \multicolumn{1}{c}{ Analysis Factor } & $\begin{array}{c}\text { Residential } \\
\text { (Installed 1981) }\end{array}$ & $\begin{array}{c}\text { Commercial } \\
\text { (Installed 1983) }\end{array}$ & $\begin{array}{c}\text { Wind Farm } \\
\text { (Installed 1983) }\end{array}$ \\
\hline Annual Load & $6000 \mathrm{kWh}$ & $120,000 \mathrm{kWh}$ & N.A. \\
WECS Ouput Applied to Load & $60 \%$ & $80 \%$ & N.A. \\
Average Annual Windspeed & $13 \mathrm{mph}$ & $13 \mathrm{mph}$ & $14 \mathrm{mph}$ \\
WECS Lifetime & 20 years & 20 years & 20 years \\
Financing & None & None & $\$ 450,000$ at $14 \%$ (10 years) \\
Sales \& Property Tax & None & None & None \\
Income Tax Adjustment & None & $50 \%$ Effective Rate & $50 \%$ Effective Rate \\
Depreciation & N.A. & Straightline, 7 years & Straightline, 7 years \\
General Inflation Rate & $10 \%$ & $10 \%$ & $10 \%$ \\
Discount Rate & $10 \%$ & $10 \%$ & $10 \%$ \\
WAPA Retail Rate (1981) & $\$ .22 / \mathrm{kWh}$ & $\$ .22 / \mathrm{kWh}$ & $\$ .22 / \mathrm{kWh}$ \\
WAPA Retail Rate Escalator & $15 \%$ & $15 \%$ & $15 \%$ \\
WAPA Buyback Rate & $50 \%$ of Retail & $50 \%$ of Retail & $50 \%$ of Retail \\
Annual Insurance Premium & $\$ 200$ & $\$ 200$ & $\$ 5000$ \\
First Year O \& M Cost & $5 \%$ of Windplant & $5 \%$ of Windplant & $5 \%$ of Windplant \\
\hline
\end{tabular}

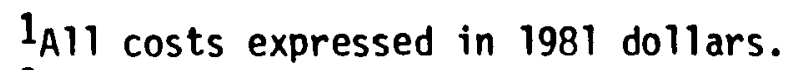

${ }^{2}$ Retail rate quoted from V. I. Energy office, June 1981. 


\subsection{Residential Application}

Three wind systems were analyzed for the typical residential application. The WECS were small generators, wi th rated power of $1 \mathrm{~kW}, 1.5 \mathrm{~kW}$, and $2 \mathrm{~kW}$.

\subsection{Levelized Cost of Energy}

Figure 1 illustrates the relative results of the three residential WECS in terms of levelized cost of energy. The dotted "utility service" line represents the levelized cost of electricity from the Virgin Islands Water and Power Authority (WAPA).

\subsection{Breakeven Analysis}

The years to breakeven on the residential WECS analyzed in this report can be found in Table 4 . The years to breakeven appears relatively lengthy due primarily to the high cost per kilowatt of capacity of the smaller WECS when compared to the larger machines.

\subsection{Sensitivity Analysis}

The impact of varying key factors in the WECS output and cost is presented in Figure 2. The percent change in the levelized cost of energy of a $1.5 \mathrm{~kW}$ WECS was calculated given percent changes in various inputs. The inputs that were varied included system cost, the wind speed, the operations, maintenance, and insurance $(O+M+I)$ cost, the sellback rate (rate WAPA might pay for surplus electricity), and the load match to output function. It can be seen that the wind speed and the load match variables had the greatest impact on levelized cost of energy.

\subsection{Cumulative Savings}

Figure 3 illustrates the profile of cumulative savings over the life of the WECS. Since WAPA currently does not buy back any excess power from small power producers, both with selliback and without are presented. It can be seen that sellback of excess power to WAPA is a much more attractive alternative than wi thout. 
FIGURE 1. LEVELIZED COST OF ENERGY

RESIIETIL APLICATIO

$\bullet$

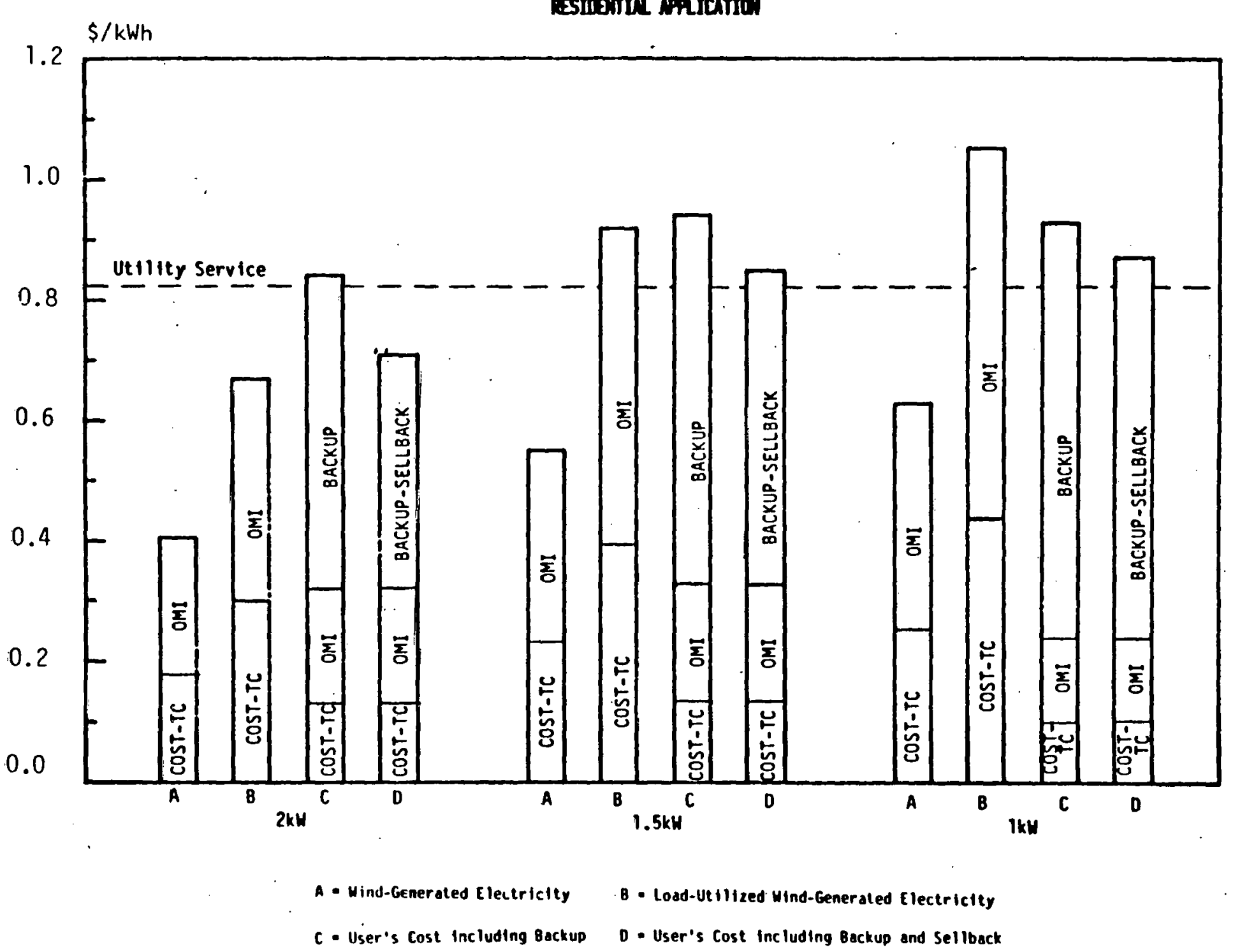


TABLE 4. COMPARISON OF WECS BREAKEVEN PERIODS

\begin{tabular}{|c|c|c|c|}
\hline \multirow[b]{2}{*}{ Application } & \multirow[b]{2}{*}{$\begin{array}{c}\text { Installed } \\
\text { System Cost }\end{array}$} & \multicolumn{2}{|c|}{ Years to Breakeven Undiscounted } \\
\hline & & With Sellback & W/O Sellback \\
\hline $1 \mathrm{~kW}$ Residential & $\$ 8,500$ & 14 & 17 \\
\hline $1.5 \mathrm{~kW}$ Residential & $\$ 12,000$ & 12 & 15 \\
\hline $2 \mathrm{~kW} \cdot$ Residential & $\$ 10,000$ & 8 & 9 \\
\hline & $\$ 12,000$ & 9 & 12 \\
\hline & $\$ 14,000$ & 10 & 13 \\
\hline $25 \mathrm{~kW}$ Commercial " & $\$ 30,000$ & 3 & 3 \\
\hline $500 \mathrm{~kW}$ Windf arm & $\$ 600,000$ & 10 & N.A. \\
\hline
\end{tabular}

In 1983 Dollars, and assumes the buyback rate is one-half of retail rate of $\$ .29$. 


\section{FIGURE 2. SENSITIVITY OF COST OF ENERGY}

\section{$1.5 \mathrm{~kW}$, Residential, With Sellback}
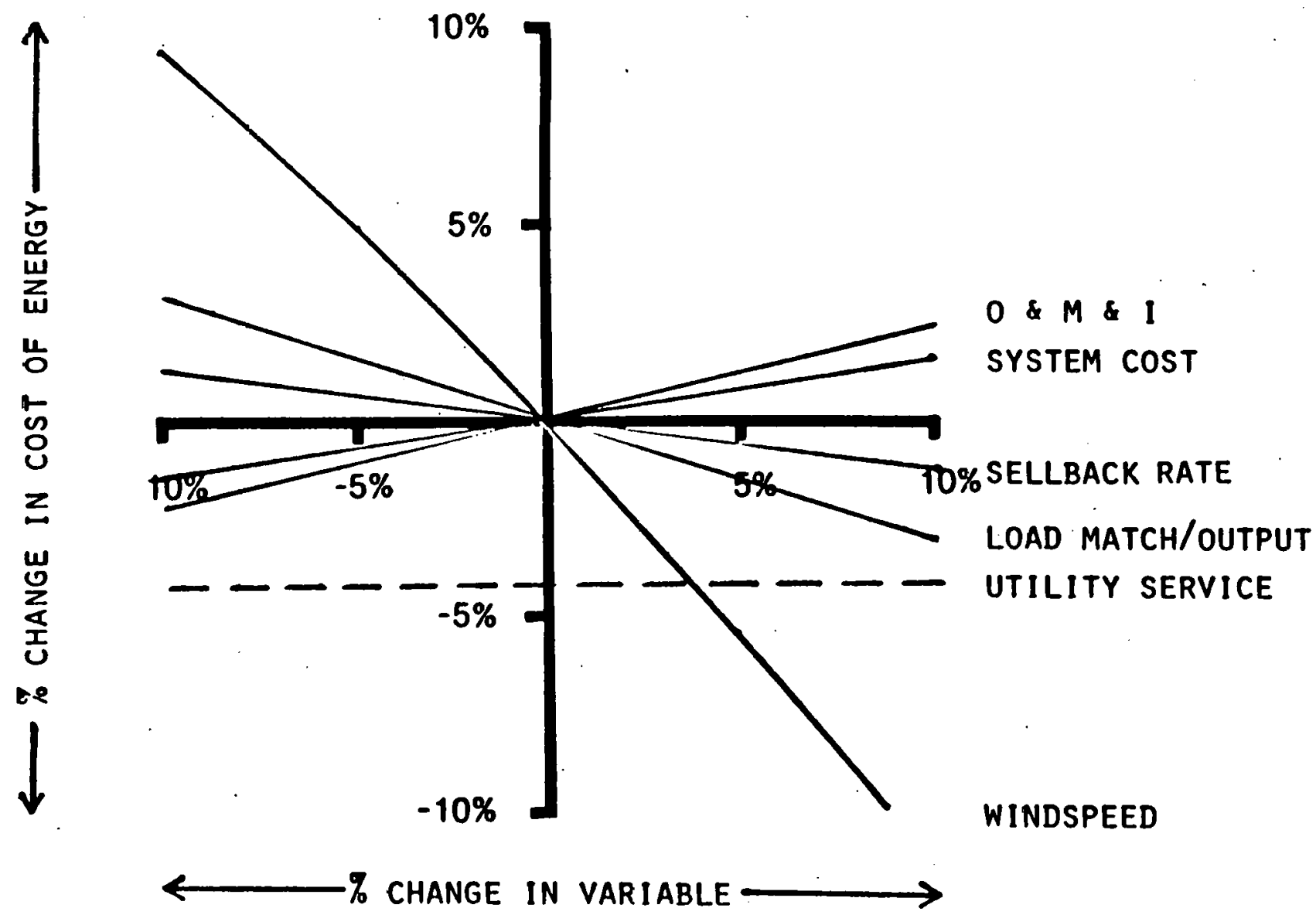

SYSTEM COST: . $\$ 12,000$

WECS OUTPUT: $\quad 3600 \mathrm{kWH} /$ YEAR

ANNUAL LOAD: $\quad 6000 \mathrm{kWH} /$ YEAR
ELECTRIC RATE: 22 $\$ / \mathrm{KWH}$

SELLBACK RATE: HALF OF RETAIL RATE

$0 \& M \& 1: \quad 4 \%$ OF INSTALLED COST 


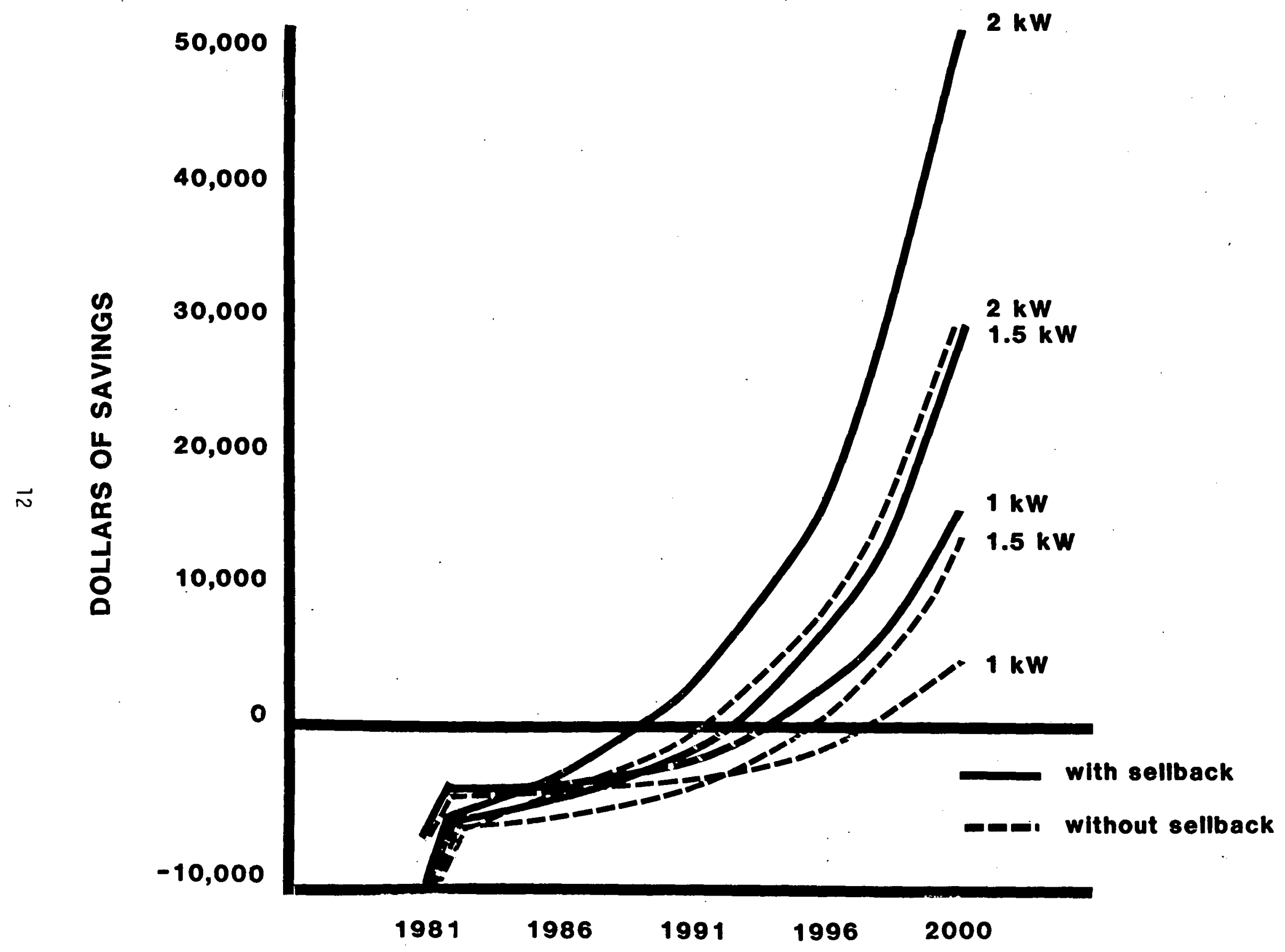




\subsection{Commercial Applications}

Commercial applications present a very promising opportunity for the utilization of wind energy, as is shown by the following analysis. Typical commercial applications for the Virgin Islands might be supplying electricity to a condominium development, a hotel, or a rum distillery.

\subsection{Levelized Cost of Energy}

The levelized cost of energy for one $25 \mathrm{~kW}$ WECS and a configuration of two $25 \mathrm{~kW}$ WECS is illustrated in Figure 4. It is important to observe that all WECS options are significantly below the levelized cost of WAPA electricity.

\subsection{Breakeven Analysis}

The commercial application of one $25 \mathrm{~kW}$ WECS provides for a three-year breakeven period (see Table 4). This emphasizes the very favorable economics for the commercial application of a $25 \mathrm{~kW}$ WECS.

\subsection{Cumulative Savings}

Since the commercial application of one $25 \mathrm{~kW}$ WECS breaks even in the third year, it is not surprising that the cumulative savings shown in Figure 5 are as impressive as the graph shows. The positive economic benefits from the $25 \mathrm{~kW}$ WECS are very significant. 
FIGURE 4. LEVEL D COST OF ENERGY

a PCIN APpitation

$\$ / \mathrm{kWh}$

$\vec{\Phi}$

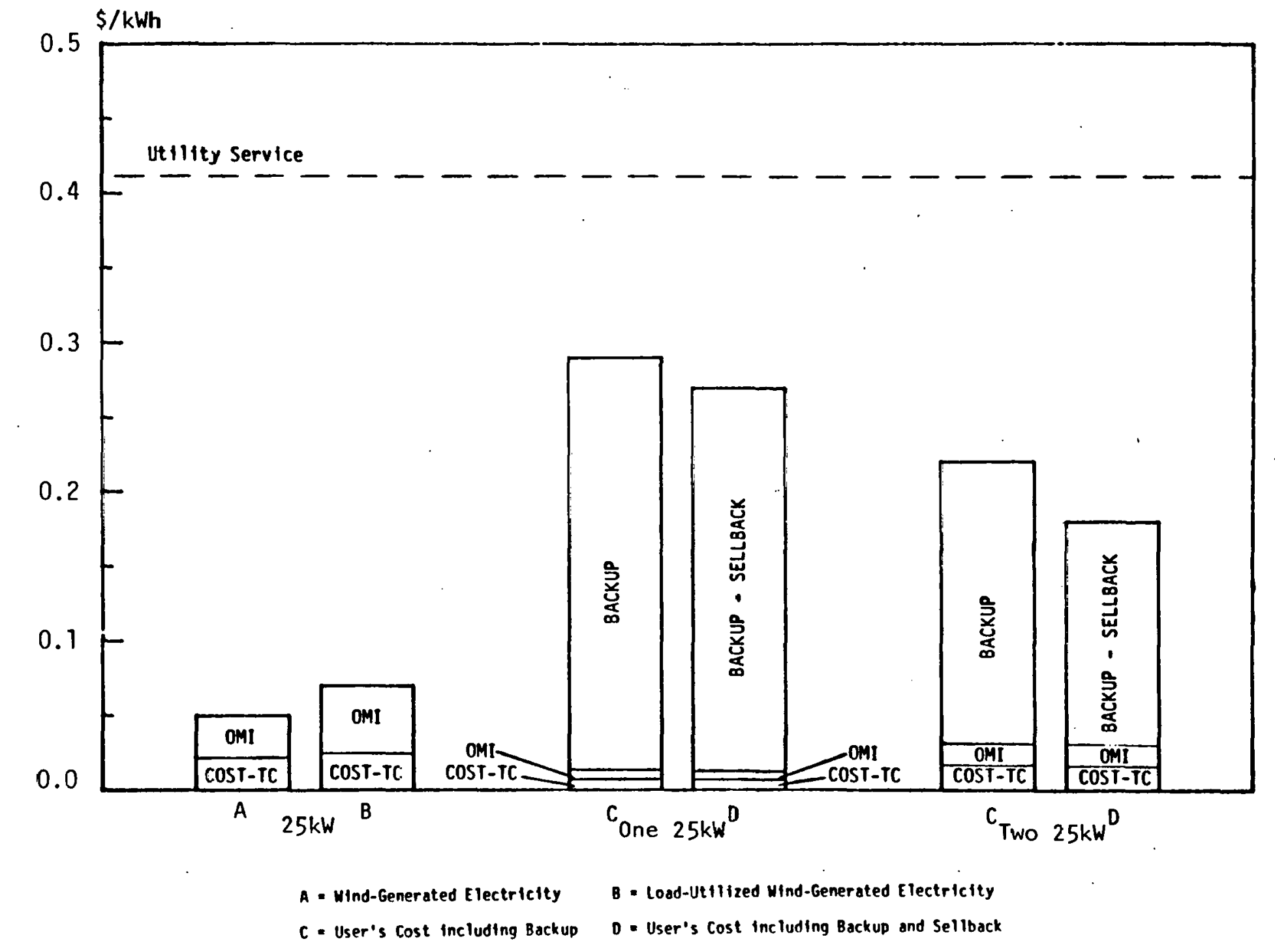


FIGURE 5. COMMERCIAL APPLIGATION: CUMULATIVE SAVINGS

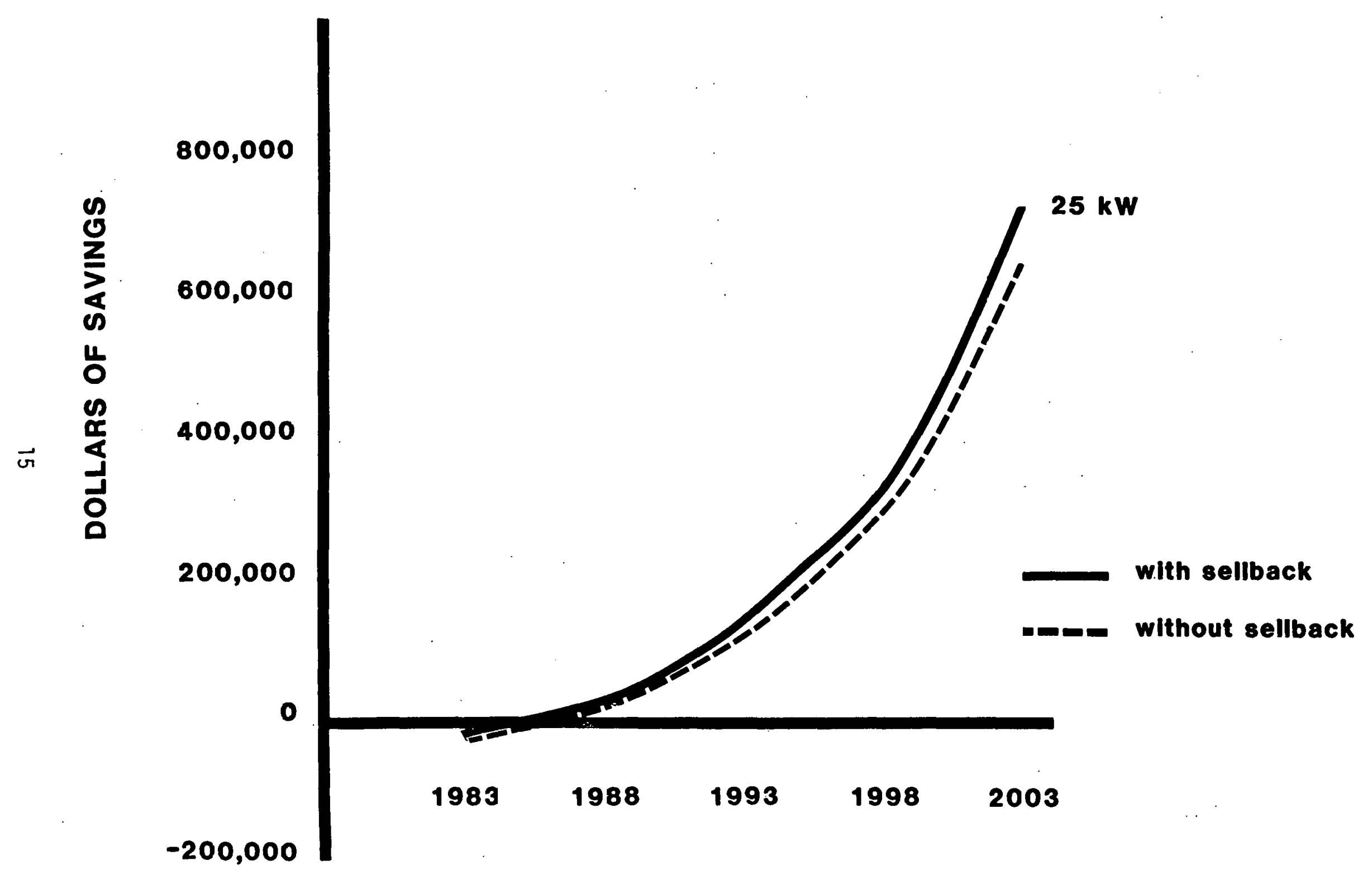




\subsection{Wind Farm Application}

Current wind energy projects in New Hampshire, California, Hawaii, and Washington of large WECS (100 kW and above) or large numbers of small WECS that produce electricity solely to sell to the electric utility have been called "wind farm" applications. The wind farm alternative analyzed for the Virgin Islands consisted of one $500 \mathrm{~kW}$ WECS, with all electricity dedicated to WAPA. The $500 \mathrm{~kW}$ WECS was assumed to be a Darrieus type machine.

\subsection{Levelized Cost of Energy}

The cost of energy expressed in Figure 6 corresponds to the manufacturer's viewpoint, $\mathrm{COE}_{1} .^{\circ}$. The levelized cost of energy equals 17.8 cents $/ \mathrm{kWh}$. Wi thout knowing WAPA's cost of generating electricity, it is not possible to compare the costs of the wind-generated electricity and WAPA-generated electricity.

\subsection{Breakeven Analysis}

Since the $500 \mathrm{~kW}$ WECS for the wind farm application was assumed to be financed, the breakeven period is the point in time when the cumulative net earnings equals the remaining amount of mortgage payments outstanding. This occurs in the tenth year for the wind farm application.

\subsection{Cumulative Net Earnings}

Figure 7 illustrates the cumulative net earnings that would come from a $500 \mathrm{~kW}$ WECS with all electricity produced sold to WAPA at half the prevailing retail rate. It can be seen from figure 7 that cumulative net earnings does not significantly accumulate until after the tenth year, when the financing costs have all been paid off. After 20 years of operation, the $\$ 600,000$ WECS returns over $\$ 2,300,000$, which provides for approximately $15 \%$ annual return on the initial cash investment of $\$ 150,000$. 
FIGURE 6. LEVELIZED COST OF ENERGY

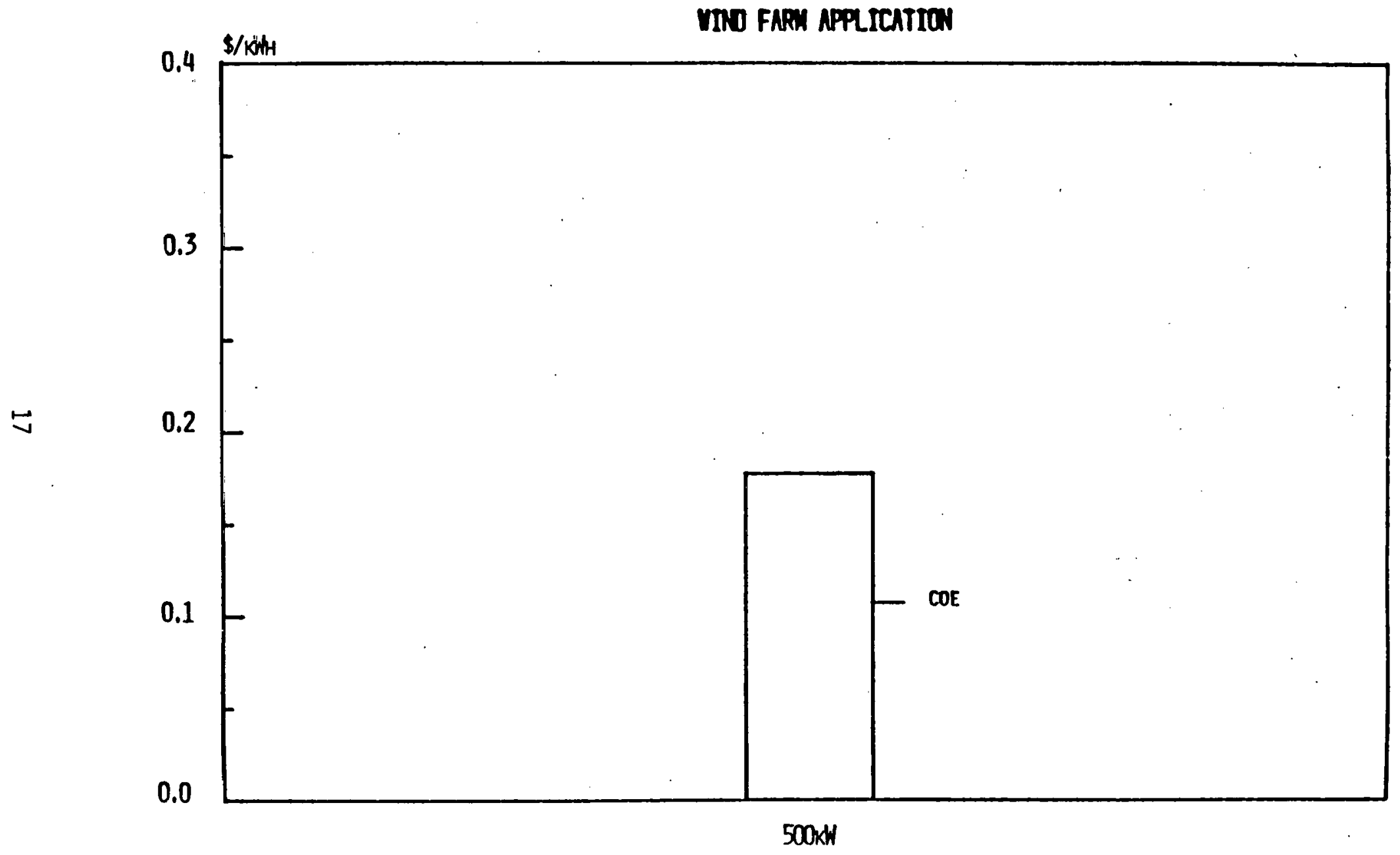


FIGURE 7. WIND FARM APPLICATION: CUMUULATIVE NET EARNINGS

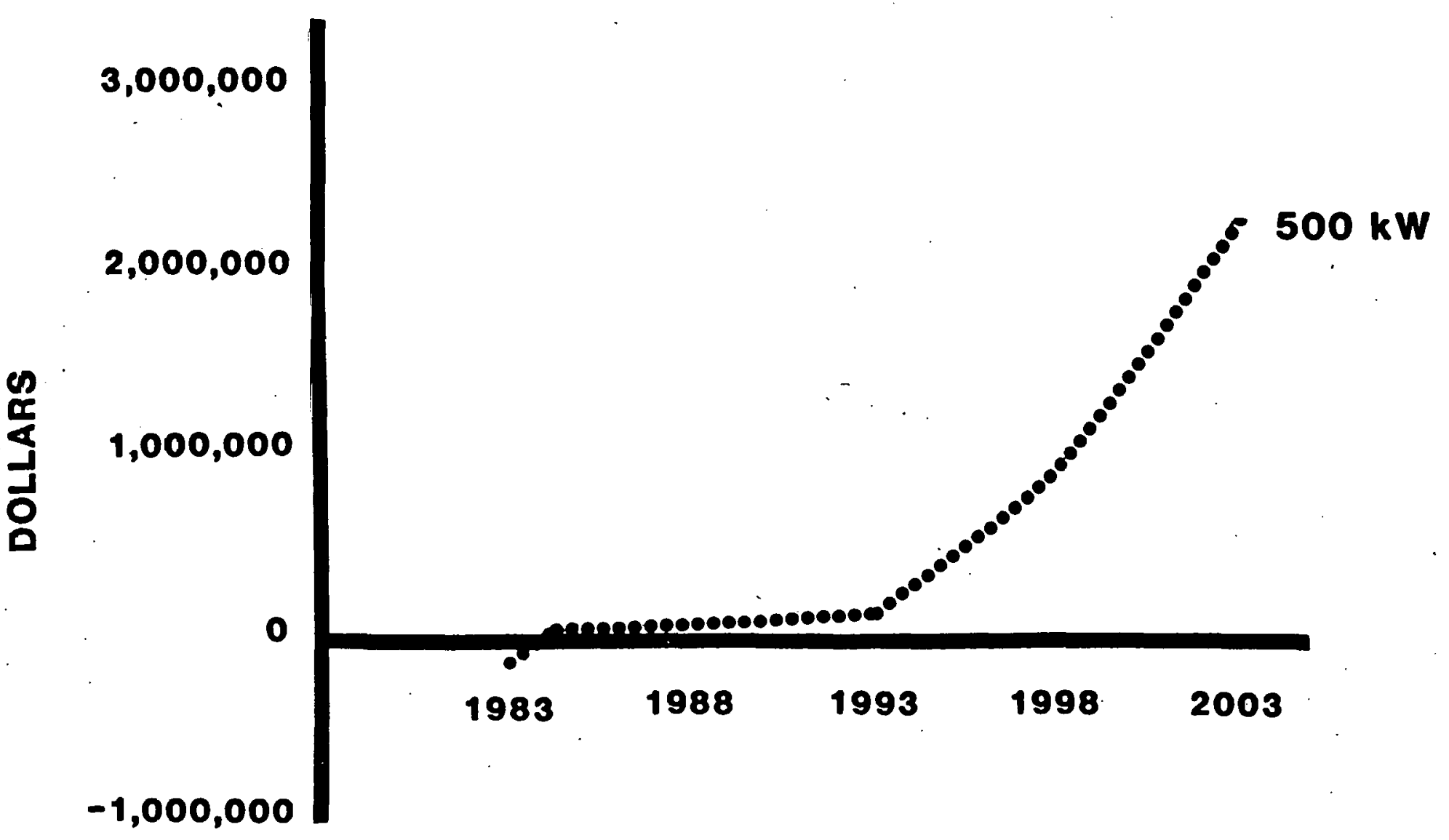




\subsection{Preliminary Conclusions}

In general, it can be determined by the preceding economic analysis that there exists good potential for wind energy utilization in U.S. Virgin Islands in the very near future. The most promising applications appear to be commercial and wind farm applications. The economic advantages are significant, in terms of levelized cost of energy compared to WAPA cost of electricity and cumulative net savings and earnings. The residential applications are not quite as financially rewarding, due to the relatively high cost per kilowatt of capacity compared to the larger WECS.

Four major factors affect the economic feasibility of wind energy use in the Virgin Islands. These factors are the WECS annual output, system sizing and load match, installed system cost, and the WAPA interconnection policies (retail and buyback rates, and interconnection regulations):

\subsection{WECS Annual Output}

As in any wind regime, the value of WECS is largely dependent on average wind speed and its variations over an annual cycle. Since wind power increases with the cube of wind velocity, finding the windiest site is critical. For example, if the wind increases from 10 to $15 \mathrm{mph}$, the wind power available does not increase by $50 \%$; instead it increases by $238 \%$.

The analysis demonstrates the sensitivity of WECS economic value to wind speed. For the $1.5 \mathrm{~kW}$ case shown, a $4 \%$ increase in wind speed would make the cost of energy equal to that of purchased electricity.

Although the Virgin Islands have estimated ridgecrest wind speed averages of 13 - $15 \mathrm{mph}$, available information tends to indicate steady winds clustered closely around the average. Winds are seldom above $22 \mathrm{mph}$ where maximum WECS output can be obtained. For larger machines this may result in outputs somewhat less than estimated by manufacturers. For instance, the $500 \mathrm{~kW}$ Darrieus does not even cut in until $14 \mathrm{mph}$ and requires $35 \mathrm{mph}$ velocity for rated power output. The problem should be much less pronounced for smaller machines having cut-in speeds of 7.5 - $10 \mathrm{mph}$ and rated output speeds of 21 $26 \mathrm{mph}$. It should be noted, however, that any such conclusions are quite preliminary and need to be verified by field measurements.

\subsection{System Sizing/Load Match}

The economics of WECS are highly sensitive to appropriate sizings. As demonstrated, small changes in load match can cause significant changes in economics. Regardless of how cheap the wind-generated electricity is, the total cost of electricity may be high unless the fraction of load met by the WECS is large. Further work on load match is envisioned, using generic load profiles for specific applications in the Virgin Islands.

\subsection{Installed WECS System Cost}

The economics become attractive when installed costs fall in the range of $\$ 1,000$ to $\$ 2,000$ per $\mathrm{kW}$ of capacity. The larger machines analyzed here $(25 \mathrm{~kW}$ and $500 \mathrm{~kW})$ have such costs. However, the smaller machines $(1-2 \mathrm{~kW})$ range 
from $\$ 6,000$ to $\$ 8,500$ per $\mathrm{kW}$ of capacity and have longer periods to breakeven. The cost estimates, including the wind turbine, tower, shipping, and installation have been based on information received from WECS manufacturers and the V.I. Energy Office.

Shipping and installation costs are currently high in the Virgin Islands, representing over $30 \%$ of the total system cost for the residential application machines. Both costs should diminish somewhat with increased sales volume and installation experience. Also, the cost of the WECS could possibly decrease as more are built.

The federal tax credits are critical to the economic feasibility of the WECS. Based on the most current interpretations of the V.I. Energy office, this analysis assumes the eligibility of WECS purchasers for the $40 \%$ residential tax credit, and the combined 25\% commercial tax credit (15\% renewable tax credit for business plus the $10 \%$ investment tax credit).

However, initial cost may not be an overriding factor for early market penetration of dispersed, non-grid connected small WECS due to the current problems with WAPA reliability and cost.

\subsection{WAPA Interconnection Policies}

WAPA does not currently have a policy regarding interconnection or buyback rates, and WAPA does not fall under the Public Utility Regulatory Policies Act, al though it appears grid connection has been allowed in several cases, with no buyback. The 22 cents/kWh retail electric rate makes the Virgin Islands prime candidates for WECS applications, as well as other renewable energy technologies. Because wind-generated electricity could reduce oil consumption and possibly avoid some capacity expansion costs, WAPA could benefit from both dispersed and central applications.

As shown in the analysis, if WAPA does purchase electricity from the WECS at $50 \%$ of retail residential rates, the economic attractiveness increases by approximately $30 \%$. In the case of a $\$ 12,000$ two $\mathrm{kW}$ machine, it would reduce the period to breakeven from 12 to 9 years. These benefits could be offset if WAPA imposes costly interconnection requirements, as has been proposed by some rural electric cooperatives in the continental United States. 


\subsection{Recommendations for Future Studies}

Further attention may need to be given to the possibility of stand-alone applications not connected to WAPA, given the frequent occurrences of power outages. The economic feasibility may be enhanced if the WECS can continue to generate electricity during WAPA outages. Battery storage options should al so be examined.

The preliminary results from the $25 \mathrm{~kW}$ and $500 \mathrm{~kW}$ WECS shows considerable promise for central station applications, either to be owned by WAPA or a private concern. More information would be required regarding WAPA's conventional generation costs and load profiles. 


\title{
REPORT C
}

PROJECT PLAN FOR FINALIZING WIND ENERGY SITE SELECTION ON THE USVI

\author{
Final Report
}

F. M. Vukovich

Research Triangle Institute

P. 0. Box 12194

Research Triangle Park, North Carolina 27709

JuTy 1981

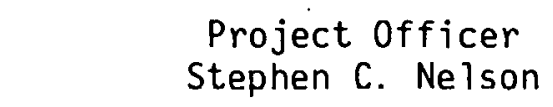

Prepared for

The Southern Solar Energy Center

61 Perimeter Park

Atlanta, Georgia 30341

DOE Contract Number DE-AC02-79CS30166

Subcontract Number SC-0102 


\section{ABSTRACT}

A project plan is developed for the utilization of a site selection technique developed by the Research Triangle Institute to finalize wind energy site selection on the United States Virgin Islands. The report includes a description of the procedure, a scenario for application of the procedure, estimated project cost, and a description of an overall program plan for the penetration of wind energy in the U.S. Virgin Islands. 
TABLE OF CONTENTS

Page

Abstract ...................... . . . . $i$

List of Tables................. ... $i$...

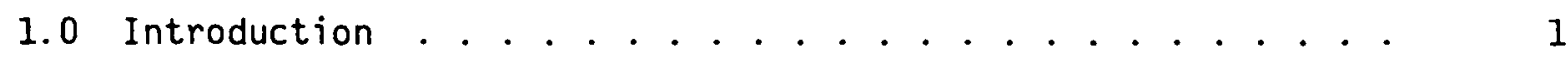

2.0 Modeling Procedures ................ 2

2.1 The Research Triangle Institutes's WECS Siting Technique 3

2.2 Model Requirements . . . . . . . . . . . . . 6

2.3 Data Requirements . . . . . . . . . . . 8

2.4 Utilization of Model Results........... . 9

3.0 Program Plan ......................... 11

3.1 Objectives .................. . . . . . 12

3.2 Estimated Project Costs . . . . . . . . . . . 14

4.0 Recommendations for Further Studies . . . . . . . . 16

5.0 References ................... 23 


\section{LIST OF TABLES}

Table

Page

1 Outline of Project Plan to Implement Wind Energy in the U.S. Virgin Islands 


\subsection{Introduction}

The Research Triangle Institute (RTI) has recently completed a study of the wind energy potential for the United States Virgin Islands (USVI). Based on the results of that assessment and a study of the topography of the island, potential sites for Wind Energy Conversion Systems (WECS) were identified on St. Croix, St. Thomas, and St. John. However, the historical wind data available for the islands was sparse and the analysis techniques used in that study were very simplified. The sites identified are by no means final, and should only be used for plan purposes. In that report, a study was recommended involving atmospheric modeling and a field measurement program to make final site selection for WECS. It is the purpose of this report to outline in detail the procedure to identify and verify WECS sites on the USVI. A scenario is presented for the initial implementation of the procedure, and further recommendations are presented in the form of tasks which must be completed in order to accomplish a realistic penetration of wind energy on the USVI. 


\subsection{Modeling Procedures}

There are basically three sufficiently sophisticated techniques which can be used to help finalize WECS site selection on the USVI: 1) the technique developed by Science Applications, Inc.; 2) the technique developed by Lawrence Livermore; and 3) the technique developed by RTI. All three of these techniques circumvent the need to saturate a region with anemometers to determine wind statistics, a procedure which is very expensive. However, these techniques require wind measurements be made at the selected sites in order to finalize the site selection.

These techniques use a mass balance or hydrodynamic model to predict the air flow in a region for a set of initial conditions as a first step in their approach. The RTI technique used the hydrodynamic model to predict the flow; the Lawrence Livermore technique uses the mass balance model; and Science Applications makes use of both a hydrodynamic model and a mass balance model to predict the flow. More resources are required in terms of computer running time to use a hydrodynamic model to predict, the flow. Both the hydrodynamic and mass balance models take into account the influence of topography on the air flow. However, only the hydrodynamic model will account for thermodynamic processes; i.e., the effects of heating and cooling on the filow. Diurnal heating and cooling markedly affect the flow on the USVI. Therefore, the model which includes thermodynamic processes must be used to predict the flow on the USVI. Of the two available techniques which utilize flow prediction models which account for thermodynamic processes, only the model developed by RTI has been verified using observed data (Vukovich and Clayton, 1977). Both Lawrence Livermore and Science Applications utilized the mass balance model in the work performed to verify their procedures for site selection (Traci et. al., 1979; and Knox, 
1979). Some work has been done on comparing the results of the hydrodynamic model of Science Applications with in situ data, but this has not been completed (Traci et. al., 1978). Therefore, the technique for WECS site selection developed by RTI is recommended for applications on the USVI, since it is the only model available for immediate use which uses a flow prediction model that accounts for thermodynamic processes.

\subsection{The Research Triangle Institute's WECS Siting Technique}

The WECS siting technique developed by RTI predicts wind statistics in remote locations where wind data are usually not available. The technique uses historical wind data from a nearby weather station and a statistical model to develop a data set at the remote location through which various wind statistics can be computed. The form of the statistical model and parameters of the model are determined using simulations based on a hydrodynamic model. The number of simulations required of the hydrodynamic model is based on wind statistics developed at the nearby weather station where historical wind data are available. Generally, the number of simulations is based on the wind speed and wind direction frequency distribution. Wind data at grid points in the hydrodynamic model near the control site (the weather station where historical wind data are available) and remote sites are extracted from the simulation cases in order to develop the statistical model.

A three-dimensional, time dependent hydrodynamic model was developed as part of a National Science Foundation funded project on optimum air pollution sampling network selection (Vukovich, Dunn, and Crissman, 1976). The model uses the primitive equations to forecast the wind, temperature, and pressure distribution throughout a volume for a given set of initial and boundary conditions. The model is hydrostatic and uses standard bound- 
ary layer to describe vertical distribution of momentum and heat. It is driven by the effects of terrain, surface roughness, and surface heating. A gridding algorithm exists as a part of the model which enables the user to specify horizontal and vertical grid spacing. The initial conditions are assumed geostrophic and time independent. The computer running time depends on the grid spacing and a number of grid points. These factors are dependent on the spatial resolution required.

The horizontal boundaries, except for the upwind boundary, are open so that heat mass and momentum are allowed to be transported through those boundaries. The upwind boundary is closed. The upper boundary is a rigid lid, and the lower, boundary conditions are specified as a. set of input parameters that include the local terrain height, the surface roughness, and the spatial distribution of temperature. The temperature distribution at the surface can be time dependent. Further details on the model can be found in the paper published by Vukovich, Dunn, and Crissman (1976).

The underlying rationale for which the statistical model is developed, relies on the assumption that a time independent relationship exists between the winds occurring at two points in the same general vicinity. The relationship is expressed by a statistical model which has the following general form:

$$
V=g\left(V^{*}, \gamma^{*}\right)+\delta^{*}
$$

where $V_{u}$ is the average wind vector at time period $t$ for a given point; $V^{*}$. is the average wind vector for any time period $t$ at a point corresponding to the location of the weather station having a historical wind record; $g$ is a function which specifies the relationship between the wind vectors at the two points; $\gamma^{\star}$ is a model parameter; $\delta^{\star}$ is a random deviation vector 
for any time period. The model is defined in terms of two fixed points. For the two points, neither the function $g$ nor the parameter $\gamma^{*}$ are allowed to depend on time. The observational time period is assumed to be sufficiently long, and the two points sufficiently close together, so that temporal and spatial lagging is unnecessary.

The time stability assumption inherent in Equation (1) suggests that if simulated wind data were available for both points for a series of cases which corresponds in a real situation to a time period, then the development of a prediction model as in Equation (1) for relating the wind vectors would follow two basic steps: 1) determination of the functional form $\mathrm{g}$; 2) estimation of the parameter vector, $\gamma^{\star}$. Both steps can be accomplished using the simulation results.

After the statistical model relating the winds at the two points has been developed, the model can be used with the historical data set available at the control site to produce a similar data set at the remote site; i.e., for each wind observation at the control site, $v^{*}$, at time $t$, Equation (1) can be used to develop a corresponding estimate of the wind observation at the remote site, $V_{0}$, at time $t$. The predicted data set at the remote site can be used to develop various statistics, such as the mean wind speed, the mean of the cube of the wind speed, the wind speed frequency distribution, etc. These statistics would form a basis to determine the ability of the site to maintain a WECS.

Thus, the methodology involves four basic steps: generation of simulated wind data; development of a statistical model form and estimation of parameters in the model using simulation. data; and generation of a predicted wind distribution using actual wind data from the control site as input to the prediction model. Predictions would be made at each grid point pair 
over the domain defined by that portion of the grid utilized by the simulation model which is of interest to the user. The control site, the site where long term wind data are available, would in all cases be one of the sites in the pair used to develop the statistical model.

\subsection{Model Requirements}

The requirements for the statistical model are much more simplified than those for the hydrodynamic model. In order to determine the form and parameters for the statistical model, simulation data are required for the grid point coinciding with the control site and for any other grid point within the domain of interest. However, in order to obtain reasonable solutions from the simulation, the simulation model will require proper characterization of the topography, initial conditions, and boundary conditions.

\subsubsection{Initial Conditions}

The hydrodynamic model requires for initial conditions the vertical profile of the wind speed and direction, and the vertical profile of temperature. The horizontal distributions of temperature and wind, and the horizontal and vertical distribution of pressure, are determined by assuming the hydrostatic and geostrophic atmosphere. The initial vertical profile of temperature can be obtained by examination of upper air data obtained in the tropical North Atlantic (e.g., the upper air data from San Juan, Puerto Rico).

In order to obtain sufficient capability to translate winds from the control site to any other site, the form and parameters of the statistical model must account for the range in wind speeds and wind directions experienced at the sites. According to the resource assessment performed for the USVI (Vukovich et. al., 1981), the wind direction is, on the average, 
within $45^{\circ}$ of east $85 \%$ of the time, and the wind speed ranges from approximately $1 \mathrm{~ms}^{-1}$ to $15 \mathrm{~ms}^{-1} 95 \%$ of the time. These factors indicate that the initial conditions need only account for wind directions from NE through $E$ to $S E$ and that the speed range from $1 \mathrm{~ms}^{-1}$ to $15 \mathrm{~ms}^{-1}$. Generally, to account for a wind speed range from $1 \mathrm{~ms}^{-1}$ to $15 \mathrm{~ms}^{-1}$. requires simulations with surface wind speeds having the following set of discrete values: 3 $\mathrm{ms}^{-1}, 6 \mathrm{~ms}^{-1}, 9 \mathrm{~ms}^{-1}, 12 \mathrm{~ms}^{-1}$, and $15 \mathrm{~ms}^{-1}$. The remaining values are determined through interpolation. Simulations would only need to account for wind directions SE, ESE, E, ENE, and NE. Because of the high frequency of occurrence of winds out from the east in the tropical regions, and through proper selection of wind speed and wind direction intervals, the number of simulations required to obtain sufficient data to yield the form and parameters for the statistical model will be severely reduced compared to regions in the mid-iatitudes where locations experience winds from practically all directions at nearly the same frequency.

The vertical profile of the wind which will be used for an initial condition for the simulation, will have the same basic variation with height as the vertical profile utilized in the report by Vukovich et al. (1981) in their determination of the wind speeds at various altitudes on the USVI. Differences in the seasonal variations of the profile can be accounted for through the range of surface wind speed over which the simulations will be performed.

\subsubsection{Topography}

In order to perform a proper simulation of the flow on the USVI, the topography of each of the islands must be properly represented in the model. In order to accomplish this, a grid will be selected which will best describe the domain of interest. The mean topography above sea level 
will be determined at each grid point using USGS maps which give topographic information. Best results will be obtained by proper integration of the grid scheme with the topographic information.

\subsubsection{Boundary Conditions}

The principal boundary conditions for the hydrodynamic model are the surface roughness and the surface temperature. The surface roughness will be obtained through integration of the USGS maps with information on the approximate value of the surface roughness as a function of terrain configuration. This information can be obtained in a report by Frost and Nowak (1979) which treat guidelines for siting wind turbines.

The other important boundary condition is the difference between the sea water temperature and the land temperature. This information can be obtained using mean sea-surface temperature analyses for the region and the meteorological information at the two weather stations at the USVI. Given the surface temperature at the weather station, boundary layer models can be utilized to obtain the ground temperature on a diurnal basis. Since the sea-surface temperatures generally are constant on a diurnal basis, the diurnal variation of the ground temperature specifies the diurnal variation of the difference between the ground and sea-surface temperature.

\subsection{Data Requirements}

The technique requires that a weather station exists within the domain of interest, and that the weather station has a long-term record on the variation of the wind speed and direction at that site. Two such stations exist in the USVI. These are the U.S. Weather stations on the island of St. Croix and that on the island of St. Thomas. At least an eight-year record of wind speed and wind direction data are available on computer tapes for each of those, stations. Longer records exist; however, these 
have not been placed on magnetic tapes.

\subsection{Utilization of Model Results}

The high resolution grid will be established for each of the islands and will be utilized by the simulation model. Initial conditions, topographic heights, and boundary conditions will be developed at each of the grid points. The number of simulations will depend on the initial conditions and boundary conditions. After the simulations have been completed, the form.and parameters of the statistical model will be developed utilizing the data from the grid point that corresponds to the control site and any other grid points. Since effects of topography and diurnal heating and cooling will produce a highly variable wind distribution over the islands, it is expected that no one statistical model form and no one set of parameters would suffice for each grid point pair. After the statistical models have been created relative to the grid point reflecting the control site, the statistical model will be used to project long-term data sets similar to that that exists at the control site, at each of the grid points. Given these data sets, the distribution of the mean wind and standard deviation on an annual and seasonal basis can be established as well as other statistics such as frequency distributions of speed and direction.

All necessary statistics will be established over the grid in the domain of interest. These statistics will be examined to determine those sites which have statistics which will more favorably support a WECS. Site selection generally will require that a certain kind of WECS, having certain operating characteristics, has already been chosen. It is those sites whose statistics best correspond to the operating characteristics of the particular WECS that will be chosen. 
Since the modeling technique described above will, as most modeling techniques do, compromise the absolute magnitude of the wind speed, the results are only reliable in the relative reference frame (i.e., the technique can be used to select sites which have better wind statistics relative to another site). It will be necessary to design a field program in which wind data would be collected at the selected sites in order to 1 ) establish a correct magnitude for the available wind energy, and 2) to determine which of the sites selected by the modeling procedure would best support the chosen wind energy system. This requires that more sites be selected than would actually be necessary to deploy the WECS. Wind data would be collected for at least one-half year (the period summer and fall which encompass the period of maximum and minimum wind). However, for best results the data collection period should be a year. As many as ten to fifteen sites may be selected on each of the islands making up the USVI, depending on the amount of supplemental electrical energy desired from wind energy systems. Anemometers would have to be set up at each of these sites in order to determine the most usable site, and finalize site selection. 


\subsection{Program Plan}

As an initial scenario for the penetration of wind energy into the USVI, WECS would be employed on St. John. St. John was selected for the initial penetration of wind energy into the USVI for several reasons. The initial assessment of wind energy on the USVI (Vukovich et. al., 1981) has suggested that only portions of the three islands making up the USVI have sufficient wind energy to support WECS. To saturate these regions with WECS is infeasible because of the availability of land and the degrading effect on the aesthetics. The best method of implementing wind energy on the islands is to penetrate a small portion of the grid with sufficient wind energy to make an impact on the diurnal usage of power; i.e., sufficient power to supplement the existing conventional power production at peak load time.

Approximately $2.0 \mathrm{MW}$ of power are required to support the island of St. John. Generally, this power comes from a submarine cable which links St. John with the St. Thomas power grid. There is an emergency generator (a $1.7 \mathrm{MW}$ generator) on St. John which has been utilized to full capacity since the power problems on the USVI have begun. Through penetration of sufficient wind energy on the island of St. John to significantly impact power usage on that island can have a two-fold effect: the necessity. of the island of St. Thomas to supply power to St. John will be minimized, and the potential exists that the emergency generator on St. John may be utilized to supply power to St. Thomas. In essence, there is a potential for a total of a $4 \mathrm{MW}$ power recovery to the St. Thomas power grid if the penetration of wind energy on St. John is successful. This will impact on the diurnal power load on St. Thomas, and would subsequently reduce the need for rotating brown-outs on that island. 
Lastly, there is a significant amount of land available on St. John to support a WECS. Less than twenty-five percent of the island is inhabited. Much of the land is part of a national park; but there is a significant portion owned by the USVI government. The government-owned land can surely be used to support a WECS. It may also be possible to use land in the national park to help solve the energy problems on the USVI.

Scenarios such as that described above can have a significant impact on power usage on the USVI. Similar scenarios may be developed for the penetration of wind energy into other portions of the power grid of St. Thomas, as well as the power grid on St. Croix. Scenarios can only develop through a detailed study of the power usage on the USVI (e.g., the portion of the power grid on St. Croix serving Fredericksted may be impacted through the penetration of wind energy separate from the portion of the grid that serves Christiansted). A description of an overall program required for the proper implementation of wind energy on the USVI is discussed in Section 4.0.

\subsection{Objectives}

The major purpose of this report is to describe the effort required to develop wind energy sites on the island of St. John in order to initiate the penetration of wind energy on the USVI. The basic objective of the required effort is to develop WECS sites utilizing the technique described in Section 2.0, and to finalize site selection through the implementation of a field program to collect wind data at those sites selected by the technique. Final site selection would be made through analysis of the observed wind data at the selected sites, and will be dependent on those sites which have wind statistics which can best support the WECS selected for use on the island. The following is a list of tasks which must be 
accomplished in order to develop the finalized WECS sites on St. John.

1) Develop initial conditions, topographic heights, and boundary conditions required for the hydrodynamic model and for the islands of St. John and St. Thomas. (Computer simulations must be done for St. Thomas and St. John because the required long-term data set for utilization of the model described in Section 2.0 does not exist on St. John, but does exist on St. Thomas. Comparisons between grid points of potential sites on the island of St. John must be made with the grid point coincident with the site where long-term wind data are available [the control site] which is on the island of St. Thomas).

2) Perform the required computer simulations for the islands of St. John and St. Thomas.

3) Develop a statistical model with each grid point pair where one of the grid point pairs is a grid point on the island of St. John and is a potential wind energy site. The other grid point is the grid point coincident with the control site on St. Thomas. The number of models required will depend on the wind variability over the island and the number of grid points used to describe the flow over the is land.

4) Develop a data set complementary to that at the control site at each grid point on St. John utilizing the data set at the control site and the statistical models relating the wind at the control site with that at each of the grid points on St. John.

5) Use the projected data sets at each of the grid points on St. John, and develop wind statistics such as mean wind speed on an annual, seasonal, and monthly basis, standard deviations, frequency distributions of wind speed and wind direction, etc.

6) Determine sites on the island of St. John that will best support wind energy systems using the wind statistics.

7) Plan a field program to collect wind data at the selected sites in order to finalize site selection. Planning should include such factors as the period of data collection, type of instrumentation to be used, availability of land near or at the selected sites, analysis procedures, etc.

Implementation of the field program should be accomplished immediately after initial site selection using the RTI technique is complete. Certain aspects of the plan for the field program, such as selection of the annemometers to be used to collect the data, can be made even before the sites 
have been selected. Also the number of anemometers used can be determined apriori. This will be dependent on the number of sites selected. Since more sites than needed should be selected to guarantee results, knowledge of the number of sites required is needed. The number of sites required will depend on the power load impact desired and the number of WECS required to accomplish that load.

The period of performance of the initial site selection program should be on the order of seven (7) months, with site selection being accomplished after the sixth month, leaving a period of approximately one (1) month to finalize the report on the results. In order to implement wind energy on St. John as quickly as possible, there should be a smooth transition between the end of the initial site selection program and the beginning of the field program, with the field program beginning at least by the eight month.

\subsection{Estimated Project Costs}

The most substantial costs for initial site selection technique will be through the implementation of the various model algorithms to obtain the statistics needed to determine best locations for wind energy systems. However, some of the costs for computer modeling are reduced because of the high frequency of wind directions between NE-E-SE. On the average, wind direction ranges from NE-E-SE about $85 \%$ of the time. If the computer simulations are centered about this wind speed range, then it would only take approximately ten to twelve simulations to produce a data set which can be utilized to establish the statistical model over the range of speed $0 \mathrm{~ms}^{-1}$ to $15 \mathrm{~ms}^{-1}$.

However, since there is no long-term data set on the island of St. John, the computer simulation of the flow on St. John must include the 
island of St. Thomas, which is the closest island to St. John having a long-term data set at the airport weather station. This requirement will significantly increase the amount of computer time necessary to perform the simulations. However, if in the future, a scenario is created in which wind power is brought directly to St. Thomas, then these computer simulations can be used to determine initial sites on St. Thomas.

The estimated cost of the initial site selection, using the modeling technique for St. John, is in the vicinity of $\$ 90,000-\$ 100,000$. Costs include simulation of the flow over St. Thomas, because St. John does not have a weather station with a long-term data set. The results from the simulations will be saved on computer tape and can be utilized, especially those for St. Thomas, for further study, particularly if a scenario is developed to use wind energy on the island of St. Thomas. The cost of the field program needed to verify sites selected by the technique cannot be appraised until the power load impact for St. John and the number of WECS required to meet that load are determined. As a part of the overall modeling study, a plan for the field program and subsequent costs would be determined. 


\subsection{Recommendations for Further Studies}

The primary objective of this report is to describe the modeling study necessary to develop initial sites for wind energy systems on the island of St. John. However, the modeling study for site selection should be only part of an overall plan to bring wind energy and potentially photovoltaics (PV) to the USVI. Wind machines have achieved a lower capacity cost than PV arrays, but significant reductions in PV system costs are being achieved and consideration should be given to them as well. Furthermore, the cost of electricity on the USVI (21\$ per killowatt-hr) is quickly approaching a value which makes it economically feasible to consider PV technology. Because of the diurnal and seasonal variation in both wind and solar insolation, and because of the physical process relationships between insolation and wind, it is conceivable that either or both in combination, may be appropriate system configuration. The appropriate wind/PV mix in the eventual system will depend on the relative source with respect to electrical system loads, source economics, hardware performance and availability, and numerous other factors that must be addressed. The activity defined addresses both source types with the recognition that their deployment time tables and relative capacities may be different, but that both have the potential for contribution to a reliable, cost-efficient energy system. RTI, therefore, believes that a plan for the USVI should be written to simultaneously address wind and PV sources. Such a plan is described on the following pages.

The plan is broken down into tasks that are designed to provide an orderly progression to the implementation of wind (and PV systems) for the USVI. Table 1 outlines these tasks. The program has been designed to provide an early deployment of a pilot (50-100 Kw) wind system that will 
Table 1. Outline of Project Plan to Implement Wind Energy in the U.S. Virgin Islands

1. Resource Assessment
a. Modeling
b. Field Program

2. Utility Characterizations
a. Generation Capacity
b. Distribution System
c. System Load
d. Financial Structure

3. Pilot Project (Small-scale System)

a. Equipment Selection

b. Engineering Designs

c. Installation

d. Performance Monitoring

4. System Analysis (Large-scale System)
a. Equipment Selection
b. Site Selection
c. Performance Studies
d. Generation Expansion Plan
e. Long-Range Plan

5. Implementation

6. Future Planning 
aid the final system analysis and design, and to begin work on the deployment of PV systems, in addition. The initial scenario, the pilot scale system, will be utilized to impact a small (St. John) portion of the overall power grid for the USVI.

Though the pilot study would only impact a portion of the power grid on the USVI, RTI's program plans are considerably more comprehensive in scope, and studies are designed to acquire information that can be utilized to impact the entire power system on the USVI.

\section{Task 1.0 Resource Assessment}

\section{Task 1.1}

RTI has completed a preliminary analysis of the available wind resource on the USVI which was extremely limited in scope due to the unavailability of data. As a result of that study, a more comprehensive program has been recommended and was discussed in the recommendations portion of the RTI report. Essentially, RTI recommends that a combined modeling and observation program take place on the island of St. John under the scenario of impacting a portion of the power grid as an initial study. Under funds provided by the U.S. Department of Energy, RTI has developed a technique to determine wind energy sites by combining the results of a hydrodynamic model with a statistical model. - This is the only model of its kind that has been validated to date. Validation of other such models is presently going on. This model is capable of determining wind statistics in remote locations where wind measurements are unavailable. Utilizing the wind statistics, sites where favorable statistics for wind energy systems can be determined. However, models such as these should never be used in the absolute sense and are most reliable in the relative sense; i.e., that is in determining that one site potentially has more wind energy than another site. In this respect, it will be necessary to initiate a field program whereby anemometers are used to measure the wind energy at the selected sites. As a result of the combined efforts of the modeling program and the observation program, final site selection would be made.

\section{Task 1.2}

To date no comprehensive measurement program has been made of the insolation both direct and diffuse on a USVI. Therefore, it would be necessary to initiate immediately an observational program on each of the three islands to measure total insolation (the sum of the direct and diffuse) and the direct radiation from the sun. Approximately one year's data should be sufficient to determine the nature of solar radiation received at the surface for PV systems; though site specific studies may be necessary due to the potential effects of local meteor- 
ological conditions. Since large committments to solar energy require the accuracy in design provided by long term data, this activity would be continued to provide that longer record.

Task 2.0 Utility Characterization

The solar generation system contemplated, either wind or PV or both, is one integrated with the existing electrical utility system, though it will be a distributed system in its final form. Therefore, it is necessary to design solar portions of the system in the context of the existing utility system. This task is basically one of assembling data necessary to carry out the remaining tasks.

\section{Task 2.1}

Existing generation capacity must be described in terms of such factors as unit type, unit capacity, fuel type, incremental heat rate, cost factors, maintenance and reliability history, location, age, operating constraints and practices. This information will be documented for each current and planned generation unit on the system.

\section{Task 2.2}

The existing transmission and primary distribution system will be documented in terms of network topology, physical location, and capacity of 1 ines, transformers, and switchgear.

\section{Task 2.3}

Total system load must be documented in as much detail as available. An hourly time series for a recent year is preferable, but a load duration curve is necessary. Peak day profiles are also required. In addition, location and characteristics of large load centers and large customers is desirable for assessing the advisability of spatially distributing solar capacity. Again, time series data are preferred.

\section{Task 2.4}

The various aspects of the current utility financial picture must be documented in terms of capital funding, fuel costs, maintenance costs, rates by customer class, tax structure, revenues by customer class, unit retirements planned, and units planned or under construction. The objective of this task is to provide adequate data for expansion planning using solar sources.

\section{Task 3.0 Pilot Phase System}

The pilot scale system for wind energy (and later PV systems) will be planned, operated, and tested for approximately one year. The pilot system capacity will be in the range of 50-100 kW. Capacity will depend on both technical factors and available funding. 
Task 3.1

A brief analysis of various generator options will be performed for wind (and PV) systems. Using the resource data from Task 1 and the definition of utility characteristics from Task 2 and system analysis in Task 3, appropriate wind (and PV) devices will be selected.

\section{Task 3.2}

The engineering designs will be prepared sufficient to complete the installation of the pilot phase system. Design will include site preparation, specifications, mechanical and electrical drawings, utility interconnection, monitoring and control devices specification and installation drawings, and bills of material. All components will be purchased and shipped to the site(s).

Task 3.3

The pilot phase system hardware will be erected.

\section{Task 3.4}

A test program will be designed and carried out to ensure the system components meets manufacturers performance specifications and that the system is operable. Following these tests, the system will be operated interactively with the utility for a period of one year to assess long-term performance, reliability, and costs of operation.

\section{Task 3.5}

A performance history of the pilot system will be completed using installed instrumentation. Actual performance will be compared to expected performance and differences, if any, will be examined to provide a basis for improvement. The appropriateness of the selected wind (and later PV) systems considering wind (and insolation) resources and utility system load will be examined. A decision whether to proceed to a larger scale and/or a number of integrated wind systems will be made.

\section{Task 4.0 System Analysis}

If wind systems (and later PV systems) are to make a contribution to the electrical power needs of the USVI, a penetration of these devices into the current system must be effected consistent with their performance and cost relative to other sources. A schedule of implementation consistent with component availability and system economics must be established to achieve the appropriate penetration level. This task provides the analysis leading to that implementation plan.

\section{Task 4.1}

Several choices of wind and PV technologies are available. For example, there are horizontal and vertical axis wind machines and flat plate and concentrating PV collectors. In addition, other system 
components such as power conditioning and control, storage batteries, and switchgear need to be considered. Under this task, design and performance data will be obtained from manufacturers and from technical literature. Contacts with users, suppliers, and government and private research organizations will be made in order to obtain operating experience and identify potential problems.

\section{Task 4.2}

Location of solar generation is sensitive to the spatial distribution of the loads, the characteristics of the existing T\&D system, the resource availability as a function of topography, and concerns dealing with environmental aesthetics. These factors will be considered in determining feasible locations for wind systems (and later PV systems). Final selection of location is also dependent on overall system performance to be considered in Task 4.3. The factors mentioned above will be examined to develop constraints on the location choices for both wind and PV systems.

Task 4.3

A study of performance of various system options, in terms of type of wind generator (and PV collector) and other components contained in each option, will be performed to select those options that best meet the system loads and satisfy other constraints in Task 4.2. A sufficient number of system options will be examined through performance simulation to assure that basic performance characteristics in the USVI environment are understood. Appropriate systems will be selected for study of T\&D requirements that give the characteristics of the sources. Final selection of the source types and locations will be made at the conclusion of this task such that long range strategic planning can be accomplished.

Task 4.4

A normal planning function of utilities is to forecast load increases of a period of up to 20 years and to develop a schedule of generation expansion to meet those loads. Such planning also takes into account retirement of old generators and other factors. In the case of the USVI, the rapidly increasing cost of oil may force the conversion of present generation capacity sooner than otherwise would be expected. This task will. carry out a generation expansion planning process taking into account the selected wind (and PV) sources as appropriate, as well as changing fuel costs and other factors to provide the basis for a long range schedule of solar implementation.

\section{Task 4.5}

All of the results of the previous work in this task will be integrated into a long range wind (and PV) implementation plan whose objective will be a dependable, reliable, and achievable power system to meet the needs of the USVI. The plan will be in the form of recommendations for a phased plan of implementation consistent with long-term needs as presently understood. 


\section{Task 5.0 Phase I Implementation}

Phase I of the long range plan will be the implementation with penetration anticipated at this time to range from 5-20 percent of power grid. This will be accomplished by penetration of systems into portions of the power grid with St. John being the initial point of penetration. The subtasks parallel those of Task 3.0 in their description and will not be repeated here. The time scale is obviously longer and the schedule implies a staged implementation made possible by the modular nature of both wind and PV capacity.

\section{Task 6.0 Future Planning}

At the conclusion of Phase I, sufficient performance history should be available so recommendations can be made for further deployment of solar capacity. This will entail updating and correcting the analysis of Task 3.0, and will take into account new information on system loads, current fuel prices, current capital costs and other pertinent factors. Recommendations for future penetration of wind (and PV) systems into the USVI power grid will be made. 


\subsection{References}

Frost, W. and D. K. Nowak, 1979: "Summary and Guidelines for Siting Wind Turbine Generators Relative to Small-Scale Two-Dimensional Terrain Features." DOE Report under Contract No. AC06-77ET20242, SWG Associates, Inc., Tulahoma, TN, 384 pp.

Knox, J. B., 1979: "LLL Wind Energy Studies (Oahu)." Presentation at the Wind Energy-Here and Now Symposium, December 19-20, 1978, Honolulu, $\mathrm{HI}, 20 \mathrm{pp}$.

Traci, R. M., G. T. Phillips, and P. C. Patnaik, 1978: "Developing a Site Selection Methodology for Wind Energy Convergence Systems." A DOE Contract Report under Contract No. AC06-77ET20280, Science Applications, Inc., LaHoya, CA, 296 pp.

Vukovich, F. M. and C. A. Clayton, 1977: "On a Technique to Determine Wind Statistics in Remote Locations." DOE Contract Report under Contract No. EY-76-C-06-2445, Research Triangle Institute, Research Triangle Park, N. C., 108 pp.

Vukovich, F. M., J. W. Dunn, and B. W. Crissman, 1976: "A Theoretical Study of the St. Louis Heat Island: Wind and Temperature Distribution." Journal of Applied Meteorology, Vol. 15, 417-440. 
THIS PAGE

\section{WAS INTENTIONALLY LEFT BLANK}


3.11. Low level wind profiles [ms ${ }^{1}$ ] constructed for St. Croix and St. Thomas/St. John using San Juan Rawin data as a structural baseline, Benedict Field Pibal data, and surface mean wind speed statistics for St. Croix and St. Thomas.

\begin{tabular}{|c|c|c|c|c|}
\hline \multirow{2}{*}{$\begin{array}{l}\text { Annual } \\
\text { Summary } \\
\text { (m MSL) } \\
\end{array}$} & \multirow{2}{*}{$\begin{array}{c}\text { San Juan } \\
\text { Baseline } \\
\underline{\left(\mathrm{ms}^{-1}\right)}\end{array}$} & \multirow{2}{*}{$\begin{array}{c}\text { Benedict } \\
\text { Field } \\
\left(\mathrm{ms}^{-1}\right) \\
\end{array}$} & \multicolumn{2}{|c|}{ USVI Low Level Wind Profiles } \\
\hline & & & $\begin{array}{l}\text { St. Croix } \\
\left(\mathrm{ms}^{-1}\right) \\
\end{array}$ & $\begin{array}{l}\text { St. Thomas/John } \\
\left(\mathrm{ms}^{-1}\right)\end{array}$ \\
\hline $\operatorname{Sfc}$ & 3.3 & & 4.3 & 4.1 \\
\hline 50 & 3.6 & & 4.6 & 4.4 \\
\hline 100 & 4.4 & & 5.4 & 5.2 \\
\hline 200 & 5.5 & & 6.5 & 6.3 \\
\hline 300 & 5.8 & & 6.8 & 6.6 \\
\hline 400 & 6.3 & & 7.2 & 7.1 \\
\hline 500 & 6.7 & & 7.6 & 7.5 \\
\hline 1500 & 6.8 & 8.2 & 7.5 & 7.5 \\
\hline
\end{tabular}

\section{Winter}

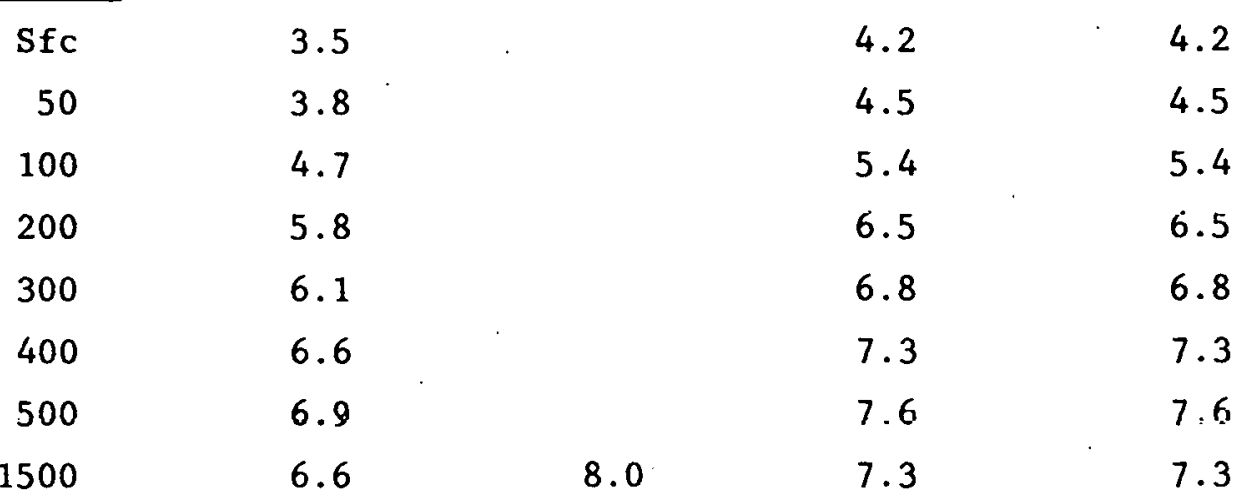

\section{Spring}

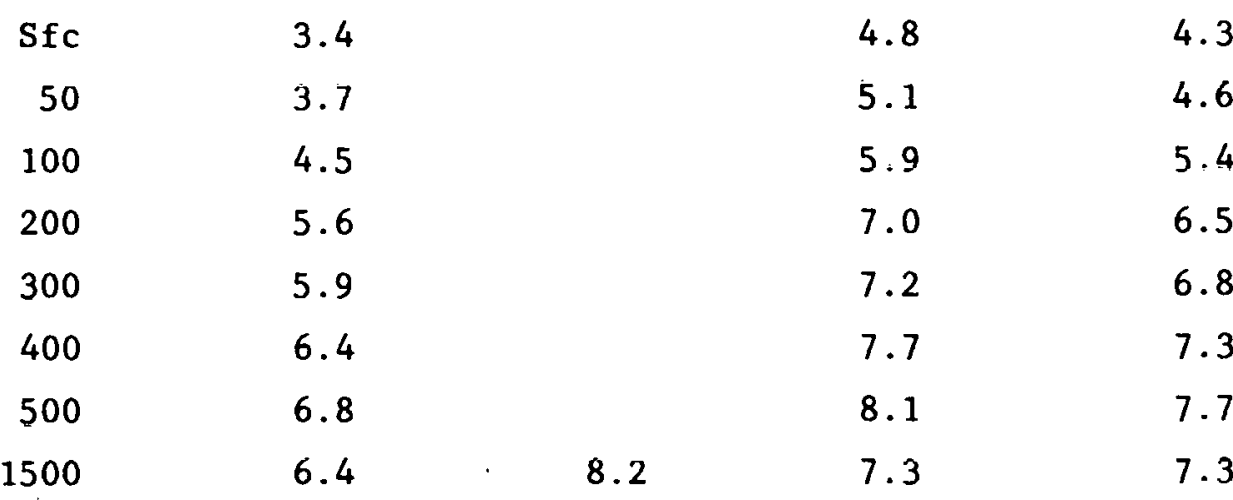

(Continued) 
Table 3.11. (Continued)

\begin{tabular}{|c|c|c|c|c|c|}
\hline Summer & San Juan & Benedict & USVI Low & Level & Wind Profiles \\
\hline $\begin{array}{l}\text { Summary } \\
\text { (m MSL) } \\
\end{array}$ & $\begin{array}{c}\text { Baseline } \\
\left(\mathrm{ms}^{-1}\right)\end{array}$ & $\begin{array}{r}\text { Field } \\
\left(\mathrm{ms}^{-1}\right)\end{array}$ & $\begin{array}{l}\text { St. Croix } \\
\left.\underline{(m s}^{-1}\right)\end{array}$ & St & $\begin{array}{l}\text { Thomas / John } \\
\left(\mathrm{ms}^{-1}\right)\end{array}$ \\
\hline Sfc & 3.3 & & 4.6 & & 4.3 \\
\hline 50 & 3.6 & & 4.9 & . & 4.6 \\
\hline 100 & 4.5 & & 5.8 & & 5.5 \\
\hline 200 & 5.6 & & 6.9 & & 6.6 \\
\hline 300 & 6.1 & & 7.3 & & 7.1 \\
\hline 400 & 6.6 & & 7.8 & & 7.5 \\
\hline 500 & 7.1 & & 8.2 & & 8.0 \\
\hline 1500 & 7.8 & 9.2 & 8.5 & & 8.5 \\
\hline \multicolumn{6}{|l|}{$\underline{\mathrm{Fall}}$} \\
\hline $\mathrm{sfc}$ & 3.0 & & 3.7 & & 3.6 \\
\hline 50 & 3.2 & & 3.9 & & 3.8 \\
\hline 100 & 3.9 & & 4.6 & & 4.5 \\
\hline 200 & 4.8 & & 5.5 & & 5.4 \\
\hline 300 & 5.2 & & 5.9 & & 5.8 \\
\hline 400 & 5.7 & & 6.4 & & 6.3 \\
\hline 500 & 6.1 & & 6.8 & & 6.7 \\
\hline 1500 & 6.2 & 7.3 & 6.8 & & 6.8 \\
\hline
\end{tabular}

Note: $\quad 1 \mathrm{~ms}^{-1}=2.24{\mathrm{mi}-\mathrm{hr}^{-1}}^{-1}$ 


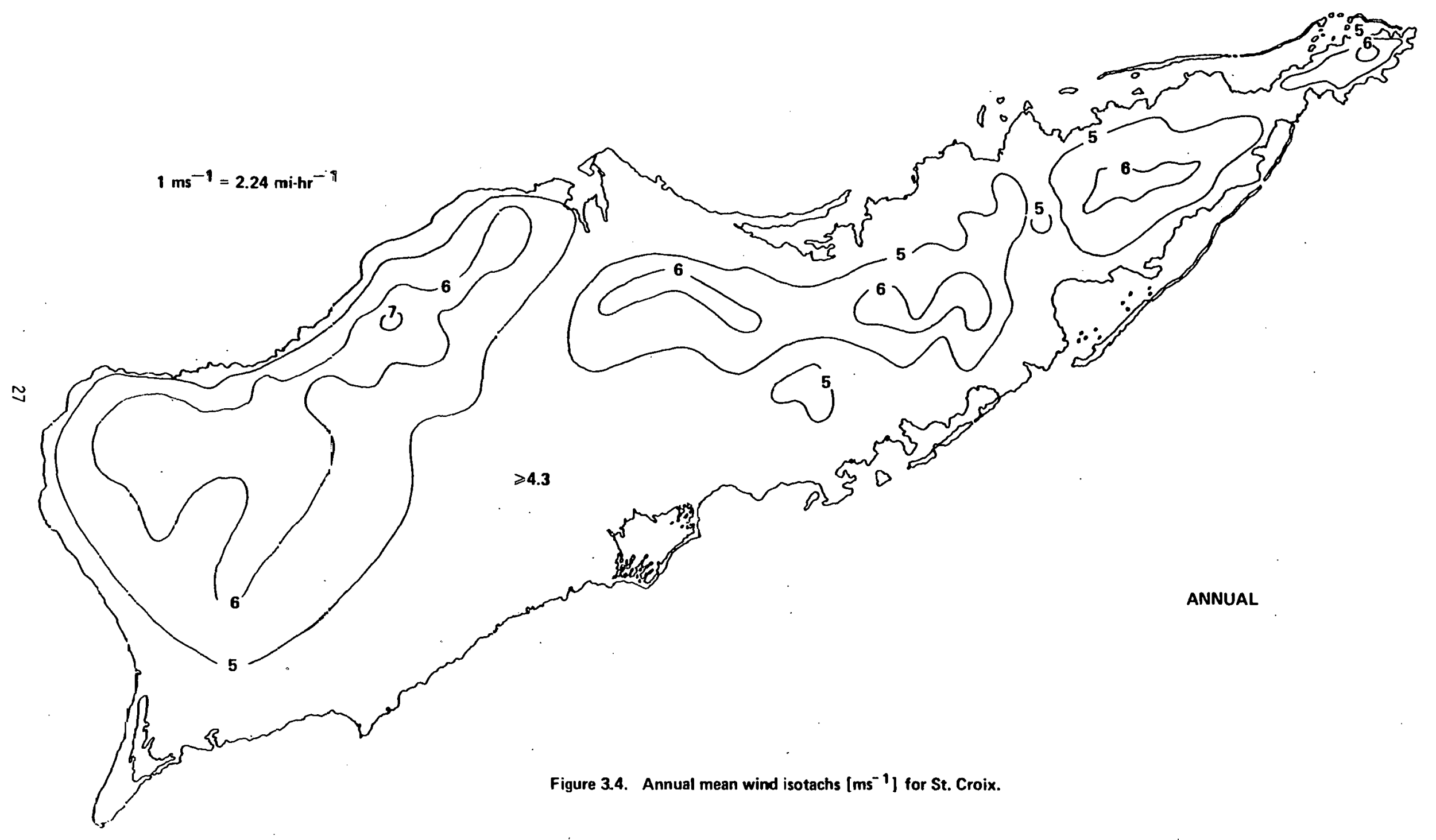




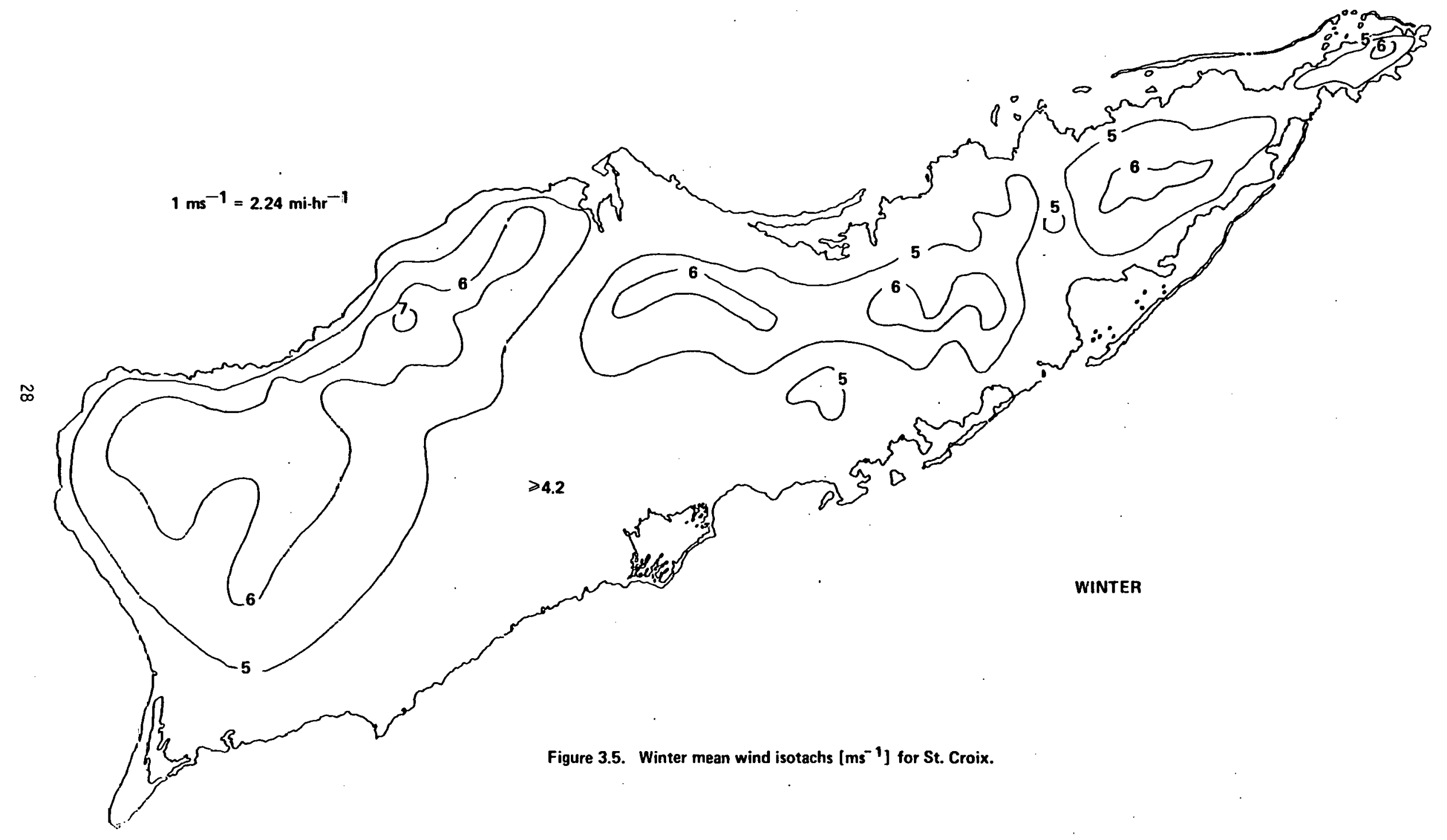




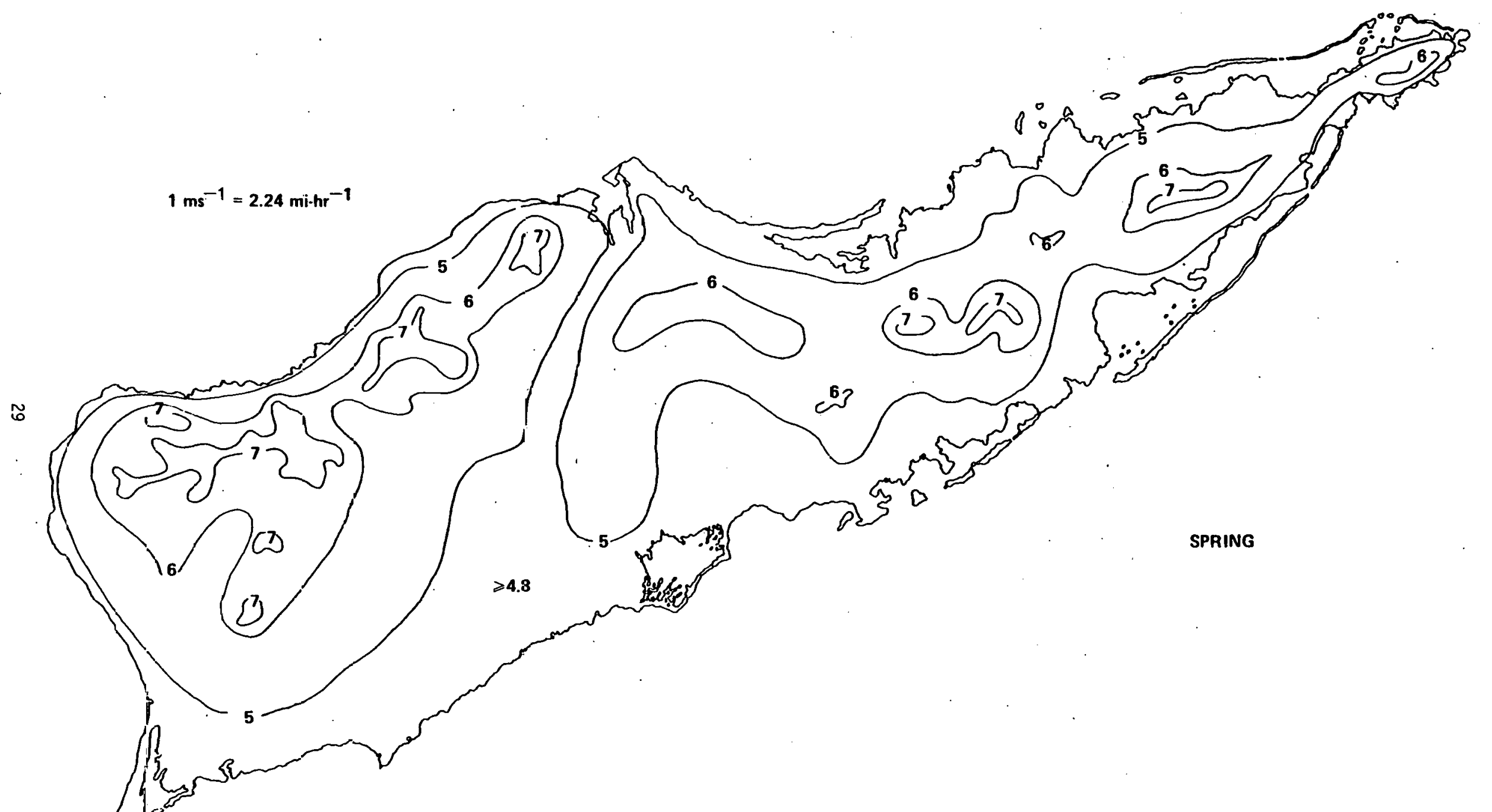

Figure 3.6. Spring mean wind isotachs $\left[\mathrm{ms}^{-1}\right]$ for St. Croix. 


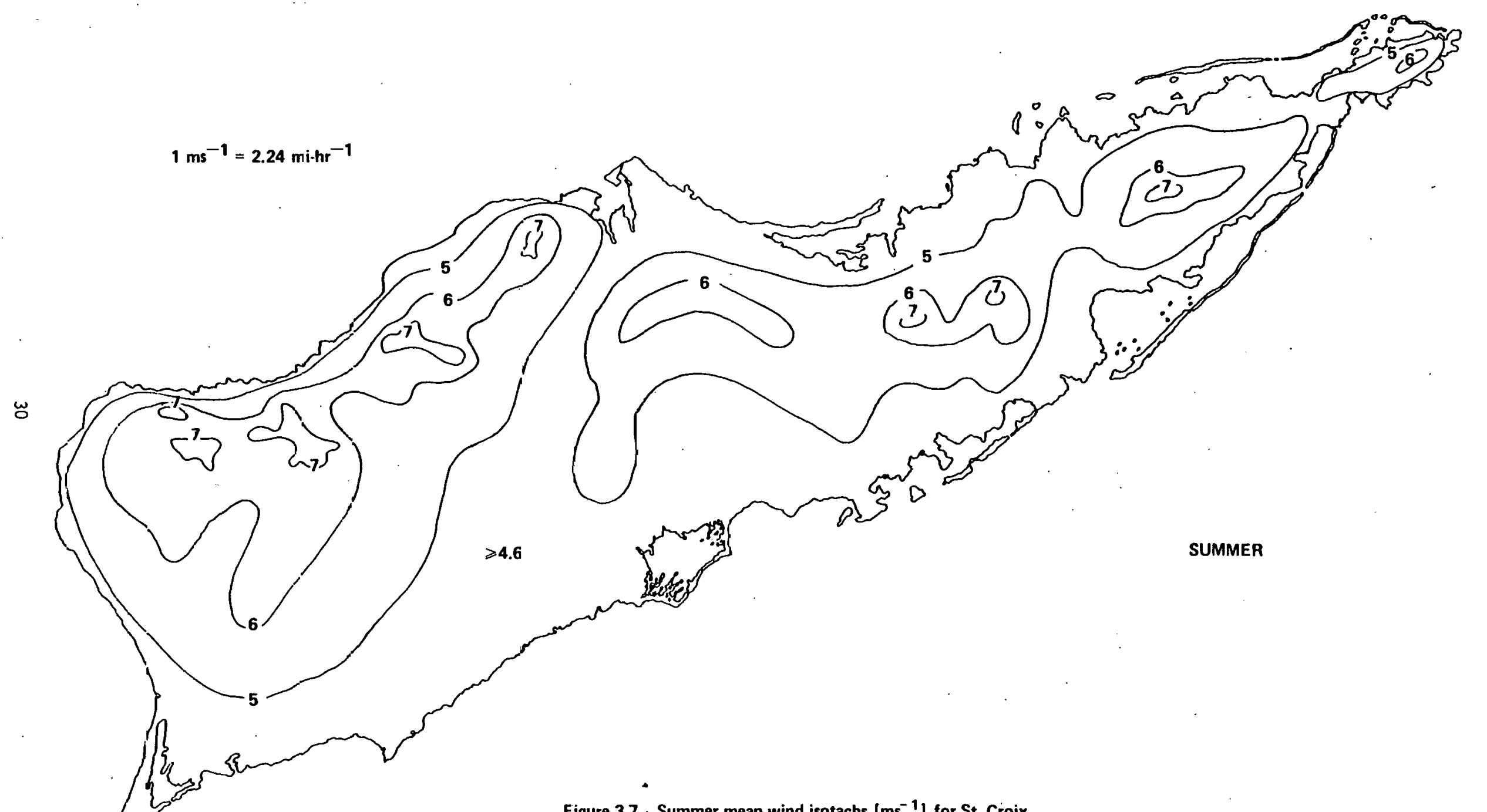

Figure 3.7. Summer mean wind isotachs $\left[\mathrm{ms}^{-1}\right]$ for St. Croix. 


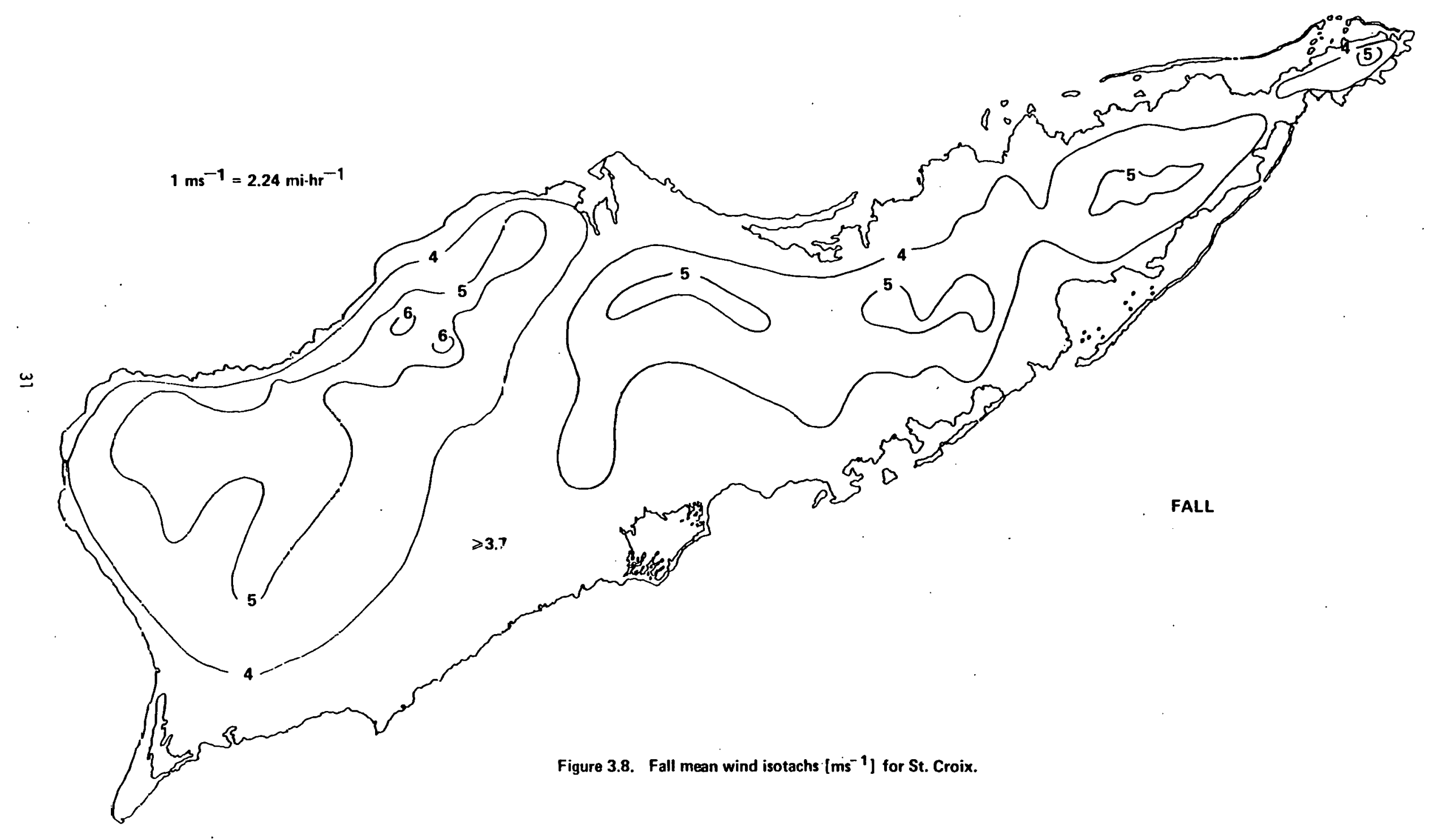




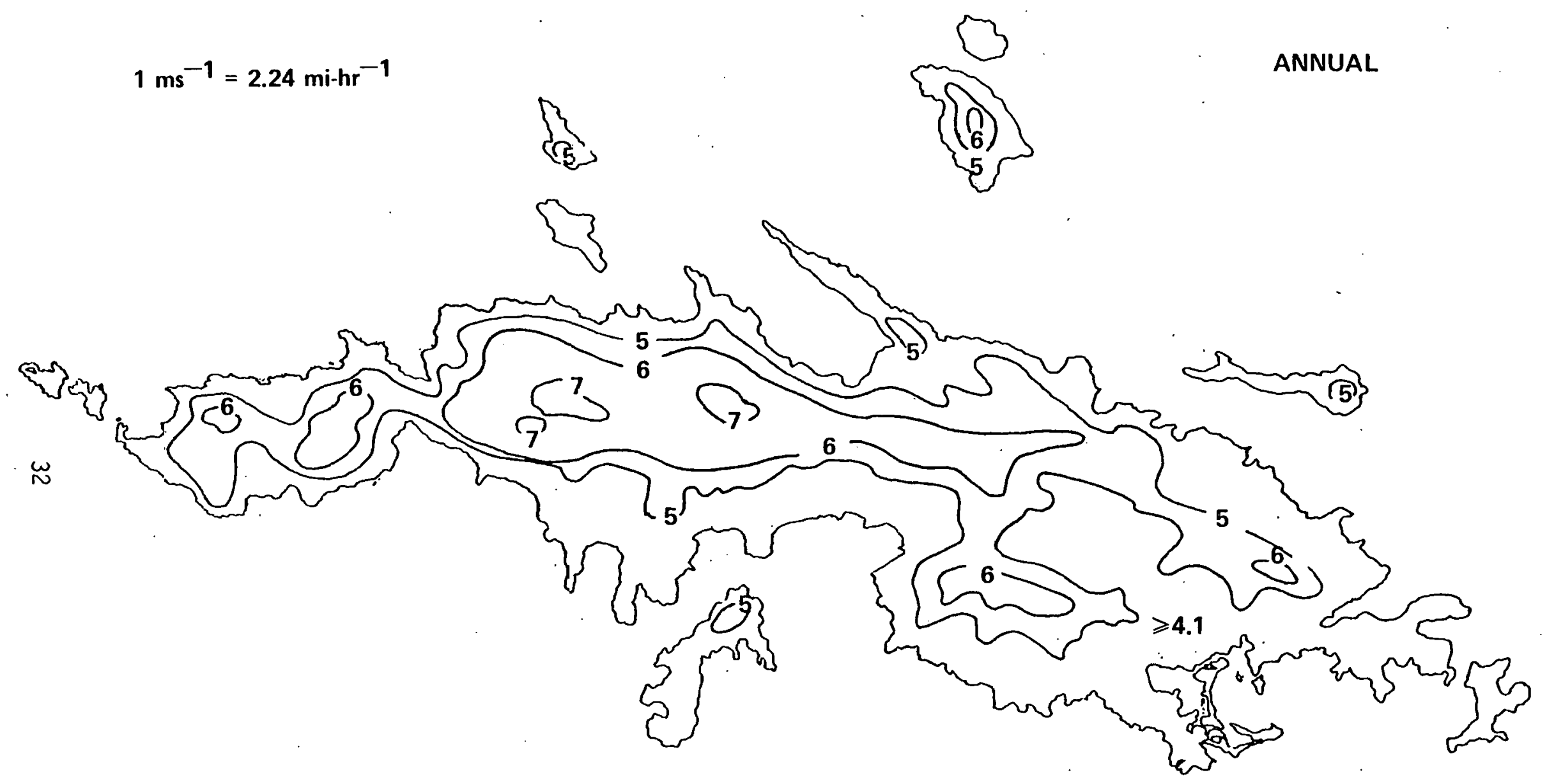

Figure 3.9. Annual mean wind isotachs $\left[\mathrm{ms}^{-1}\right]$ for St. Thomas. 


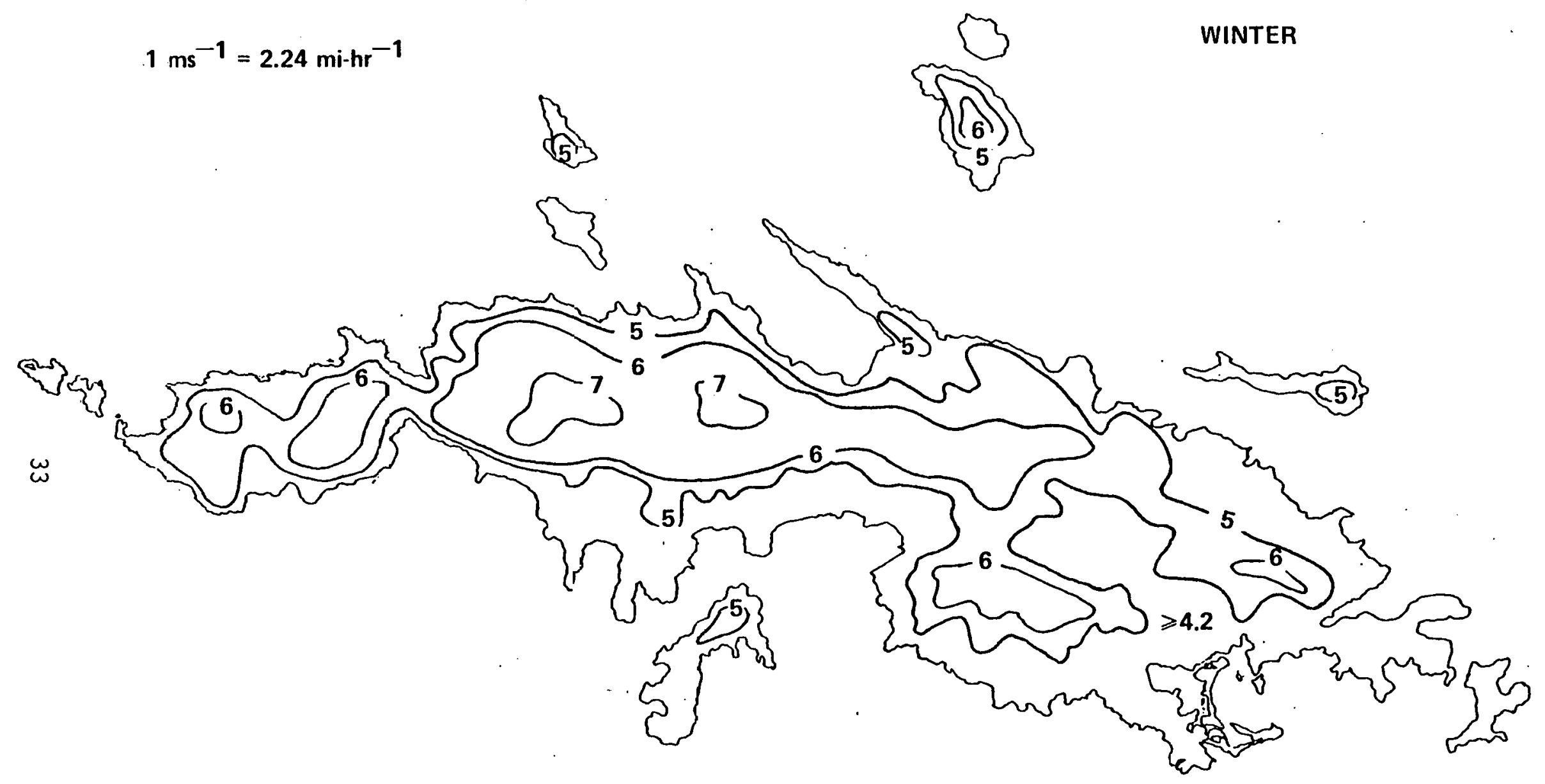

Figure 3.10. Winter mean wind isotachs $\left[\mathrm{ms}^{-1}\right]$ for St. Thomas. 


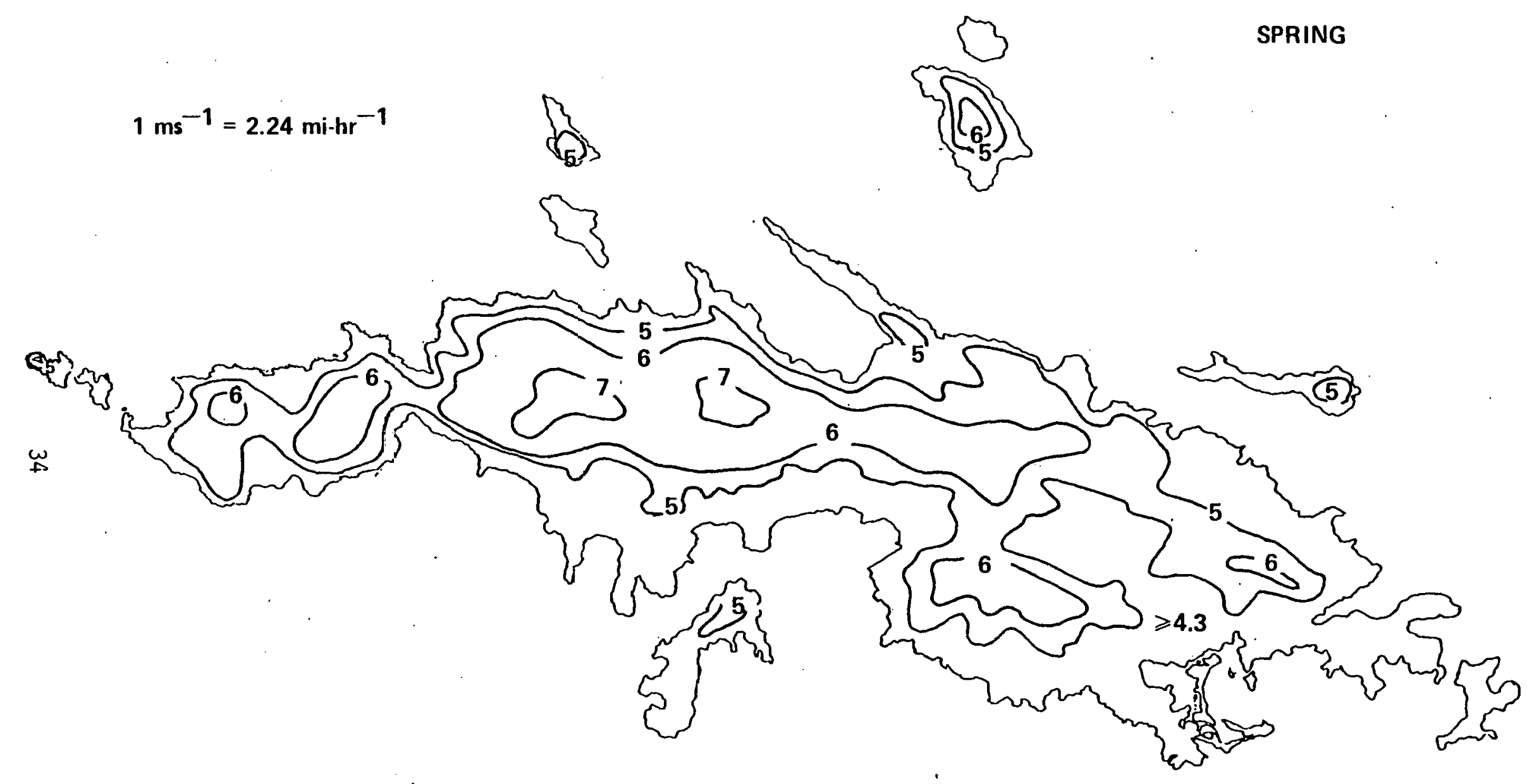

Figure 3.11. Spring mean wind isotachs $\left[\mathrm{ms}^{-1}\right]$ for St. Thomas. 


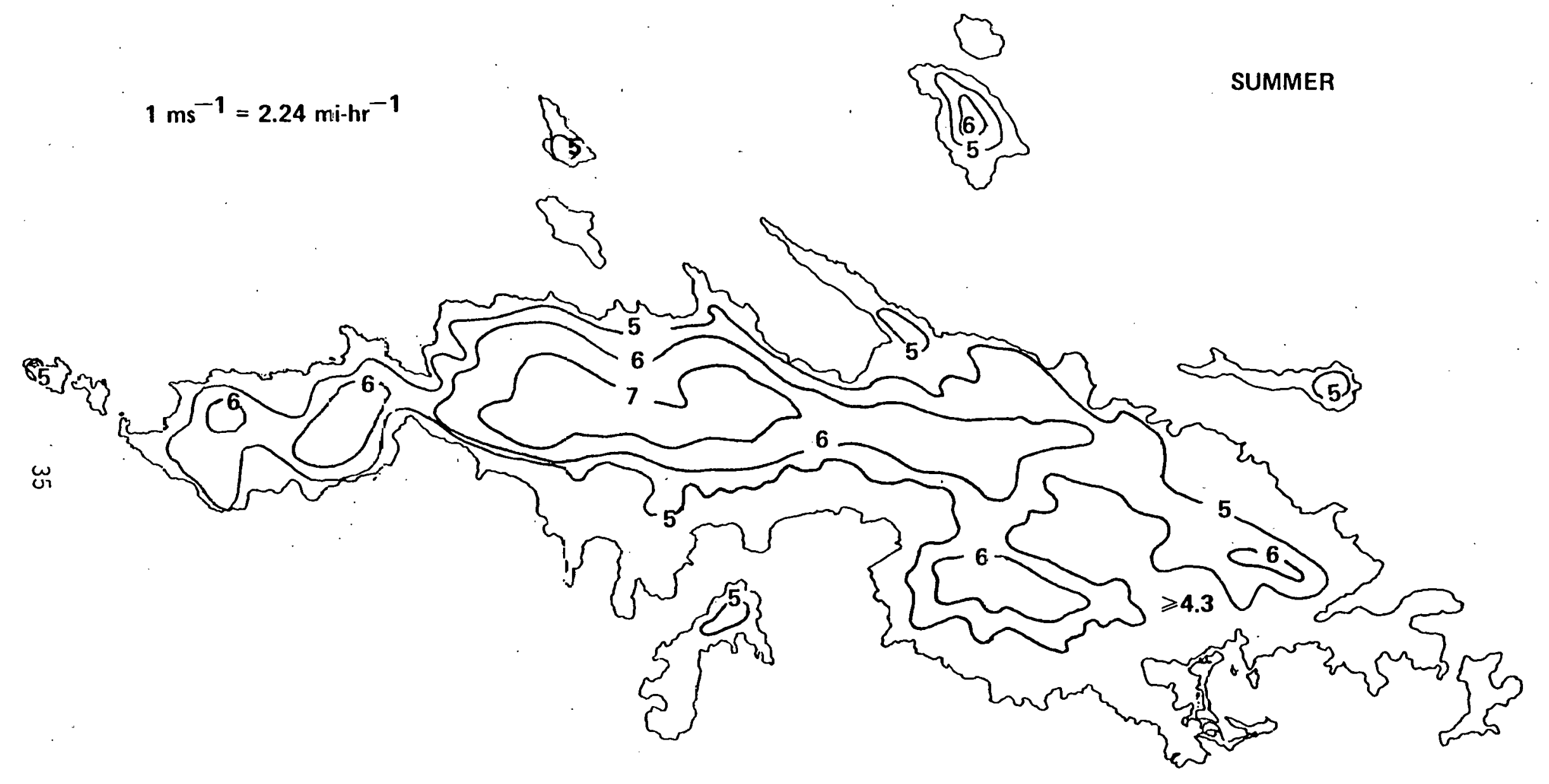

Figure 3.12. Summer mean wind isotachs $\left[\mathrm{ms}^{-1}\right]$ for St. Thomas. 


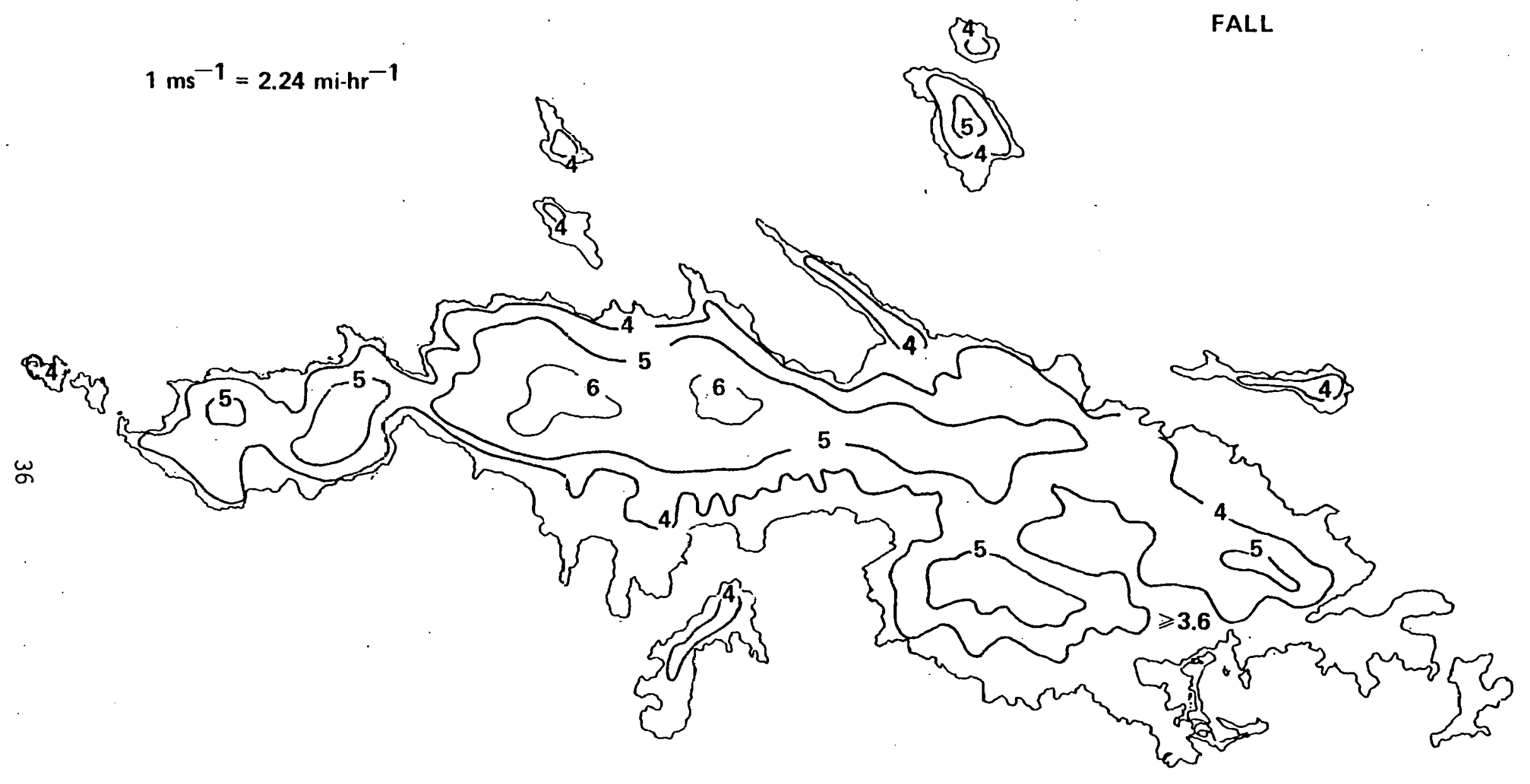

Figure 3.13. Fall mean wind isotachs $\left[\mathrm{ms}^{-1}\right]$ for St. Thomas. 
ANNUAL

$1 \mathrm{~ms}^{-1}=2.24{\mathrm{mi}-\mathrm{hr}^{-1}}^{-1}$

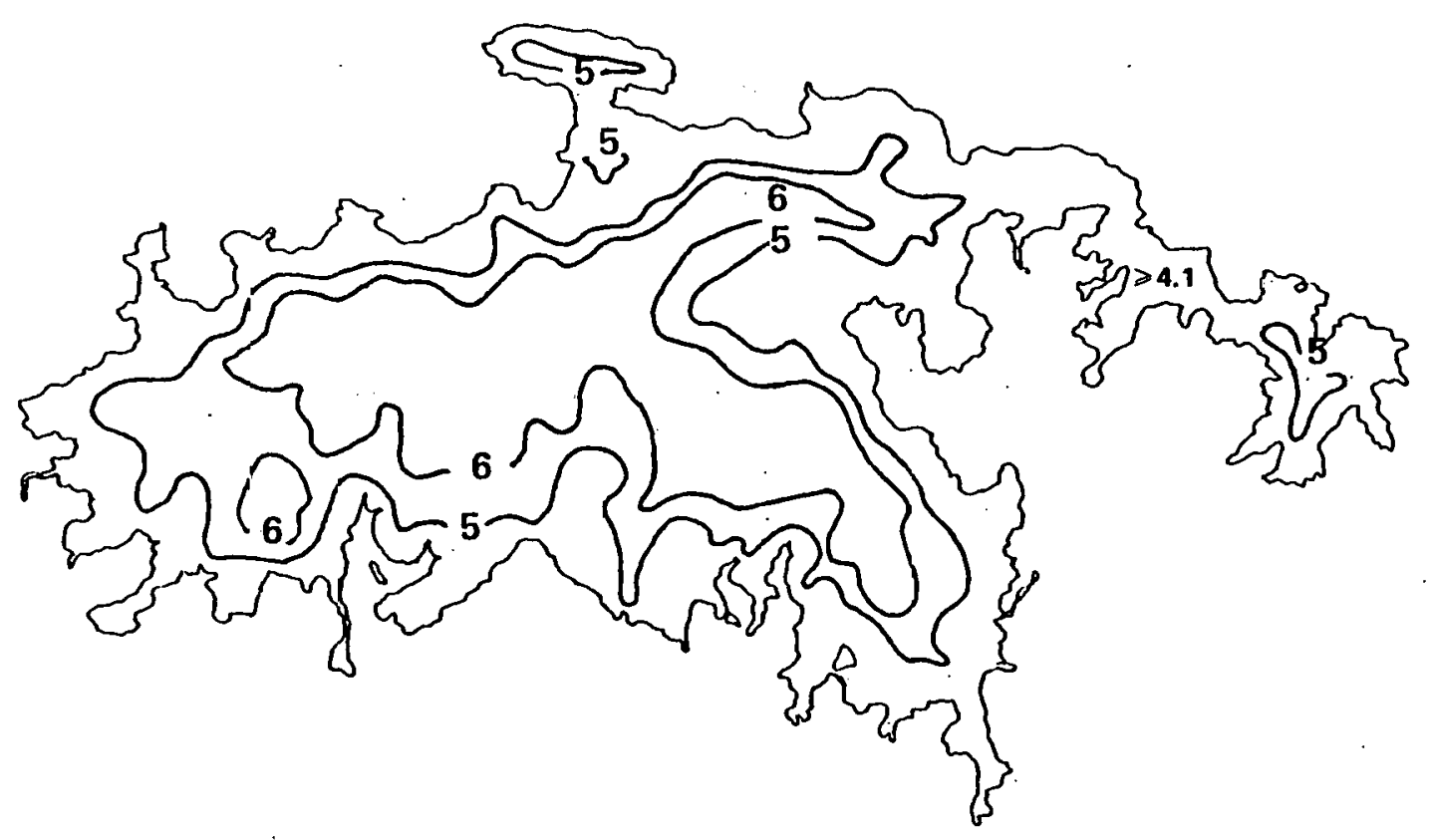

Figure 3.14. Annual mean wind isotachs $\left[\mathrm{ms}^{-1}\right]$ for St. John. 
WINTER

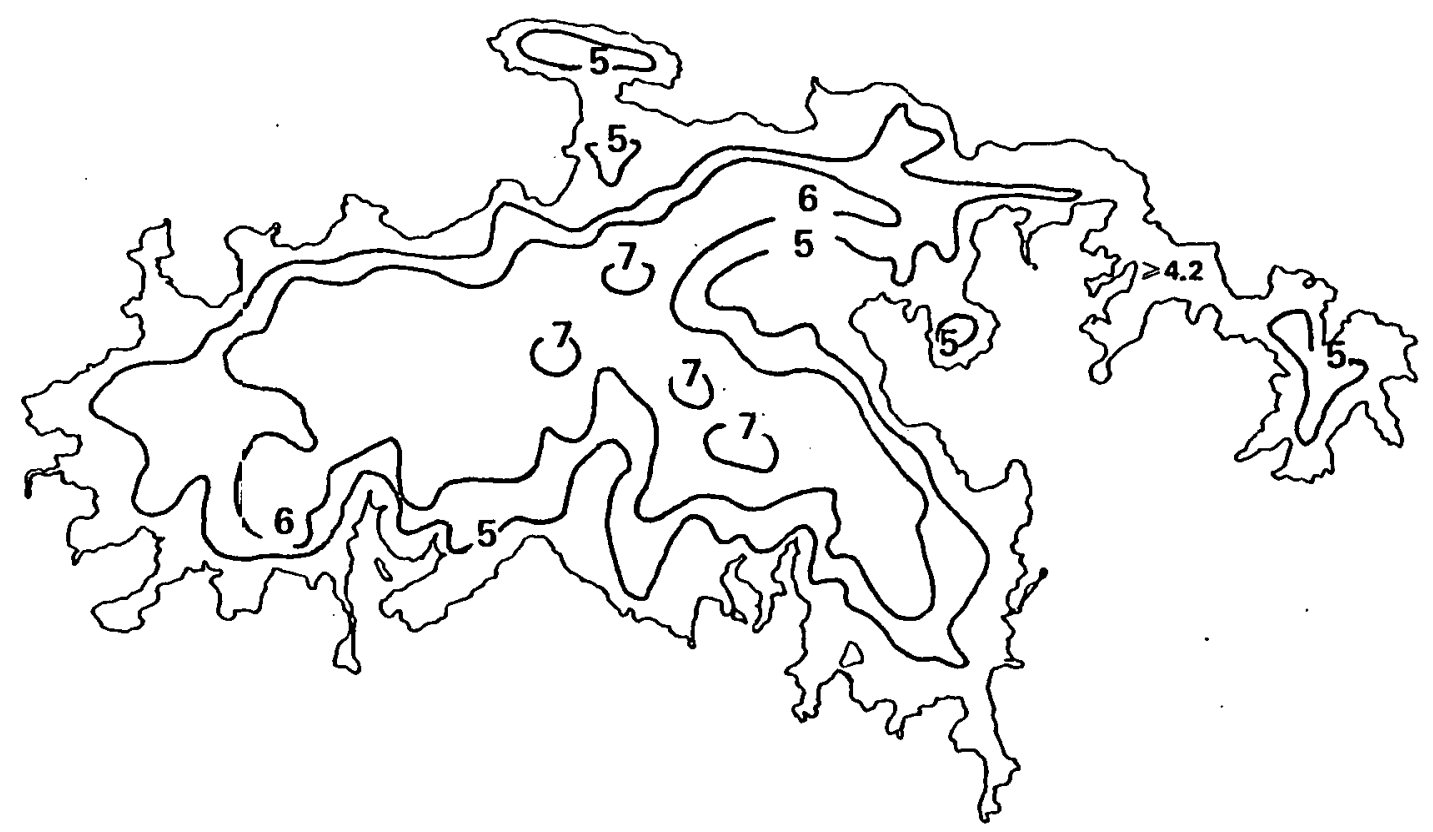

Figure 3.15. Winter mean wind isotachs $\left[\mathrm{ms}^{-1}\right]$ for St. John. 
SPRING

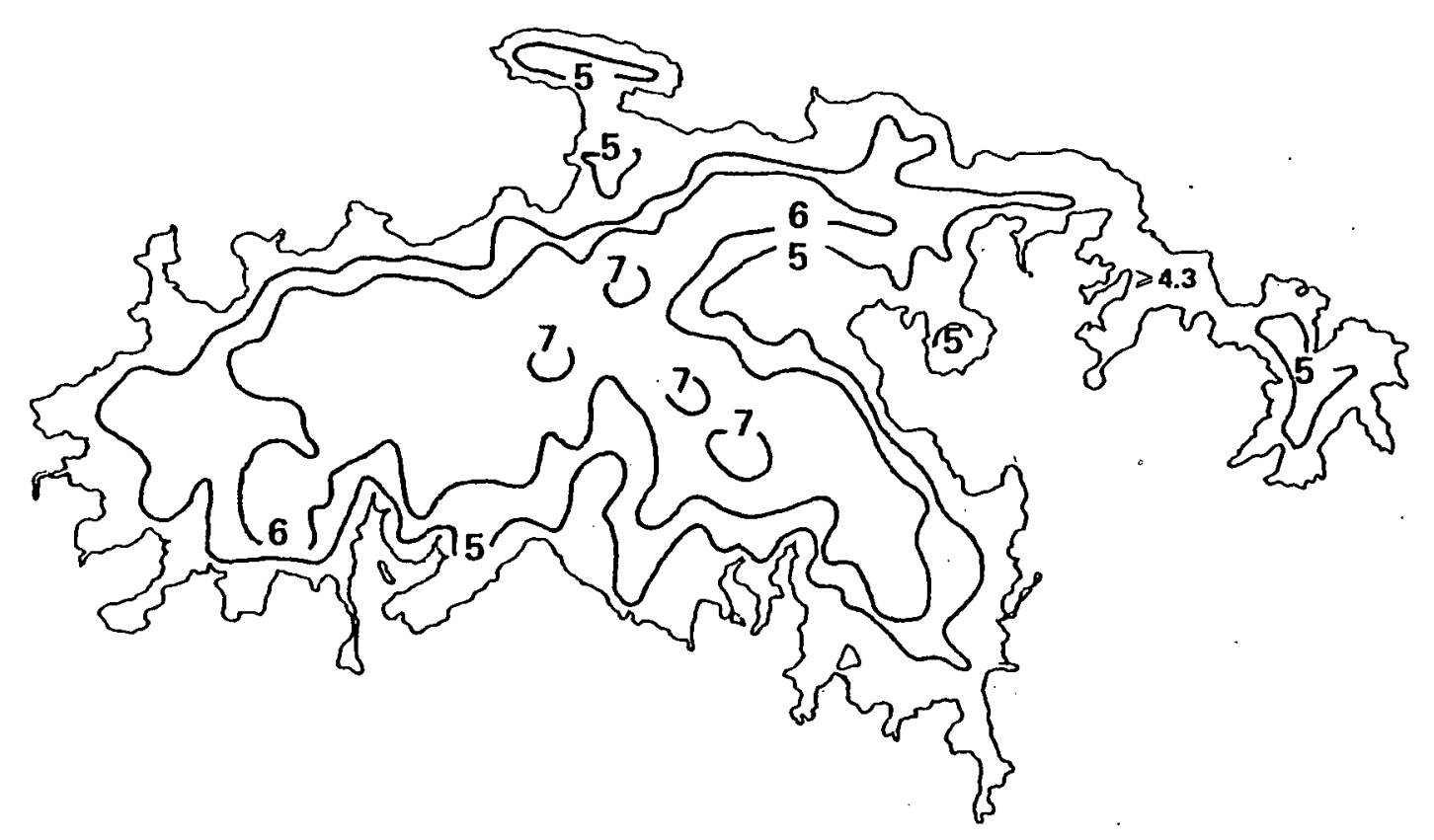

Figure 3.16. Spring mean wind isotachs $\left[\mathrm{ms}^{-1}\right]$ for St. John. 
SUMMER

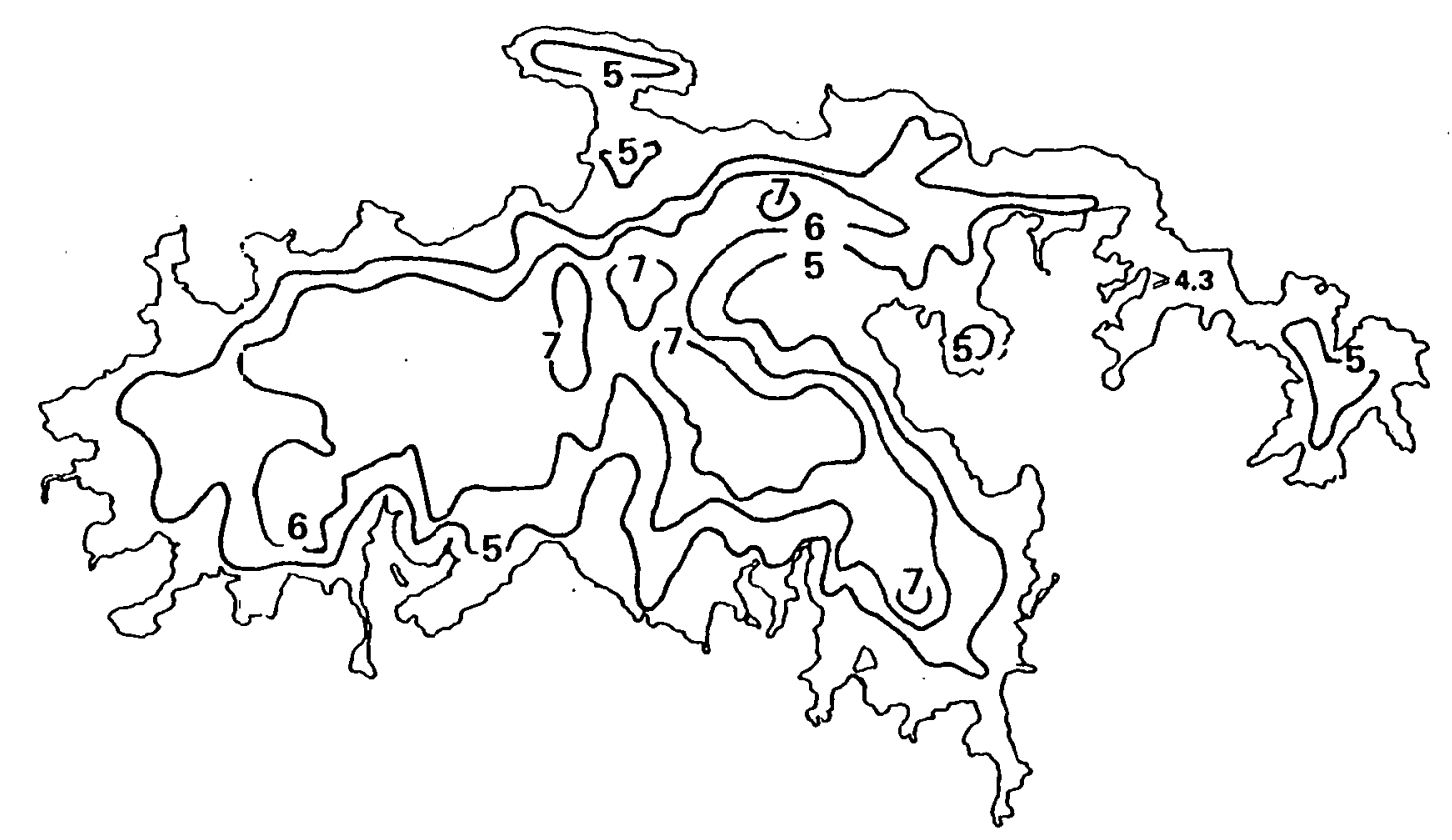

Figure 3.17. Summer mean wind isotachs $\left[\mathrm{ms}^{-1}\right]$ for St. John. 
FALL

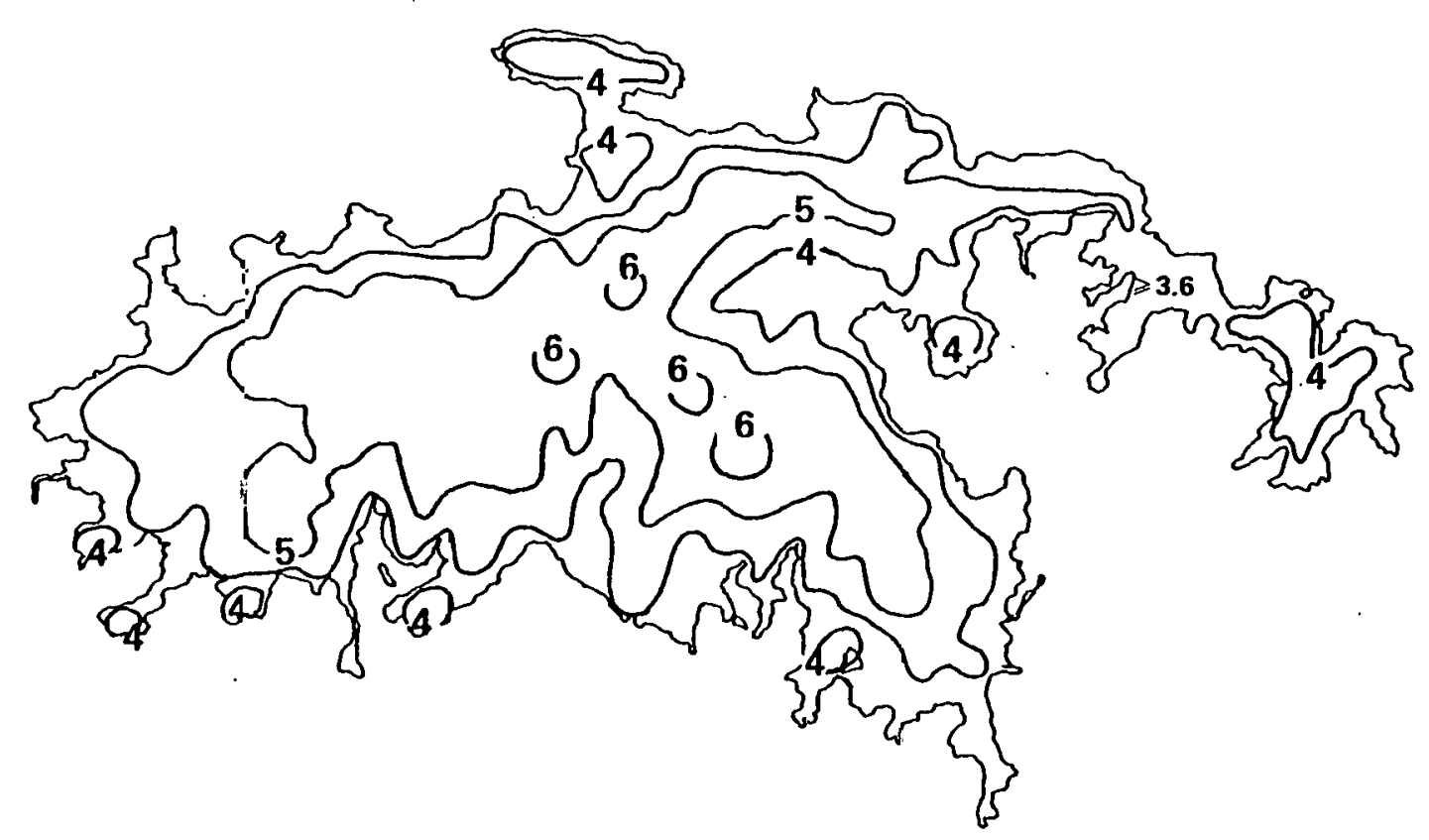

Figure 3.18. Fall mean wind isotachs $\left[\mathrm{ms}^{-1}\right]$ for St. John. 
Note that at the higher elevations, mean wind speeds of greater than 7 $\mathrm{ms}^{-1}$ (15.7 $\mathrm{mi}^{-\mathrm{hr}^{-1}}$ ) occur over large areas in the Spring and Summer on all three islands. The upper elevation mean wind speeds drop to a minimum of just over $6 \mathrm{~ms}^{-1}\left(13.4 \mathrm{mi}^{-1} \mathrm{hr}^{-1}\right)$ in the Fall. 


\subsection{Preliminary WECS Site Selection}

\subsection{Site Selection Criteria and Procedures}

Combining a knowledge of local topography (Appendix B) and the role of terrain in enhancing the wind (Appendix A) with the insight gained from analyzing a substantial block of climatic data (Section 3), several potential WECS sites are identified for each of the main islands in the USVI group. The specific criteria used for selecting sites included the degree of windward exposure reasonably free of turbulence; the elevation of the site; the enhancement potential of the terrain; and the proximity of the site to a roadway which was assumed to have a commercial power line running along it. Generally, elevated sites near windward shorelines were chosen over locations further inland or on lee shores. Winds arriving at the coastline after long fetches over open water are stronger than they are further inland where speeds are reduced by friction losses to the ground and by turbulent losses caused by rough terrain. There follows, in no particular order, a listing and discussion of the candidate WECS sites. Note that the identification of these sites is based upon the results of a preliminary wind energy assessment in which relatively unsophisticated analysis techniques were applied to a sparse data base. These sites thus represent a preliminary selection process and must be subjected to a more dețailed study before any final selections are made.

\subsection{Candidate WECS Sites}

\subsubsection{Sites on St. Croix (Figure 4.1)}

1) Sugarloaf Hill (205 m MSL) is the tallest of the Goat Hills and is located $1.4 \mathrm{~km}(0.9 \mathrm{mi})$ west of East Point, the extreme eastern tip of St. Croix. The easterly trades thus have an uninterrupted fetch over open ocean to Sugarloaf Hill. Annual mean wind speeds exceed 6 $\mathrm{ms}^{-1}\left(13.4 \mathrm{mi}^{-\mathrm{hr}} \mathrm{-}^{-1}\right)$. A road runs up the leeward side of the hill to 
within $0.2 \mathrm{~km}(0.1 \mathrm{mi})$ of the peak offering access to the site. The north and south upper flanks and peak of Sugarloaf Hill are candidate locations for WECS units [see A-3 in Appendix A].

2) The windward-most peak of the Seven Hills has an elevation of $248 \mathrm{~m}$ MSL and is only $2.4 \mathrm{~km}(1.5 \mathrm{mi})$ inland from the beach at Turner Hole. Winds from E through ESE have an uninterrupted fetch to this hill where annual mean wind speeds exceed $6 \mathrm{~ms}^{-1}\left(13.4 \mathrm{mi}^{-\mathrm{hr}^{-1}}\right)$. Several roads come within $1 \mathrm{~km}(0.6 \mathrm{mi})$ of the peak. The peak and the north and south upper flanks (including the little saddle on the south flank) are candidate WECS sites [see A-3 and A-4 in Appendix. A].

3) The narrow north/south ridge between lang Peak (233 m MSL) and Prospect Hill (229 m MSL) measures $200 \mathrm{~m}$ MSL at its lowest point. This $0.6 \mathrm{~km}(0.4 \mathrm{mi})$ long ridge forms a portion of the west wall of the little valley extending from Great Pond and is just $1 \mathrm{~km}(0.6$ mi) west of Lowery Hill Road. Its orientation perpendicular to the prevailing easterlies, which exceed $6 \mathrm{~ms}^{-1}\left(13.4 \mathrm{mi}^{-\mathrm{hr}^{-1}}\right)$ on the annual average at this location, gives excellent potential for enhancement of the wind all along the upper windward flank of the ridge [see $\mathrm{A}-2$ and $\mathrm{A}-4$ in Appendix $\mathrm{A}$ ].

4) Windsor Peak (270 m MSL) is only $4.1 \mathrm{~km}(2.6 \mathrm{mi})$ east of the coast line that runs northwest out of Christiansted Harbor. Winds reaching Windsor from the ENE and $E$ have an uninterrupted fetch over open water. Winds from the ESE and SE experience some channelling up a narrow valley [see A-4 in Appendix A]. Another peak (264 m MSL) just $0.5 \mathrm{~km}(0.3 \mathrm{mi})$ to the NNE helps form a saddle on Windsor's north flank. Scenic Drive runs along the saddle. The saddle and 
ज

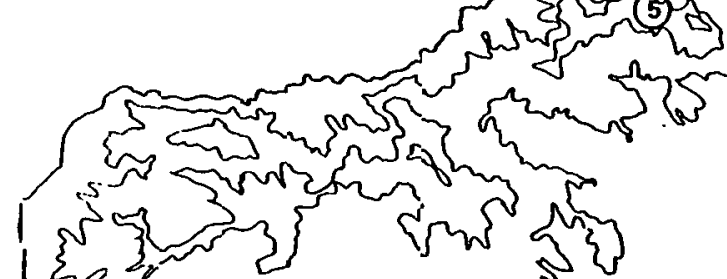

है। की है।

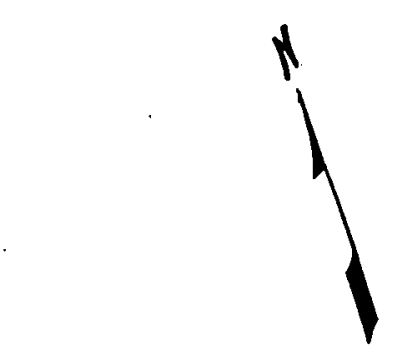
$12 \pi$

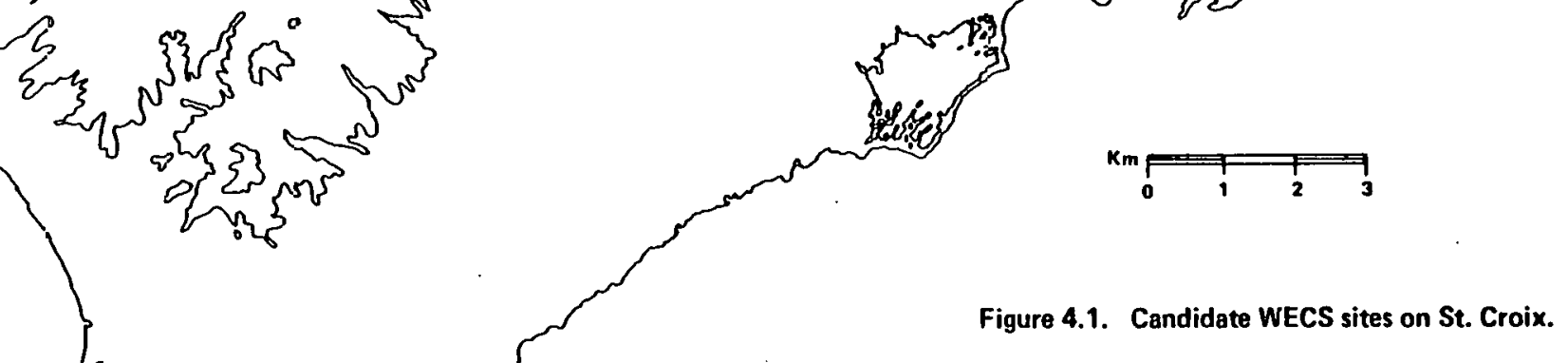

s (3) (4) 50

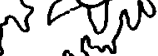
sins $r^{2}$

Figure 4.1. Candidate WECS sites on St. Croix.

(1) Sugarloaf Hill

(2) Windward peak of Seven Hills

(3) Lang/Prospect Ridge

(4) Windsor Peak

(5) Mount Eagle/Blue Mountain
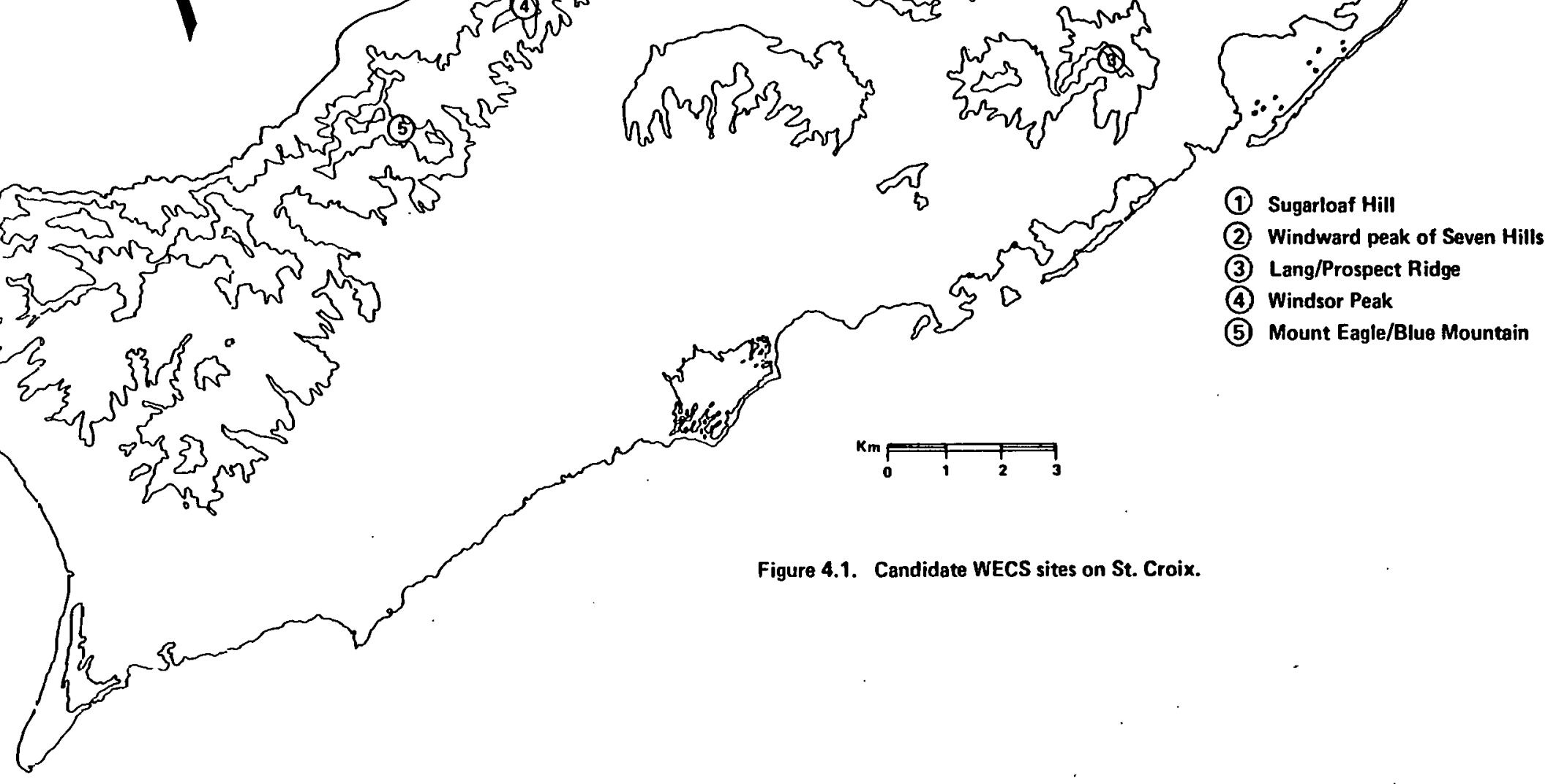
north and south upper flanks of both peaks are candidate WECS locations [refer to $A-3$ and $A-4$ in Appendix A].

5) Mount Eagle (355 m MSL) and Blue Mountain (334 m MSL), $1.1 \mathrm{~km}$ (0.7 mi) to the southeast of Mt. Eagle, are the highest peaks on St. Croix and their upper flanks are candidate WECS sites, particularly the north flank of Eagle and the south flank of Blue. The NW-SE oriented ridge between the two peaks dips to $270 \mathrm{~m}$ MSL at its lowest point and may also have some potential for a WECS installation due to enhancement of the wind by the ridge/saddle effect [refer to A-2

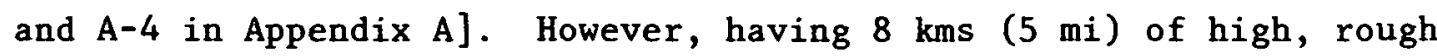
terrain upwind may cause turbulence problems for the Eagle/Blue location. Scenic Drive passes between the two peaks.

\subsubsection{Sites on St Thomas (Figure 4.2)}

1) Benner Hill (165 m MSL) is just $1.5 \mathrm{~km}$ ( $0.9 \mathrm{mi})$ inland from Redhook Point near the east end of St. Thomas and is the most windward of the high hills on the island. The top of Benner Hill is relatively flat so candidate WECS sites are on the windward slope near the peak and on the north and south upper flanks [refer to A-2 and A-3 in Appendix A] where the annual mean wind speed approaches $6 \mathrm{~ms}^{-1}(13.4$ $\left.\mathrm{mi}-\mathrm{hr}^{-1}\right)$. Major roads are within $1 \mathrm{~km}(0.6 \mathrm{mi})$ of the hill.

2) Nulliberg Peak (264 m MSL) has an annual mean wind speed of over 6 $\mathrm{ms}^{-1}$ (13.4 $\mathrm{mi}^{-\mathrm{hr}^{-1}}$ ) and is the first hill reached by an ESE wind across Jersey Bay. A large gully on the upwind side of Nulliberg enhances the wind around the upper northern flank [refer to A-4 in Appendix A]. Major roads and commercial power lines are within $1 \mathrm{~km}$ $(0.6 \mathrm{mi})$ of the summit. 


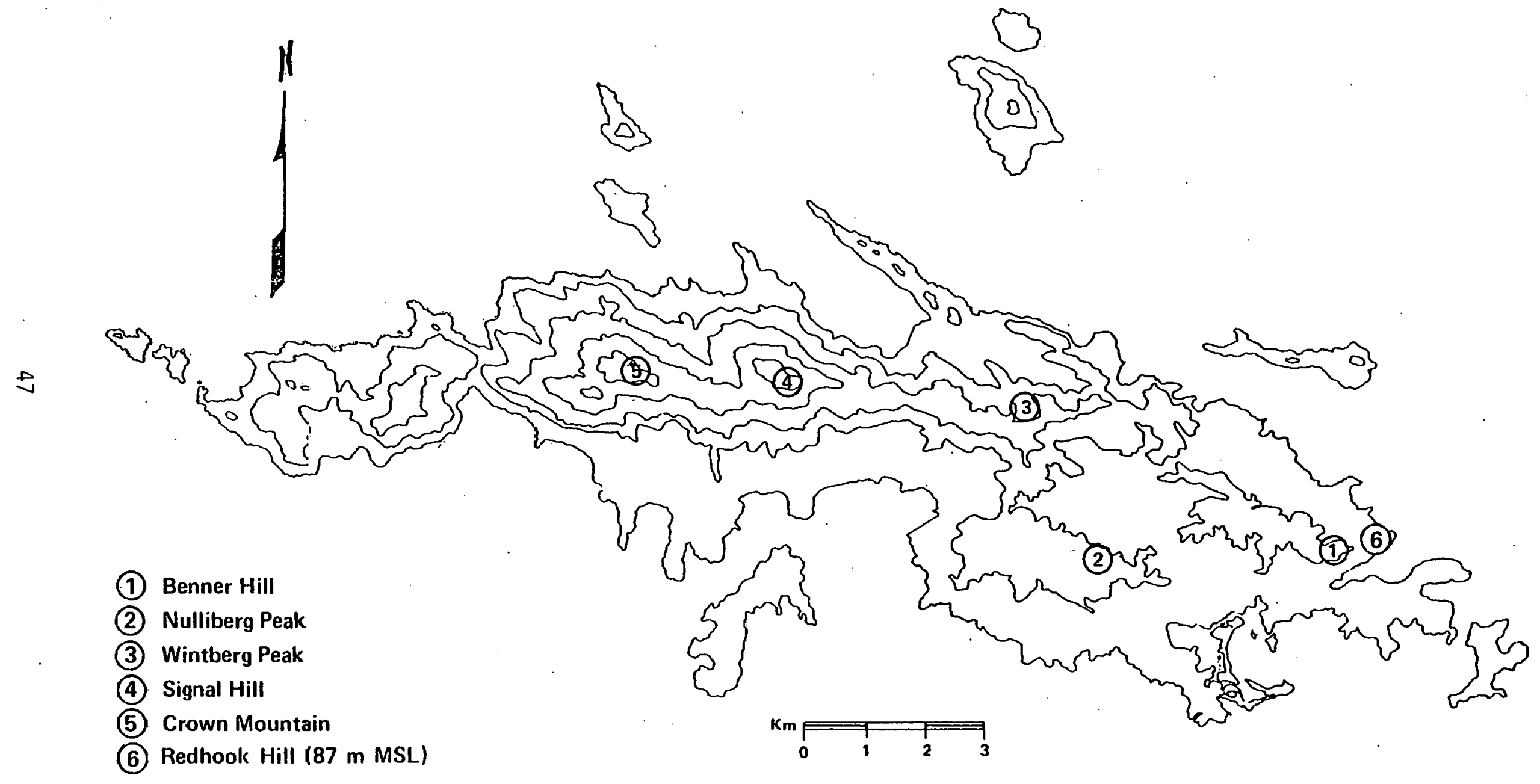

Figure 4.2. Candidate WECS sites on St. Thomas. 
3) Wintberg Peak (293 m MSL) is the windward-most hill of the east-west ridge that dominates the central portion of St. Thomas. The annual mean wind speed approaches $6.5 \mathrm{~ms}^{-1}\left(14.5 \mathrm{mi}^{-\mathrm{hr}^{-1}}\right)$. Skyline Drive passes close to the summit offering access to the site. A ridge protruding from the south flank of Wintberg along with the upper windward slope and north flank are potential WECS sites [refer to A-2 in Appendix A]. The east-west pass between Wintberg and Flag Hill (294 m. MSL) $2 \mathrm{~km}(1.2 \mathrm{mi})$ to the south has wind enhancement potential [refer to A-4 in Appendix A] but turbulence induced by upstream terrain may be a problem. Despite its elevation, Flag Hill, being directly in the lee of Nulliberg, has only marginal potential for a WECS installation.

4) Signal Hill (453 m MSL) has WECS site potential by virtue of its elevation and $7 \mathrm{~ms}^{-1}\left(15.7 \mathrm{mi}^{-\mathrm{hr}^{-1}}\right)$ annual average wind speed, but because it is $6 \mathrm{~km}(3.7 \mathrm{mi})$ east of the nearest shoreline with rough terrain in between, the site may experience turbulence induced by the upwind terrain. Signal Hill would give good exposure to winds north of east, the predominant direction on St. Thomas. A road runs to the summit.

5) Crown Mountain ( $474 \mathrm{~m} \mathrm{MSL}$ ) was chosen because it is the tallest peak on St. Thomas with an annual wind speed well in excess of $7 \mathrm{~ms}^{-1}$ (15.7 mi-hr ${ }^{-1}$ ), but it may experience turbulence because it is just $2 \mathrm{~km}(1.2 \mathrm{mi})$ downwind of Signal Hill. The little saddle running over to Hawk Hill from Crown's southern flank may provide good exposure and enhancement potential [refer to A-4 in Appendix A] for winds south of east. 
6) Redhook Hill ( $87 \mathrm{~m} \mathrm{MSL}$ ) is the lowest hill chosen in this preliminary assessment. However, Redhook is located at the extreme eastern end of St. Thomas and thus has an uninterrupted exposure to the easterly trades and an annual average wind speed of nearly $5 \mathrm{~ms}^{-1}$ (11 mi-hr $\left.{ }^{-1}\right)$. A road passes just west of the hill.

\subsubsection{Sites on St. John (Figure 4.3)}

The predominant topographic feature of St. John is a horseshoe shaped ridge, open to the windward that traverses the east end of the island from the north shore to the south shore. The ridge is formed by Ajax Peak, Mamey Peak, Bordeaux Mountain, and Minna Hill. The area offers potential enhancement of the easterly trades by funneling up the horseshoe valley and flow up and over the crest of the ridge [refer to A-2 and A-4 in Appendis A].

1) Ajax Peak ( $300 \mathrm{~m}$ MSL) is the highest point of an east-west ridge that forms the north wall of the little horseshoe valley east of Coral Harbor. Flow along the south flank of Ajax is funneled by the valley. The north and south upper flanks as well as the peak of Ajax have excellent exposure to the easterly trades, where annual average wind speeds exceed $6.5 \mathrm{~ms}^{-1}\left(14.5 \mathrm{mi}^{-\mathrm{hr}^{-1}}\right)$. Centerline Road passes just south of the peak, offering access to the site.

2) Mamey Peak (350 m MSL) sits at the extreme west end of the horseshoe valley, and with an east wind would benefit most from the channelling of the wind up the valley. Regardless, Mamey presents excellent WECS potential by virtue of its elevation with annual average wind speeds well over $6.5 \mathrm{~ms}^{-1}\left(14.5 \mathrm{mi}^{-1} \mathrm{hr}^{-1}\right)$. Besides the peak, Mamey offers WECS sites along the ridge running northeast through King Hill to Ajax Peak and along the ridge running southeast to Bordealux Mountain. Mamey Peak is also served by Centerline Road. 


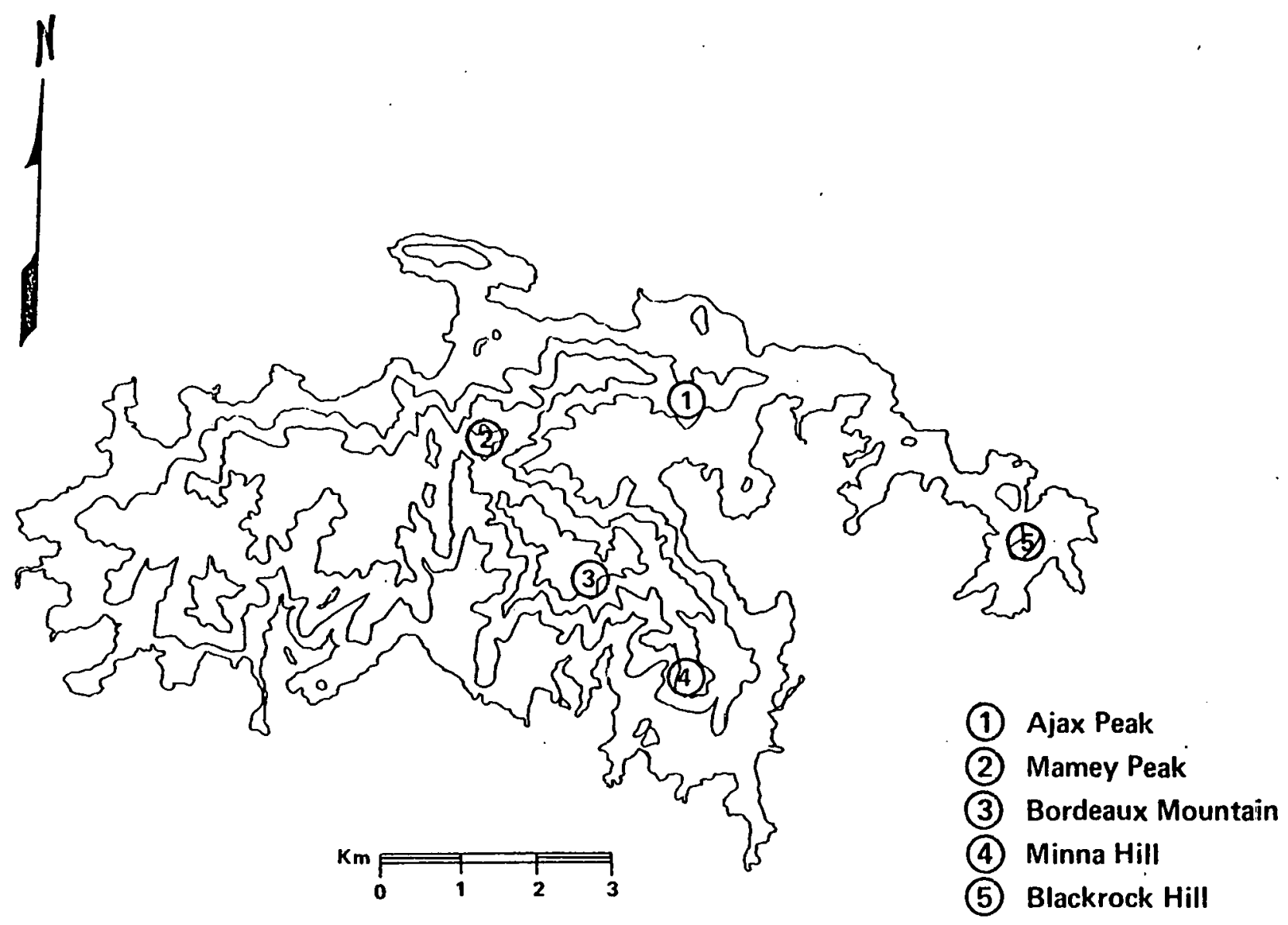

Figure 4.3. Candidate WECS sites on St. John. 
3) Bordeaux Mountain (389 m MSL) is St. John's highest peak and has an annual mean wind speed of nearly $7 \mathrm{~ms}^{-1}\left(15.7 \mathrm{mi}^{-\mathrm{hr}^{-1}}\right)$. The mountain top itself is relatively flat, but there is a gently sloping area to the windward side of the summit that is an excellent candidate WECS site. Bordeaux Mountain is served by a road.

4) Minna Hill (302 $\mathrm{m}$ MSL) is at the southern extremity of a ridge running southeast and south from Bordeaux Mountain. The average annual wind speed exceeds $6.5 \mathrm{~ms}^{-1}\left(14.5 \mathrm{mi}^{-\mathrm{hr}^{-1}}\right)$. The north-south portion of the ridge north of Minna is perpendicular to the prevailing easterlies [refer to A-2 in Appendix A] and has a totally uninterrupted fetch across the mouth of Coral Bay to the Caribbean. Minna Hill is not served by a road but is only $1 \mathrm{~km}(0.6 \mathrm{mi})$ west of John's Folly.

5) Blackrock Hill (150 m MSL) sits on a promitory that forms the east end of the island. Blackrock and Nancy Hill (160 m MSL), $1 \mathrm{~km}(0.6$ mi) to the north, are totally exposed to the easterly trades, both being less than $1 \mathrm{~km}(0.6 \mathrm{mi})$ inland, and have annual average wind speeds of nearly $6 \mathrm{~ms}^{-1}\left(13.4 \mathrm{mi}^{-\mathrm{hr}}{ }^{-1}\right)$. Blackrock and Nancy have East End village in their lee. 


\subsection{Recommendations}

Considering the capital investment required for purchasing and installing a commercially available WECS, proper siting of the system is an economic necessity. Good long-term surface data sets exist at the airport on St. Croix and St: Thomas. Using these climatic wind data and various assumptions, a preliminary assessment of the wind power potential for the USVI has been constructed and indicates considerable promise from a number of aspects: the strength and steadiness of the free air flow; the directional stability of the trade winds; and the potential for the enhancement of the wind in a number of locations on the windward side of the islands.

However, there is a major question as to the representativeness of the airport wind data since both airports are located on the downwind side of the islands. The free air flow of the easterly trades would be altered by the time it reached either airport, modified by frictional effects as the air flows over the rough topography and by thermodynamic effects resulting from heating and cooling of the surface. Instantaneous wind speed measurements made on the upwind sides of all three of the islands suggest that the winds along the windward shores may be considerably stronger than those found on the downwind side. Therefore, the initial recommendation is to design a field measurement program to obtain at least one year of wind data on the windward sides of the three islands. Though these data would significantly increase our understanding of the windfield on the islands, they would not be sufficient to develop a dependable resource assessment upon which site selection can be based. Therefore, it is further recommended that final site selection be made through the combination of a modeling study and a field measurement program.

Since the USVI's power problems are immediate, RTI feels an accelerated site selection/installation program, which can be accomplished in about one 
and one-half to two years, should be initiated. A description of this three step program is given below.

\section{Step 1}

A hydrodynamic model should be utilized to simulate the flow over the Virgin Islands. The model should incorporate the dynamic and thermodynamic features which influence the flow. Such a model can yield a high resolution analysis of the flow and identify those factors which will markedly influence the flow such as terrain enhancement and thermodynamic effects. For example, it was noted in a recent visit to the USVI that the wind speed at high elevations on the downwind side of the island was much less than expected, whereas the windspeed on the upwind side was on the order of 6 to $8 \mathrm{~ms}$ (13-18 $\mathrm{mi}^{-\mathrm{hr}^{-1}}$ ). It has been hypothesized that surface heating--the heat island or convective heating on the windward side of the hills--was responsible for this phenomenon. Through modeling of the flow, further insight can be obtained as to cause and effect relationships. The simulation data from the hydrodynamic model would be utilized along with observed data to select sites for the WECS. Modeling would provide data on resolution (too costly to acquire using in situ measurement procedures) and would identify those regions where the air flow is accelerated and thus provides more wind energy relative to other locations.

\section{Step 2}

The second step would be to establish a field program to measure the wind at the sites selected using the modeling approach in Step 1. Because of the stability of the wind regime in this portion of the tropics, it may only be necessary to collect data for at most a year and maybe only six months. The observed data would verify the sites selected utilizing the modeling technique and would help the investigator choose the best sites from those selected.

\section{Step 3}

In Step 3, the WECS systems would be installed at the selected sites and the operation of the wind energy systems would begin.

These recommendations are purely from a site selection point of view.

Other parallel studies must also be accomplished before installation of the WECS is accomplished. These include, but are not limited to, economic and environmental impact studies and studies on procedures to link the WECS to the existing USVI power grid. 


\subsection{References}

Atkinson, Gary D., Major USAF, 1971: "Forecaster's Guide to Tropical Meteorology". Technical Report 240, U. S. Air Force, Air Weather Service.

Frost, Walter, and Dieter K. Nowak, 1979: "Summary and Guidelines for Siting Wind Turbine Generators Relative to Small-Scale Two-Dimensional Terrain Features". RLO-2443-77/1, U. S. Department of Energy.

Neumann, C. J., G. W. Cry, E. L. Caso, B. R. Jarvinen, 1978: Tropical

Cyclones of the North Atlantic Ocean, 1871-1977. U. S. Department of Commerce, National Climatic Center and National Hurricane Center.

Rieh1, Herbert, 1954: Tropical Meteorology, McGraw-Hill Book Company, Inc.

Riehl, Herbert, 1979: Climate and Weather in the Tropics, Academic Press.

Sandborn, V. A., 1977: "Placement of Wind Power Systems". EY-76-S-06-2438, U. S. Department of Energy.

Wegley, Harry L., Montie M. Orgill, and Ron L. Drake, 1978: "A Siting Handbook for Small Wind Energy Conversion Systems", PNL-2521, U. S. Department of Energy.

Wegley, Harry L., 1979: "Regional Wind Energy Resource Assessment for Puerto Rico and the Virgin Islands", Batelle, Pacific Northwest Laboratories (Draft Report). 


\section{APPENDIX A}

TERRAIN ENHANCEMENT OF THE WIND

\section{A-1 Terrain Enhancement}

The windward or eastern sides and mountainous interiors of the main islands in the U. S. Virgin Islands (USVI) group present a number of terrain features that have the potential of enhancing available wind power due to both elevation and to aerodynamic influences. These topographic features include ridges, bluffs, cliffs, hills, mountains, passes, saddles and valleys. Enhancement due to increased elevation is easily understood. A land form projecting above the surrounding terrain is exposed to air flow further above the ground and away from the mitigating effects of surface friction. Generally, wind speed increases with elevation in the lower 200 meters of the atmosphere (Figure A-1). Elevation also removes a potential wind energy site from the undesirable effects of diurnal surface cooling and heating, particularly the near calm conditions associated with the nocturnal. surface-based temperature inversion and the late afternoon turbulence due to an unstable boundary layer.

In all cases, upwind surface roughness must be considered. The surface roughness parameter, $z_{0}$, indicates the thickness of the layer above the ground cover that is disturbed by contact with the ground cover. The minimum height at which wind can be measured $\left(z_{n}\right)$, is that obtained by adding the surface elevation ( $z)$, the depth of the ground cover $\left(z_{g}\right)$, and the surface roughness parameter $\left(z_{0}\right)$. Typical values of $z_{0}$ found in the USVI are as follows:

\section{Feature}

Sea Eurface (calm)

Sea surface (rough)
$\underline{\mathrm{O}(\mathrm{cm})}$

0.03

4 to 20 


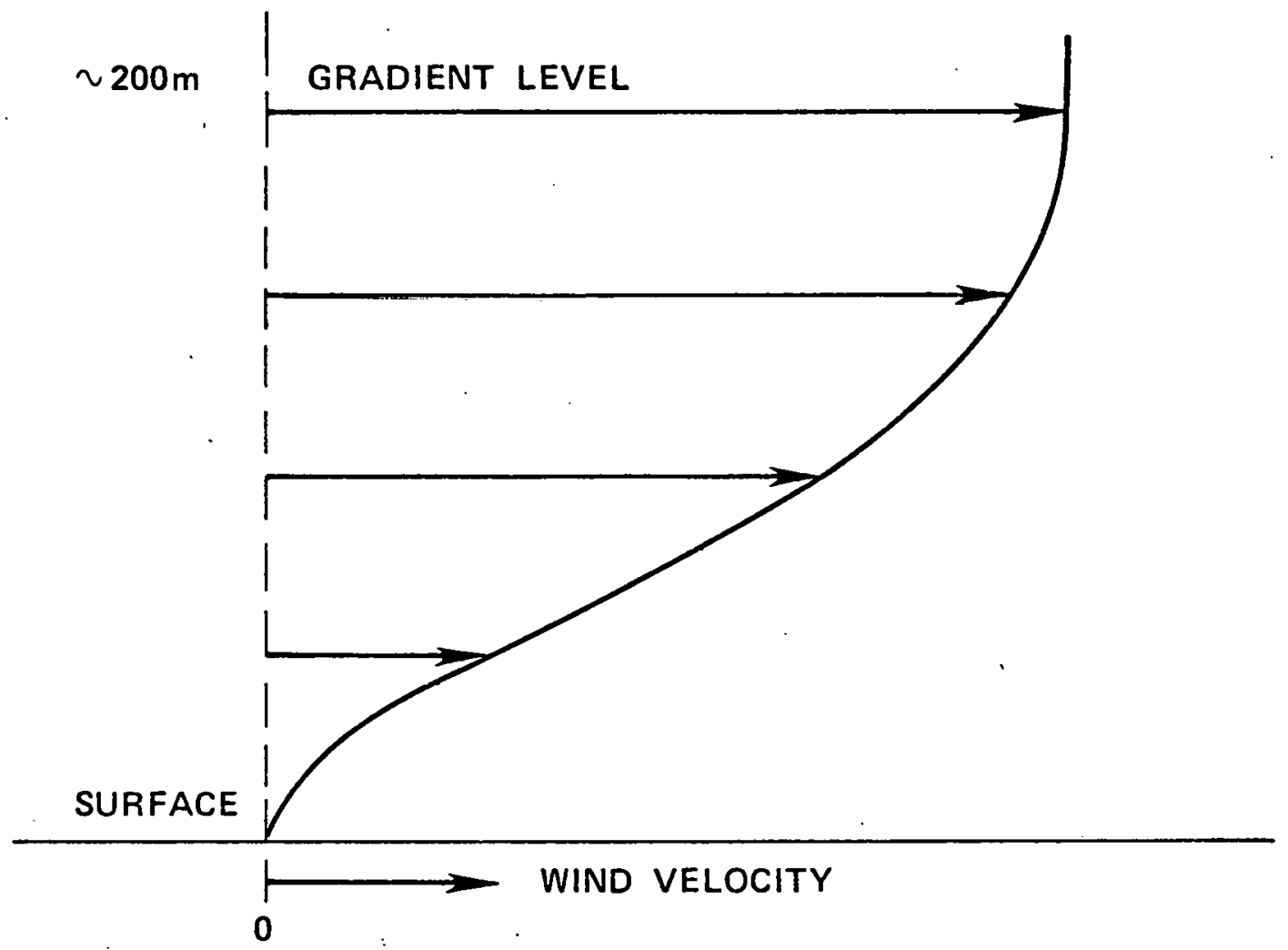

Figure A-1. Typical low altitude wind profile illustrating the mitigating effects of surface friction. 
Sand

Flat land (grasslands)

Flat land (low crops)

Forest (dense low trees)

Forest (dense tall trees)
0.01 to 0.1

$$
\begin{aligned}
& 3 \text { to } 7 \\
& 6 \text { to } 8 \\
& 10 \text { to } 50 \\
& 50 \text { to } 90
\end{aligned}
$$

Generally, the windward sides of land forms provide the more suitable locations for WECS equipment, as lee sides are areas of eddy generation, strong turbulence and significant windshear, all caused by terrain, for the most part, and all of which have deleterious effects on wind generators. The aerodynamic characteristics of various topographic features common to the USVI are discussed below.

\section{A-2 Ridges, Cliffs and Bluffs}

A ridge is simply an elongated hill rising several hundred meters above the surrounding terrain. The ideal ridge, with respect to wind power enhancement, has very little flat, level area along its crest. Air flowing across the longitudinal axis of a ridge experiences an acceleration due to the reduced cross-sectional area through which it must flow (Figure A-2). This quasi-venturi effect is maximized just downwind of the crest of the ridge. However, downwind of the crest is also an area of eddy generation and turbulence that would adversely affect WECS power generation. Generally, the steeper the ridge and the stronger the wind, the more severe the lee side turbulence. Thus the ideal wind power site is slightly upwind of the ridge crest.

The shape of the ridge (that is, its cross-section), physical dimensions, and orientation with respect to the axis of the wind are of major importance in judging cnhancement. Sandborne (1977) ranked ridge cross-sections as to 


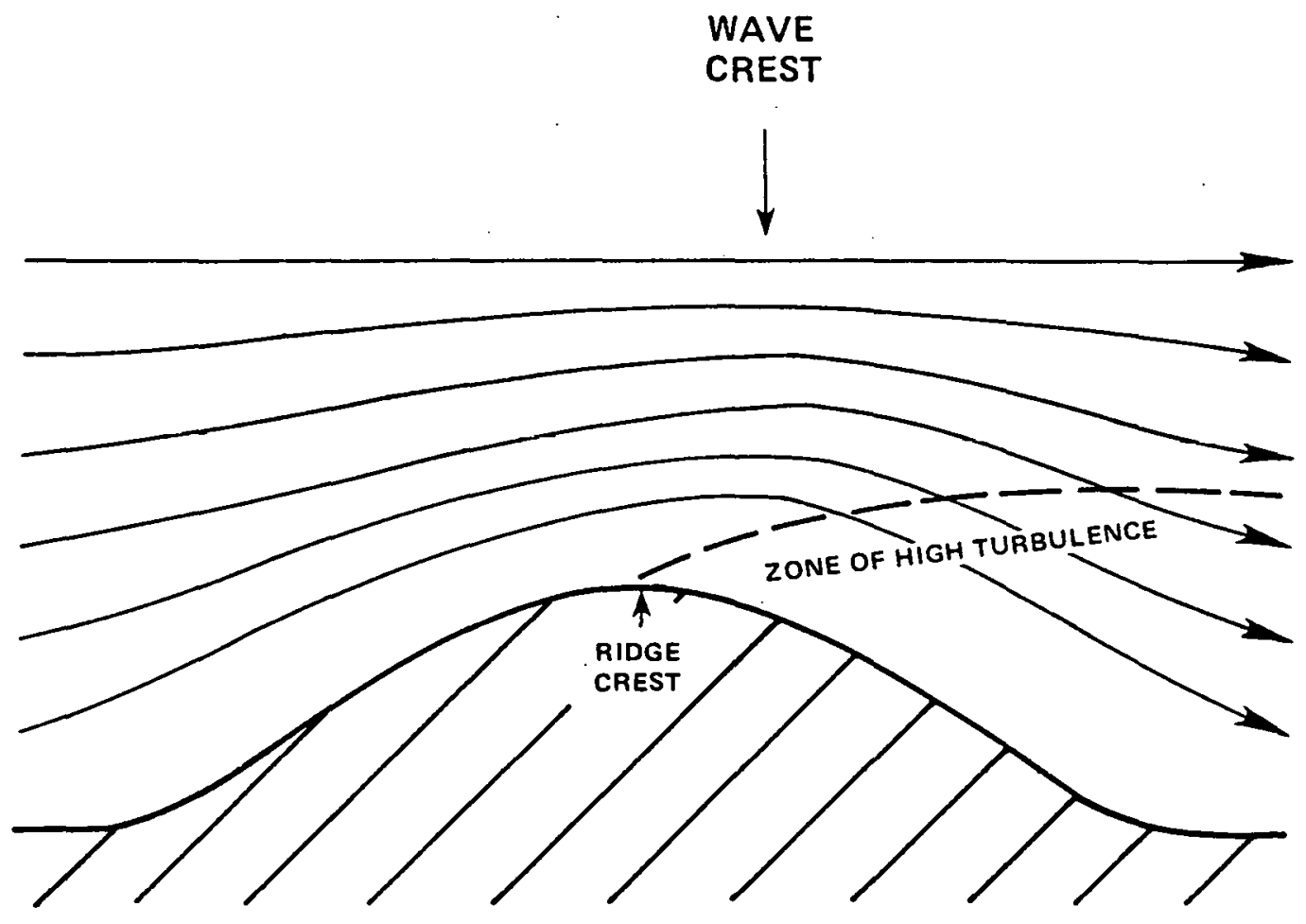

Figure A-2. Air flowing across a ridge is accelerated by a quasi-venturi effect. Maximum acceleration occurs first downwind of the ridge crest. 
the amount of enhancement expected. when flow is perpendicular to the longitudinal axis of the ridge. A broad triangular cross-section with gradual slope and a pointy crest produced maximum acceleration. A similar configuration with a slightly rounded crest proved nearly as effective. Flat-topped ridges and ridges with steep slopes up to and including cliffs and bluffs, are much less effective wind accelerators because of increased drag, severe eddy generation, and a pronounced shear zone (Figure A-3).

\section{A-3 Isolated Hills and Mountain Tops}

Hills are somewhat less effective wind accelerators than ridges. Fluids seek the path of least resistance. For hills, the path of least resistance is up and around rather than up and over. There is some compression at streamlines on the side of the hills, in this case. Thus, the zones of maximum enhancement are on the upper flanks on either side of the hilltop (Figure A-4).

For wind power calculations, mountains are defined as having elevations greater than 2000 feet $(610 \mathrm{~m})$. Since there are no peaks that high in the Virgin Islands, the two basic outcrop landforms considered are hills and ridges.

A-4 Passes, Saddles and Valleys

Passes, saddles, and valleys all produce channeling of the wind. Passes and saddles are basically notches in a barrier-type landform. These depressions may be breaks, in a ridge or merely the low area between two hilltops or mountain tops. Air flow through a saddle or pass is accelerated by a venturieffect (Figure A-5). Generally, the steeper the slope of the hillsides, the narrower the pass, and the higher the floor of the pass, the greater the acceleration and the wind energy potential. Of course, maximum enhancement is realized when the prevailing wind blows along the axis of the pass. 


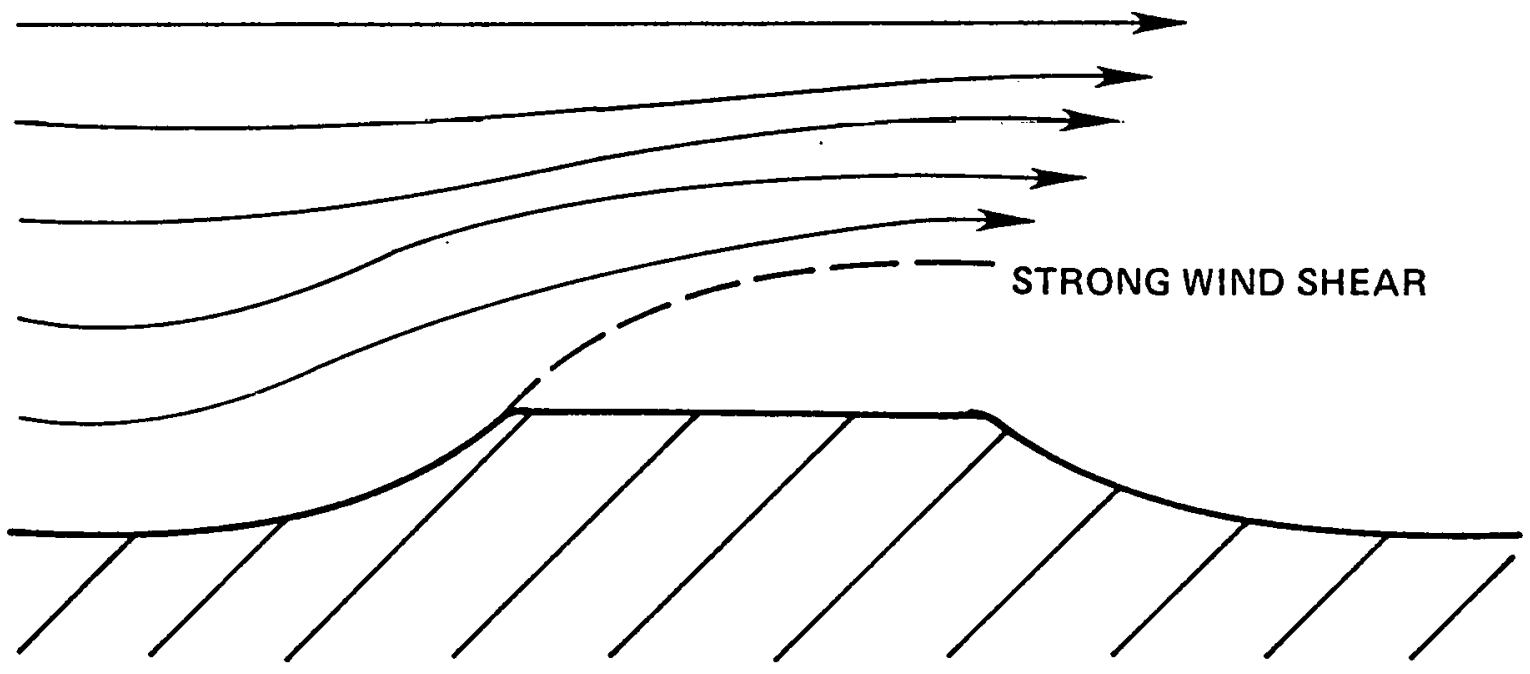

Figure A-3. The shear zone associated with some cliffs and bluffs and most flat-topped ridges would create unequal blade loading on WECS equipment. 


\section{MAXIMUM \\ ACCELERATION}
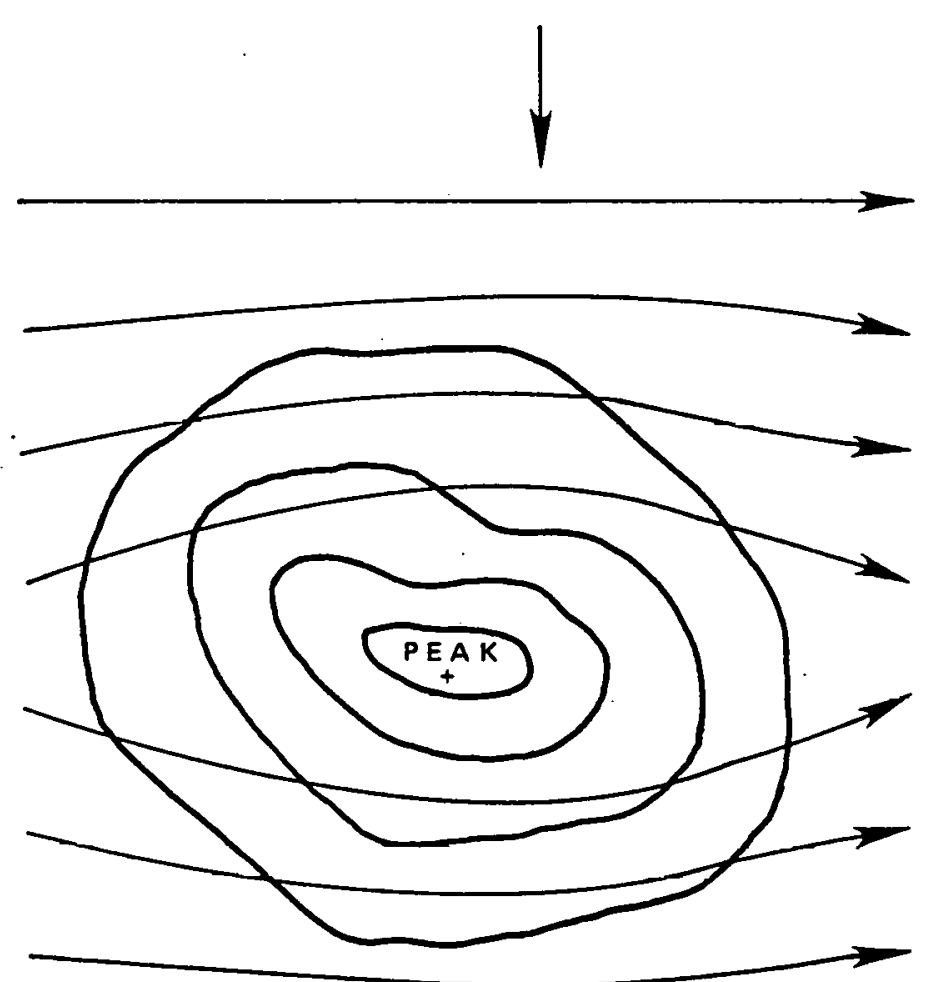

Figure A-4. Plan view of a hill illustrating the compression of stream lines as the air flows around the peak. Tangential flow along the upper flank of the hill is accelerated. 


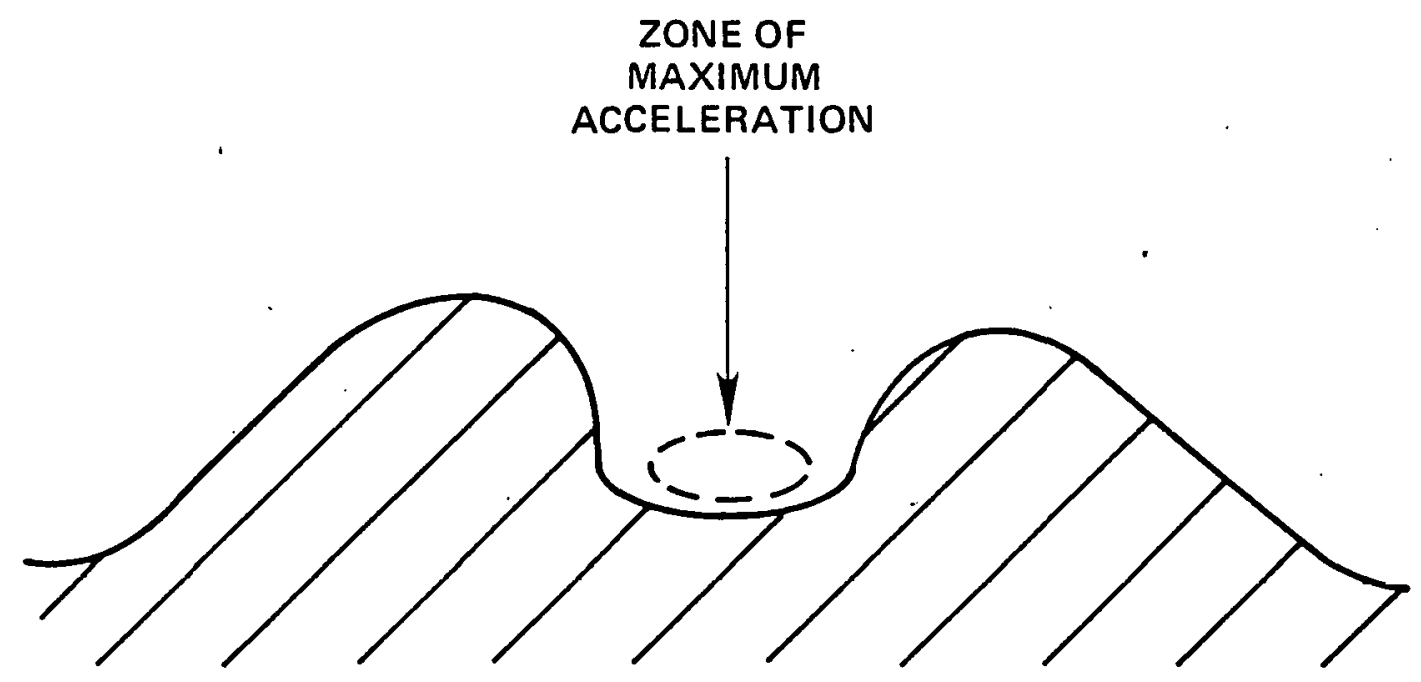

Figure A-5. Saddles and passes have excellent wind enhancement characteristics. 
Valleys also produce channeling. Valleys are normally bounded by ridges or hills. The most desireable type of valley for wind power generation is the horseshoe valley or box canyon, particularly if it is open to the prevailing wind. First the air is accelerated as it is funneled into the valley and thus compressed. Then at the closed end, the air is further accelerated as it is forced up and over the ridge (see Figure A-2, ridge enhancement).

\section{A-5 Estimating Terrain Enhancement}

Basically, terrain enhancement is acceleration of the wind as air flows around and over some obstructing landform. Flow over a cliff or ridge is compressed only in the vertical. Flow up a valley, through a pass or saddle, and around the upper flanks of a peak or hill is compressed both vertically and horizontally. Flow through a valley with a level floor is compressed horizontally. These relationships are defined in the following simple equations. Each equation is based on the principal of conservation of momentum and gives a rough estimate of the amount of enhancement due to terrain.

Equation A.1. Velocity due to terrain enhancement $\left(v_{e}\right)$ at the top of a ridge, around the upper flanks of a hill or mountain, and around the upper flank of an end of a ridge:

$$
\mathrm{v}_{\mathrm{e}}=\left[1.4\left(\mathrm{v}_{\mathrm{o}}\right)^{2}\right]^{\frac{1}{2}}
$$

where $v_{0}=$ velocity near the surface just upwind of the obstructing landform.

Equation A.2. Velocity due to terrain enhancement $\left(v_{e}\right)$ at the top of the barrier landform at the closed end of $a$ box canyon or horeeshoe valley and at the high point of a pass or saddle:

$$
v_{e}=\left[\begin{array}{lll}
1.4 & \frac{S_{1}}{S_{2}} & \left(v_{0}\right)^{2}
\end{array}\right]^{\frac{1}{2}}
$$


where $v_{0}=$ velocity near the surface just upwind of the mouth of the canyon, valley, pass, or saddle.

$$
\begin{aligned}
& S_{1}=\text { width of the mouth of the canyon, etc. } \\
& S_{2}=\begin{array}{l}
\text { width of the narrowest portion of the } \\
\text { canyon, etc. }
\end{array}
\end{aligned}
$$

Equation A.3. Velocity due to terrain enhancement $\left(v_{e}\right)$ in the center of a level floor valley at its narrowest point:

$$
\left.v_{e}=\left[\begin{array}{l}
s_{1} \\
s_{2}
\end{array} v_{0}\right)^{2}\right]^{\frac{1}{2}}
$$

where $v_{0}=$ velocity near the surface just upwind of the mouth of the valley.

$$
\begin{aligned}
S_{1}= & \text { width of the mouth of the valley. } \\
S_{2}= & \text { width of the narrowest portion of } \\
& \text { the valley. }
\end{aligned}
$$

The free stream velocity $\left(v_{f}\right)$ at the point atop the obstructing landform can be obtained from a low level wind profile. The actual wind velocity (V) at the top of the landform can be obtained by adding the incremental increase in wind speed due to terrain enhancement $\left(v_{e}\right.$ minus $\left.v_{o}\right)$ to the free stream velocity $\left(v_{f}\right)$ :

$$
v=v_{f}+\left(v_{e}-v_{o}\right)
$$




\author{
APPENDIX B \\ MAJOR TOPOGRAPHIC FEATURES \\ OF THE U. S. VIRGIN ISLANDS
}

\title{
St. Croix
}

The major topographic features of St. Croix are shown in Figure B.1. From the windpower standpoint the topography of St. Croix is somewhat less definitive than that of St. Thomas and St. John. The Goat Hills at the extreme eastern tip of St. Croix, featuring Sugarloaf Hill (205 m MSL), have wide open exposure to the easterly trades. Some $6 \mathrm{~km}(3.7 \mathrm{mi})$ to the west are Seven Hills, an east-west oriented ridge line with excellent exposure and peaks up to $265 \mathrm{~m}$ MSL. There is a horseshoe shaped ridge featuring Lang Peak (233 m MSL) and Prospect Hill (229 m MSL).

The highest peaks are along the north shore on the west end of the island: Windsor Hill (270 m MSL), St. George Hill (263 m MSL), Mt. Stewart (249 m MSL), Mt. Eagle (355 m MSL), and Blue Mountain (334 m MSL) have high wind energy potential. There is a saddle between the peaks of Mt. Eagle and Blue Mountain, and a NW-SE oriented valley on the lee side of Blue Mountain and Mt. Eagle. 


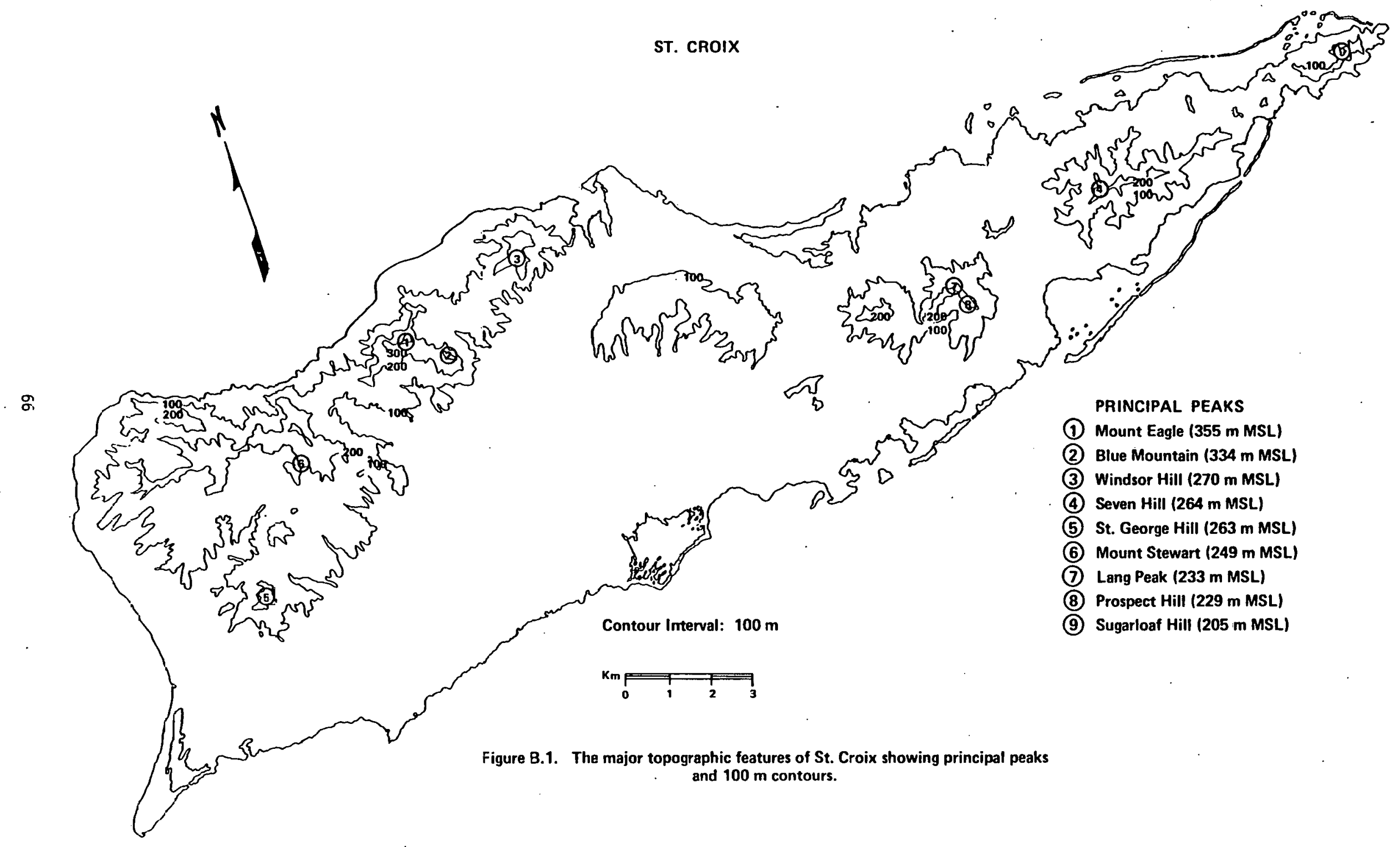


St. Thomas.

The major topographic features of St. Thomas are shown in Figure B.2. The primary feature is the east-west ridge in the central portion of the island. The highest peaks are Signal Hill (453 m MSL) $1.5 \mathrm{~km}(0.9 \mathrm{mi}) \mathrm{NW}$ of Charlotte Amalie and Crown Mountain (474 m MSL) $2 \mathrm{~km}$ (1.2 mi) north of Harry S. Truman Airport. These peaks and their north and south shoulders have high wind energy potential by virtue of their elevation. Between Wintberg Peak (293 m MSL) $2 \mathrm{~km}$ (1.2 mi) east of Charlotte Amalie and Flag Hill (294 m MSL) 2 $\mathrm{km}$ ( $1.2 \mathrm{mi})$ south of Wintberg Peak is an east-west oriented pass. Benner Hill (165 $\mathrm{m} \mathrm{MSL)} \mathrm{has} \mathrm{excellent} \mathrm{exposure} \mathrm{at} \mathrm{the} \mathrm{windward} \mathrm{end} \mathrm{of} \mathrm{the} \mathrm{island,} \mathrm{as} \mathrm{does}$ the slightly smaller Redhook Hill ( $87 \mathrm{~m}$ MSL) just east of Benner. 
ST. THOMAS
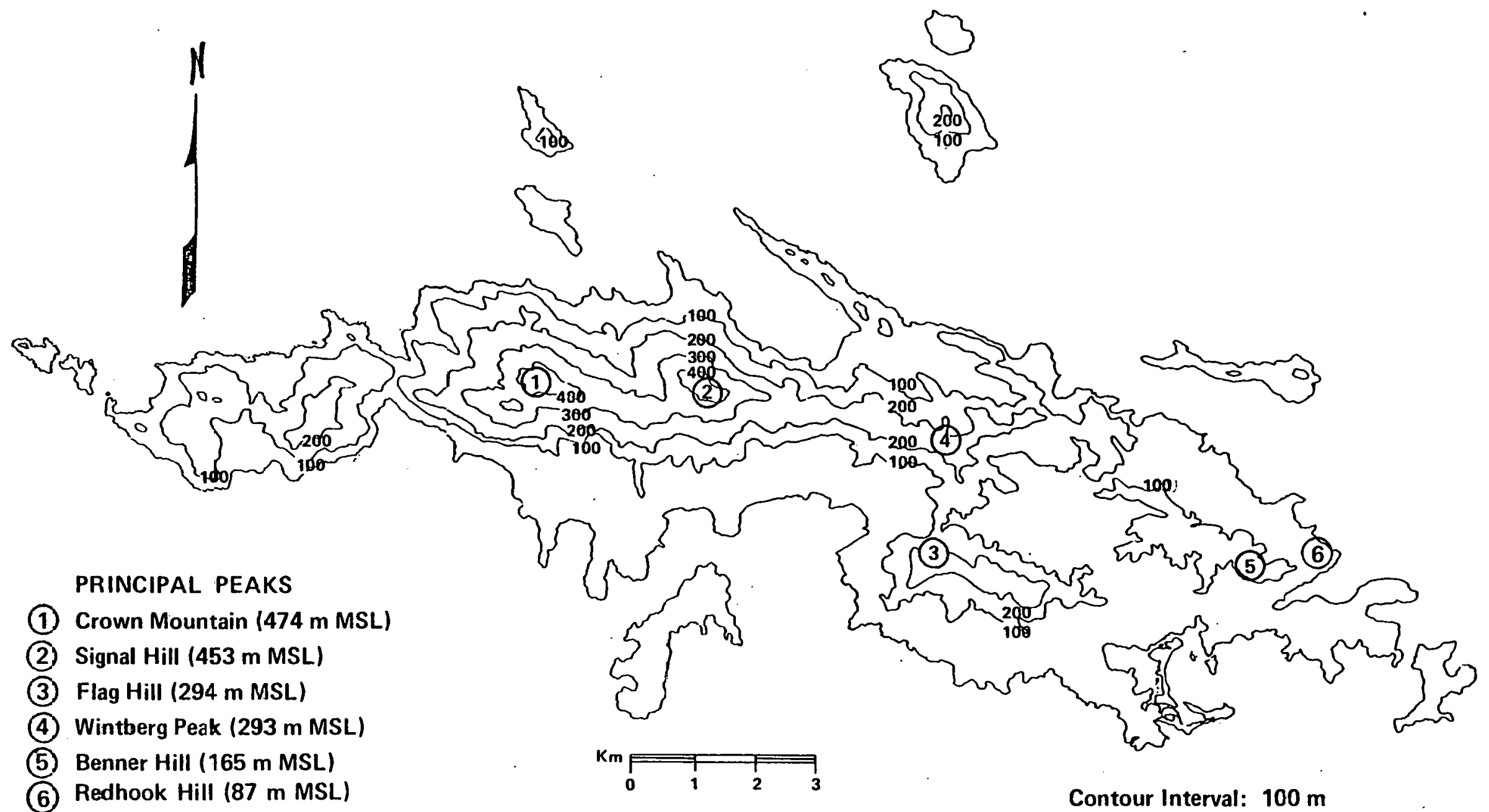

1) Crown Mountain (474 m MSL)

(2) Signal Hill ( $453 \mathrm{~m} \mathrm{MSL}$ )

(3) Flag Hill (294 m MSL)

(4) Wintberg Peak (293 m MSL)

(6) Redhook Hill $(87 \mathrm{~m} \mathrm{MSL}$ )

Figure B.2. The major topographic features of St. Thomas showing principal peaks and $100 \mathrm{~m}$ contours. 
St. John.

The major topographic features of St. John are shown in Figure B.3. There is a $2 \mathrm{~km}(1.2 \mathrm{mi})$ long ridge line running along the west side of Coral Bay. This ridge extends from the eastern slope of Bordeaux Mountain (389 m MSL) SSE to Minna Hill (302 m MSL). To the north of Bordeaux Mountain is a horseshoe shaped valley, open to the windward. The west end of the valley is bounded by Mamey Peak ( $350 \mathrm{~m}$ MSL), and the north wall is formed by a ridge line that features Ajax Peak (300 m MSL).

The mountains in the central portion of the island are quite high, Camelberg (364 m MSL) and Peter (295 m MSL). The extreme east end of St. John features several hills ( $120 \mathrm{~m}$ to $160 \mathrm{~m}$ MSL) whose open exposure to the trade winds gives them excellent wind power potential. 


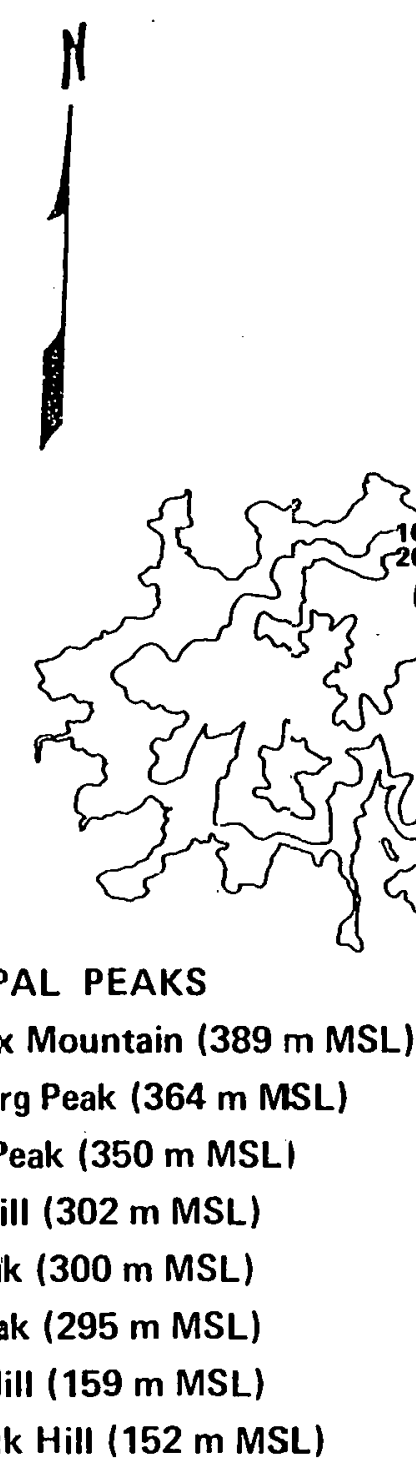

ST. JOHN

\section{PRINCIPAL PEAKS}

(1) Bordeaux Mountain (389 m MSL)

(2) Camelberg Peak (364 m MSL)

(3) Mamey Peak ( $350 \mathrm{~m}$ MSL)

(4) Minna Hill (302 $\mathrm{m} \mathrm{MSL}$ )

(5) Ajax Peak (300 m MSL)

6) Peter Peak (295 m MSL)

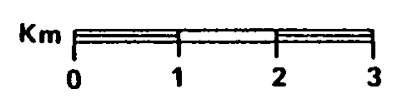

(7) Nancy Hill (159 $\mathrm{m} \mathrm{MSL}$ )

(8) Blackrock Hill (152 m MSL)

Figure B.3. The major topographic features of St. John showing principal peaks and $100 \mathrm{~m}$ contours. 